\title{
ECONOMICS
}

\section{SEXUAL SELECTION, CONSPICUOUS CONSUMPTION AND ECONOMIC GROWTH}

\author{
by \\ Jason Collins \\ Business School \\ University of Western Australia
}

and

Boris Baer

Centre for Integrative Bee Research (CIBER)

ARC CoE in Plant Energy Biology

University of Western Australia

and

Ernst Juerg Weber

Business School

University of Western Australia

DISCUSSION PAPER 12.15 
by

\author{
Jason Collins \\ Business School \\ University of Western Australia \\ and \\ Boris Baer \\ Centre for Integrative Bee Research (CIBER) \\ ARC CoE in Plant Energy Biology \\ University of Western Australia \\ and \\ Ernst Juerg Weber \\ Business School \\ University of Western Australia
}

Draft version: 13 July 2012

DISCUSSION PAPER 12.15

The evolution by sexual selection of the male propensity to engage in conspicuous consumption contributed to the emergence of modern rates of economic growth. We develop a model in which males engage in conspicuous consumption to send an honest signal of their quality to females. Males who engage in conspicuous consumption have higher reproductive success than those who do not, as females respond to the costly and honest signal, increasing the prevalence of signalling males in the population over time. As males fund conspicuous consumption through participation in the labour force, the increase in the prevalence of signalling males who engage in conspicuous consumption gives rise to an increase in economic activity that leads to economic growth.

Key words: conspicuous consumption, sexual selection, human evolution, economic growth

For their comments we thank participants in seminars with the Economics Discipline and the Centre for Evolutionary Biology at the University of Western Australia, the Experimental Ecology and Theoretical Biology Groups at the ETH Zurich, and the Behavioural Ecology Group at the University of Zurich. 


\section{Introduction}

In the majority of species, females invest more into offspring than males, as they produce costly eggs instead of cheap sperm, invest substantial amounts of resources into offspring during pregnancy or provide extensive brood care of young. Consequently, females are choosy and prefer males that provide them or their offspring with fitness enhancing benefits (Trivers 1972). Males compete against each other for access to females, with competition for mates often resulting in significant differences in reproductive success between population members (Bateman 1948; Wade 1979). The resulting sexual selection can generate rapid genetic and phenotypic change (Maynard Smith 1978; Andersson 1994).

Males have evolved a range of traits that are advantageous when competing with rival males and that make them more attractive to females. This includes extravagant traits that are costly for the bearer, such as the plumage of peacocks, the bright coloration of butterflies or ornamental morphological structures such as the antlers of deer (Zahavi 1975). By imposing a cost (a handicap) on the male that cannot be borne by males with limited abilities or resources, these secondary sexual characteristics can provide an honest signal of underlying quality (Grafen 1990a, 1990b). ${ }^{1}$ As such signals are honest, females benefit if they prefer males with such signals, and the increase in mating opportunities for the males compensates for the cost of the signal.

Sexual selection has been an important force in human evolution, as emphasized by Darwin (1871). Sexual selection is suggested by the significant variation in male reproductive success and the higher variance in reproductive success for men than for women (Fisher 1930; Brown, Laland \& Mulder 2009). Using estimates of genetic diversity from a range of studies, Wade and Shuster (2004) estimated that sexual selection accounts for an average of 54.8 per cent of total selection in Homo sapiens (with an estimated range of 28.4 per cent to 77.7 per cent).

As a woman deciding on a partner for sexual reproduction may not be able to directly observe the quality of her potential mate, humans have also evolved secondary sexual characteristics to signal their quality. These characteristics include the propensity to

\footnotetext{
${ }^{1}$ Spence (1973) observed the requirement of differential cost for an honest signal in his analysis of job signaling markets.
} 
engage in conspicuous consumption, which is the attainment of costly goods and services for the purposes of displaying wealth and status. Through its cost, conspicuous consumption can provide an honest signal of quality and give those who engage in conspicuous consumption greater reproductive success (Frank 1999; Miller 1999, 2001; Saad 2007).

From Veblen's (1899) identification and naming of conspicuous consumption to Frank's (1999) analysis of economic behaviour, conspicuous consumption has been identified as an economic preference. However, economic models typically ascribe no evolutionary foundation for consumption. In standard economic models, it is assumed that people prefer more consumption to less consumption. Yet, from an evolutionary perspective, investments in consumption will only persist in a population if it increases the fitness of the agent relative to those who do not invest in it. Thus, an assumption that people seek to maximise consumption can only hold if maximising consumption enhances the fitness of those individuals. De Fraja (2009) sought to address this problem by providing an evolutionary foundation to the economic hypothesis that humans maximise consumption. Using modified versions of Grafen's (1990a, 1990b) models on biological signals as handicaps, he demonstrated that conspicuous consumption could be explained as an honest signal of males quality.

This paper extends previous analysis of the evolutionary foundations of conspicuous consumption by examining conspicuous consumption as a heritable secondary sexual characteristic in a dynamic framework. We hypothesise that a female's preference for male conspicuous consumption for mate choice results in males being under strong selection, which increases the prevalence of the genes underlying the behaviour and the level of conspicuous consumption in the population. To fund conspicuous consumption, a male must participate in activities to obtain the resources to consume. This might involve autonomous activities such as developing art or other objects of beauty in traditional societies, or in modern contexts, participating in the labour force. As female choice increases male investment in conspicuous consumption and the level of economic activities to fund it, we propose that sexual selection was a contributing factor to the emergence of modern levels of economic growth.

We present a model in which some males carry a gene that predisposes them to signal their quality through engaging in conspicuous consumption, while others do not. Males fund conspicuous consumption through labour participation in a luxury sector, which 
carries a cost in that it reduces the time available for subsistence activities and therefore reduces the probability of survival. Males will only signal through conspicuous consumption if the fitness benefits through increased mating opportunity outweigh the handicap of lower survival probability.

We show that a separating equilibrium exists in which signalling males increase in prevalence, with the female preference for high-quality males who signal their quality through conspicuous consumption compensating for the survival cost of the signal. The higher prevalence of signalling males increases economic growth through two avenues: increased labour engaged in productive uses and a scale effect (Romer 1990; Kremer 1993) whereby the level of human capital engaged in production drives technological progress. The greater labour participation and innovation associated with conspicuous consumption contributed to the emergence of modern rates of economic growth.

The model provides a basis for the observation that males engage in work effort and consumption at levels above that required for survival (or at the cost of survival) and proposes that these behaviours have significant economic effects. As it is likely that other evolutionary changes to qualitative traits such as IQ or time preference are relevant to long-term economic growth, we do not propose that the desire to engage in conspicuous consumption and fund that consumption is the sole "trigger" for modern economic growth. Rather, the need for males to signal quality to choosy females might be considered a contributing factor for economic growth.

\section{Related literature}

A growing literature deals with the link between the evolution of traits in the population and economic growth. In a seminal paper, Galor and Moav (2002) proposed that changes in prevalence of a genetically based preference for quality or quantity of children were a trigger for the Industrial Revolution. A similar economic framework was applied by Galor and Michalopoulos (2011), who posited that selection for a genetically determined entrepreneurial spirit (proxied by risk aversion) could have triggered the Industrial Revolution. These papers did not consider the effects of female choice and consequent sexual selection on population genetics. Instead, selection of individuals was based on survival due to availability of resources above a subsistence level and allocation of those resources to children. 
Sexual selection may explain the observations of Clark (2007) concerning fertility before the Industrial Revolution. Clark found that fertility was higher among wealthier men and proposed that the increasing prevalence of children with the preferences and habits of their wealthy parents contributed to the Industrial Revolution. Clark's findings match other evidence of higher reproductive success of men with more resources, particularly in hunter-gatherer societies and among pastoralists (Mulder 1987; Borgerhoff Mulder 1990; Cronk 1991; Hopcroft 2006).

Finally, Zak and Park (2002) incorporated sexual selection into a model of economic growth as part of a broader analysis of gene-environment interactions and their economic effects. In their agent-based model, sexual selection affects the transmission of cognitive ability, as females prefer smarter males. As those with higher cognitive ability were selected for in the evolutionary process, human capital and economic growth increased.

Recent research in evolutionary psychology has linked conspicuous consumption with mating displays. Griskevicius et al. (2007) found that men who are shown photos of women or who read a romantic scenario were more willing to spend on conspicuous luxuries than others who were exposed to neutral images. Women did not change their desired level of conspicuous consumption when primed with male photos or in response to the romantic scenario. Sundie et al. (2011) showed that men looking for short-term partners wished to spend more on conspicuous consumption when primed with mating scenarios. Women asked to rate two otherwise identical men who had purchased either a cheap or expensive car rated the male with the expensive car as more desirable as a short-term partner. In contrast, men showed no response to female conspicuous consumption.

\section{Model with evolution of male preference}

This section describes an evolutionary model in which males with a genetic propensity to signal their quality through conspicuous consumption increase in prevalence in the population as their additional mating opportunities outweigh the cost of the signal. All females observe male signals and use this information to assess male quality.

As conspicuous consumption requires the acquisition of resources to consume, the model agents participate in activities that can lead to accumulation of a surplus, such as labour force participation. The increased labour force participation and the innovation 
driven by this participation in productive pursuits cause an increase in economic growth.

\subsection{The agents}

The model comprises a population of male and female agents who live for one mating season. The number of males and females at the start of generation $t, M(t)$ and $F(t)$, are held constant such that $M(t)=M(t+1)$ and $F(t)=F(t+1)$.

Males vary in inherent quality $\left(0<h^{k} \leq 1\right)$, which is allocated randomly at birth. It is assumed that males can be of high $\left(h^{H}\right)$ or low $\left(h^{L}\right)$ quality with probability $p$ and 1- $p$. The assumption of random allocation of quality allows the dynamics and effects of conspicuous consumption to be analysed without conflating the analysis with inherited changes in the agents' qualitative traits.

The male agents are haploid: that is, a single gene codes for each trait. Each male has one locus (the location of a gene), with the allele (variant of the gene) at that locus expressing for signalling behaviour in the male. There are two alleles, signalling $(S)$ and not signalling $(N)$, which are transmitted directly from father to son. The frequency of each male genotype in the population is denoted by $\pi^{i k}(i \in S, N ; k \in H, L)$. For example, $\pi^{S H}$ indicates the frequency of high-quality signalling males in the population. $\pi^{i}$ denotes the prevalence of males of genotype $i$ of either level of quality.

The utility of a male, which is equal to his fitness, depends on the number of viable children he fathers. The male utility function can only be defined in terms of the particular model details, so is given below in equations (24) and (25) after the model is further specified.

Female agents are identical and are passive, except for their mating decision. Females prefer males of higher quality, as the number of surviving children, $n$, is a function of the quality of the male with whom she mates.

$$
n\left(h^{k}\right)=\beta h^{k} \quad \beta \geq 1
$$


The utility of a female, which is equal to her fitness, depends on the number of surviving children.

$$
u^{F}=n\left(h^{k}\right)
$$

Females are assumed to have a pre-existing preference for observing male signals and, as they cannot directly observe male quality, use male conspicuous consumption to decide if they will mate with a male. This reflects a situation where male evolution is shaped by a pre-existing female sensory bias (Basolo 1990; Ryan 1990, 1998; Miller 2001). Rather than male and female behaviour co-evolving, which is explored in the second model in this paper, the female preference is based on factors independent of sexual selection.

\subsection{The economy}

The economy consists of two sectors: the subsistence sector, which enables survival, and the luxury sector, which produces goods suitable for conspicuous consumption. The proportion of time that a male is engaged in subsistence activities is $s^{i k}$, with the remaining time, $l^{i k}=1-s^{i k}$, being spent in the luxury sector. The aggregate quantity of labour engaged in survival activities in the subsistence sector in generation $t$ is:

$$
S(t)=M(t) \sum_{i=S, N} \sum_{k=H, L} \pi^{i k} s^{i k}
$$

The subsistence sector is assumed to have zero technological progress. If there were technological progress in a Malthusian economy, technological progress would be matched with population growth, effectively constraining income growth. As the population in this model is normalised to a fixed level for each generation, the assumption of zero technological progress in the subsistence sector allows for maintenance of a Malthusian environment without introducing population growth into the model.

The luxury sector comprises labour market activities to access a surplus with which to engage in conspicuous consumption. In early evolutionary times before a modern division of labour, luxury sector activities might have involved conspicuous leisure (Veblen 1899), production of art or ornaments, body ornamentation or other costly displays of underlying quality (Miller 2001). When the development of agriculture 
allowed greater specialisation, time engaged in the luxury sector expanded to include specialised production activities and ultimately participation in the modern labour force.

$L(t)$ is the aggregate quantity of efficiency units of labour engaged in the luxury sector in generation $t$. The number of efficiency units of labour is a function of the quantity of labour and the quality of that labour.

$$
L(t)=M(t) \sum_{i=S, N} \sum_{k=H, L} \pi^{i k}\left(1-s^{i k}\right) h^{k}
$$

Beside labour, production uses a scarce environmental factor, such as land, $X$, whose quantity is fixed. Aggregate output, $Y(t)$, is given by the sum of output in the two sectors.

$$
\begin{aligned}
& Y(t)=S(t)^{\rho} X^{1-\rho}+A(t) L(t)^{\alpha} X^{1-\alpha} \\
& \rho \in(0,1) \quad \alpha \in(0,1)
\end{aligned}
$$

The parameters $\rho$ and $\alpha$ are the elasticity of output with respect to labour input in each sector. The shift factor $A(t)$ is the level of technology in the luxury sector.

The level of technology is determined endogenously in the model. It is assumed that technological progress, $g(t)$, is an increasing and concave function of the proportion of the population engaged in the luxury sector. This is similar to the scale effect as a driver of technological progress in Romer (1990), in which technological progress is a function of the human capital engaged in research, or Kremer (1993), who assumed that technological progress is a function of population size.

$$
g(t+1) \equiv \frac{A(t+1)-A(t)}{A(t)}=g(L(t))
$$

where $g_{L}>0 ; \quad g_{L L}<0 ; \quad g(0)=0$

Agents receive the product of their own subsistence labour, which determines survival probability. The wage per unit of labour in the subsistence sector is:

$$
r(t)=\left(\frac{X}{S(t)}\right)^{1-\rho}
$$


Assuming there are no property rights over land, the return to land is zero and the wage per efficiency unit of labour in the luxury sector, $w(t)$, is:

$$
w(t)=A(t)\left(\frac{X}{L(t)}\right)^{1-\alpha}
$$

As this wage is per efficiency unit, low-quality males will receive a lower wage per unit of time engaged in the luxury sector than high-quality males.

\subsection{The mating season}

Each generation lives for one mating season, which comprises three stages denoted by $\mathrm{A}, \mathrm{B}$ and $\mathrm{C}$ respectively. The mating season can be thought of as a single year in which agents can mate, as a sequence of "serial monogamy" during a lifetime, or as a complete monogamous life. In stage A males work and in stages B and $\mathrm{C}$ mating takes place. In this section we describe how males and females move from stage $\mathrm{A}$ to $\mathrm{B}$ to $\mathrm{C}$ in the mating season. For ease of notation, the indicator $t$ relating to the generation is omitted in this section.

Equal numbers of males and females are born and enter stage A:

$$
M_{A}=F_{A}
$$

Males have one unit of time that they allocate between subsistence activities and participation in the labour market to fund conspicuous consumption. Only males who carry the signalling allele $S$ engage in conspicuous consumption.

In allocating resources between subsistence activities and conspicuous consumption, $c^{i k}$, males are subject to the following budget constraint.

$$
\begin{aligned}
c^{i k} & \leq w h^{k} l^{S k} \\
& =w h^{k}\left(1-s^{S k}\right)
\end{aligned}
$$

As low-quality males receive a lower wage for their participation in the labour force, they face a higher effective cost for conspicuous consumption. Therefore, these males experience higher signalling costs. 
Males suffer from pre-breeding mortality in stage A. Male survival probability, $\delta^{i k}$, is a function of their participation in subsistence activities.

$$
\begin{aligned}
& \delta^{i k}=\delta\left(r s^{i k}\right) \quad \delta_{s}^{i k}\left(r s^{i k}\right)>0 \quad \delta_{s s}^{i k}\left(r s^{i k}\right) \leq 0 \\
& \delta(0)=0 \quad \delta(r) \leq 1
\end{aligned}
$$

The number of surviving males who are available to mate in stage B is:

$$
M_{B}=\sum_{k=H, L}\left(\pi_{A}^{S k} \delta^{S k}+\pi_{A}^{N k} \delta^{N k}\right) M_{A}
$$

As the mortality is not uniform across types, the prevalence of males of each type in stage $B$ varies from that in stage A:

$$
\pi_{B}^{i k}=\pi_{A}^{i k} \delta^{i k} \frac{M_{A}}{M_{B}}
$$

The number of females does not change from stage A to stage $\mathrm{B}$ as there is no female mortality.

$$
F_{B}=F_{A}
$$

Two mating periods follow signalling and pre-breeding mortality. In stages $\mathrm{B}$ and $\mathrm{C}$, males and females are randomly paired and the female chooses whether to mate with the male. As males are polygynous and make no investment in the offspring, they can mate in both periods. Females can mate only once, as they must make a maternal investment in their children. While this paper has two mating periods, the results can be generalised to more than two mating periods.

The probability of a male or female being matched depends on the number of males and females alive and present in the mating pool at that stage. In stage B, the probability of being matched is one for a male, as male mortality ensures that there are fewer males than females.

$$
q_{B}^{M}=q\left(M_{B}, F_{B}\right)=1
$$




$$
\begin{aligned}
q_{B}^{F} & =q\left(M_{B}, F_{B}\right) \\
& =\frac{M_{B}}{F_{B}} \\
& =\sum_{k=H, L}\left(\pi_{A}^{S k} \delta^{S k}+\pi_{A}^{N k} \delta^{N k}\right)
\end{aligned}
$$

When a female is paired in stage $\mathrm{B}$, she decides whether she will mate with the male. If she does, the female exits the mating pool and gives birth to that male's children. A male always agrees to mate with the female he is matched with, as there is no cost to mating for a male.

There is no further mortality of males after stage A. The number of males and the ratio of types of males do not change between stages B and C.

$$
\begin{aligned}
& M_{C}=M_{B} \\
& \pi_{C}^{i k}=\pi_{B}^{i k}
\end{aligned}
$$

The number of females available for mating in stage $\mathrm{C}$ comprises the females who did not mate in stage B.

Depending on male mortality in stage $\mathrm{A}$ and the frequency of mating acceptance in stage $B$, it is possible for males and females to be unmatched in stage $C$, which is the final breeding period. A female's probability of being matched in stage $\mathrm{C}, q_{C}^{F}$, will be greater than the corresponding probability in stage $\mathrm{B}$ as some females mate and exit the breeding population in stage $\mathrm{B}$, whereas the number of available males remains constant.

$$
\begin{aligned}
& q_{C}^{M}=q\left(M_{C}, F_{C}\right)=\min \left\{1, \frac{F_{C}}{M_{C}}\right\} \\
& q_{C}^{F}=q\left(M_{C}, F_{C}\right)=\min \left\{1, \frac{M_{C}}{F_{C}}\right\}
\end{aligned}
$$

In stage $\mathrm{C}$, both females and males will mate with whomever they are matched with as females will have no further opportunities to mate and mating for males does not 
involve a cost. Offspring from the mating in stages $\mathrm{B}$ and $\mathrm{C}$ are then born and form the next generation.

\subsection{Female optimisation}

The female decision whether to agree to mate with a given male is a binary decision: yes or no. A female will mate in stage B if the benefit of mating with the male she is paired with is greater than the benefit she expects to receive from mating in the future. The future benefit is a function of the probability that she will be matched to a male in stage $\mathrm{C}$ and the expected quality of that male. She will mate with the male of quality $h^{k}$ in stage B if:

$$
n\left(h^{k}\right) \geq q_{C}^{F} \sum_{i=S, N} \sum_{k=H, L} \pi_{C}^{i k} n\left(h^{k}\right)
$$

As $q_{C}^{F}\left(M_{C}, F_{C}\right) \leq 1$ and $n\left(h^{L}\right)<n\left(h^{H}\right)$, a female will always mate in stage $\mathrm{B}$ if she is paired with a high-quality male. She will only mate with a low-quality male in stage B if:

$$
n\left(h^{L}\right) \geq \frac{q_{C}^{F} \sum_{i=S, N} \pi_{C}^{i H}}{1-q_{C}^{F} \sum_{i=S, N} \pi_{C}^{i L}} n\left(h^{H}\right)
$$

If all females are paired in stage $\mathrm{C}$, this condition cannot be met as $n\left(h^{L}\right)<n\left(h^{H}\right)$. Equation (21) is only likely to be satisfied if there is a low probability of being paired with a male in stage $\mathrm{C}$. This might occur if male mortality rates were high in stage $\mathrm{A}$ and few females mate in stage B. As selection of signalling males occurs only if there is a separating equilibrium between high and low-quality males, we will assume that the condition in equation (21) is not met. Females will hence reject low-quality males in stage B. Assuming that there will not be a significant male shortage in stage $\mathrm{C}$ is a weak assumption and reflects the low investment in mating made by a male.

As a female observes conspicuous consumption rather than inherent quality, the decision of the female depends on whether the level of conspicuous consumption is sufficient, with the threshold level denoted by $\bar{c}$.

$$
\alpha\left(c^{i k}\right)= \begin{cases}0 & \text { if } c^{i k} \leq \bar{c} \\ 1 & \text { if } c^{i k}>\bar{c}\end{cases}
$$


Given the assumption that equation (21) is not met, a female will set $\bar{c}$ at a level that will only be achieved by high-quality males.

If we assume that females mate with a male and exit the breeding pool only if they are matched with a high-quality signalling male, we can state the number of females available to mate in stage $\mathrm{C}$ as:

$$
F_{C}=\left(1-q_{B}^{F} \pi_{B}^{S H}\right) F_{B}
$$

In this specification of the model, females who delay their mating decision incur no cost to the delay beyond the small probability of not being paired in stage $\mathrm{C}$. The model could incorporate costs to delay such as a probability of death before the second mating period (as was included in the model by De Fraja (2009)) or by recognising the increased relative fertility inherent with a shorter time between generations.

\subsection{Male optimisation}

The male's utility (fitness) function can now be stated. The number of children fathered by a male is a function of his survival probability, whether a female accepts him as a mating partner, and the male's quality. Survival probability and acceptance by females are a function of the level of conspicuous consumption. If females only mate with high-quality signalling males in stage $\mathrm{B}$, the signalling and non-signalling males vary in the manner in which they optimise the number of children. Their respective utility functions are:

$$
\begin{aligned}
& u^{S k}=\delta^{S k}\left(\alpha\left(c^{i k}\right) q_{B}^{M}+q_{C}^{M}\right) n\left(h^{k}\right) \\
& u^{N k}=\delta^{N k} q_{C}^{M} n\left(h^{k}\right)
\end{aligned}
$$

Substituting the budget equation (9) into equations (24) and (25), a male of each genotype faces the following optimisation problem:

$$
\begin{aligned}
& \left\{s^{S k}\right\}=\operatorname{argmax}\left\{\delta^{S k}\left(\alpha\left(w h_{k}\left(1-s^{S k}\right)\right) q_{B}^{M}+q_{C}^{M}\right) n\left(h^{k}\right)\right\} \\
& \left\{s^{N k}\right\}=\operatorname{argmax}\left\{\delta^{N k} q_{C}^{M} n\left(h^{k}\right)\right\}
\end{aligned}
$$


If the decision function of the female is a differentiable function, equation (26) for the signalling genotype can be solved to give:

$$
\delta_{s}^{S k}\left(\alpha q_{B}^{M}+q_{C}^{M}\right)=\delta^{S k} w h^{k} \alpha_{s} q_{B}^{M}
$$

Equation (28) shows that the male will invest in survival activities until the marginal gain in reproductive opportunity from increased survival (left-hand side) is equal to the marginal loss in breeding opportunity through reduction in signalling (right-hand side). In terms of consumption, the male will invest in signalling until the marginal loss of reproductive opportunity from increased mortality is equal to the marginal gain in breeding opportunity through signalling.

If the females mate with all males above a threshold level of conspicuous consumption, and there is a separating equilibrium between high and low-quality and signalling and non-signalling males, we can derive a more specific condition from equation (26). High-quality signalling males will maximise utility by signalling if:

$$
\delta^{S H}\left(q_{B}^{M}+q_{C}^{M}\right) \geq \delta^{N H} q_{C}^{M}
$$

The gain from the additional mating opportunity in stage B must be balanced by the increased probability of death.

As $q_{B}^{M}=1$, if $M_{C}<F_{C}$, equation (29) becomes:

$$
2 \delta^{S H}>\delta^{N H}
$$

This condition reflects that high-quality signalling males mate twice, in both stages B and $\mathrm{C}$, compared with only in stage $\mathrm{C}$ for all other types. The signalling allele will only decrease in prevalence in the population if the survival probability of the signalling high-quality males more than halve due to their signalling behaviour. If there were more than two mating periods, the required decrease in survival probability before the signalling high-quality males would have lower fitness and tend to extinction would be even greater.

If $M_{C}>F_{C}$, equation (29) is satisfied where:

$$
\delta^{S H}\left(1+q_{C}^{M}\right)>\delta^{N H}
$$


The condition in equation (31) is easier to satisfy than that in equation (30), as the reduced probability of being paired in stage $\mathrm{C}$ makes the opportunity to pair in stage $\mathrm{B}$ relatively more important.

The non-signalling and low-quality males spend all of their time on survival activities.

$$
\begin{aligned}
& s^{S L}=1 \\
& s^{N k}=1
\end{aligned}
$$

\subsection{Offspring}

Offspring are born and raised at the end of the mating season. Assuming the females accept the high-quality males that signal, the offspring born from mating in stage B are:

$$
n_{B}^{S}=\pi_{A}^{S H} \delta^{S H} n\left(h^{H}\right) M_{A}
$$

The mating during stage $\mathrm{C}$ results in offspring of both types:

$$
\begin{aligned}
& n_{C}^{S}=\sum_{k=H, L} \pi_{C}^{S k} n\left(h^{k}\right) \min \left\{M_{C}, F_{C}\right\} \\
& n_{C}^{N}=\sum_{k=H, L} \pi_{C}^{N k} n\left(h^{k}\right) \min \left\{M_{C}, F_{C}\right\}
\end{aligned}
$$

The number of offspring born in each stage can be used to determine the prevalence of each genotype in the next generation. The prevalence of the signalling genotype in generation $t+1$ is:

$$
\pi_{A}^{S}(t+1)=\frac{n_{B}^{S}+n_{C}^{S}}{n_{B}^{S}+n_{C}^{S}+n_{C}^{N}} \equiv \pi\left(p, \pi_{A}^{S}, h^{L,} h^{H}\right)
$$

The prevalence of the signalling type in the population increases if:

$$
\pi_{A}^{S}(t+1)>\pi_{A}^{S}(t)
$$

Equations (33) to (37) can be used to derive the conditions for the male deciding to signal as shown in equations (30) and (31), which illustrates that the signalling allele increases in prevalence if these conditions are met. 


\subsection{Signalling equilibrium}

In our specification of the model, we assume that there is a separating equilibrium where only high-quality signalling males engage in conspicuous consumption, that females use this signal for mate choice, and that females choose to mate only with highquality males in stage B. This section establishes the basis for those assumptions.

As shown by Grafen (1990a, 1990b), the core condition for the emergence of a separating equilibrium on the basis of a signalling handicap is that the signallers of different quality experience different costs (or benefits) to their signalling behaviour. The low quality male must experience greater costs (or lower benefits) for the same size signal as that produced by a high-quality signaller.

This is illustrated in Figure 1, which shows the costs and benefits of signalling for males. The cost of a certain amount of conspicuous consumption is larger for the low-quality male as they receive a lower wage for their labour and must sacrifice a greater quantity of subsistence activity to match a high-quality male's signal. The slope of the cost curve for each quality of male is $1 / w h^{k}$. The benefit of conspicuous consumption, which is shown by the horizontal line, is the same for all males, irrespective of their quality. The mating benefit is constant because the female decision to mate is binary. The benefit as drawn in the chart is hypothetical, and would drop to zero for any signal strength that a female decides to reject.

Accordingly, there is a range of signal strength that a low-quality male will not match as the cost is above the mating benefit, while the lower cost for the high-quality male makes signalling worthwhile. A low-quality male will set conspicuous consumption at or below $c^{*}$, while a high-quality male is prepared to signal up to a level of $c^{\prime}$. 


\section{Figure 1: Costs and benefits of signalling}

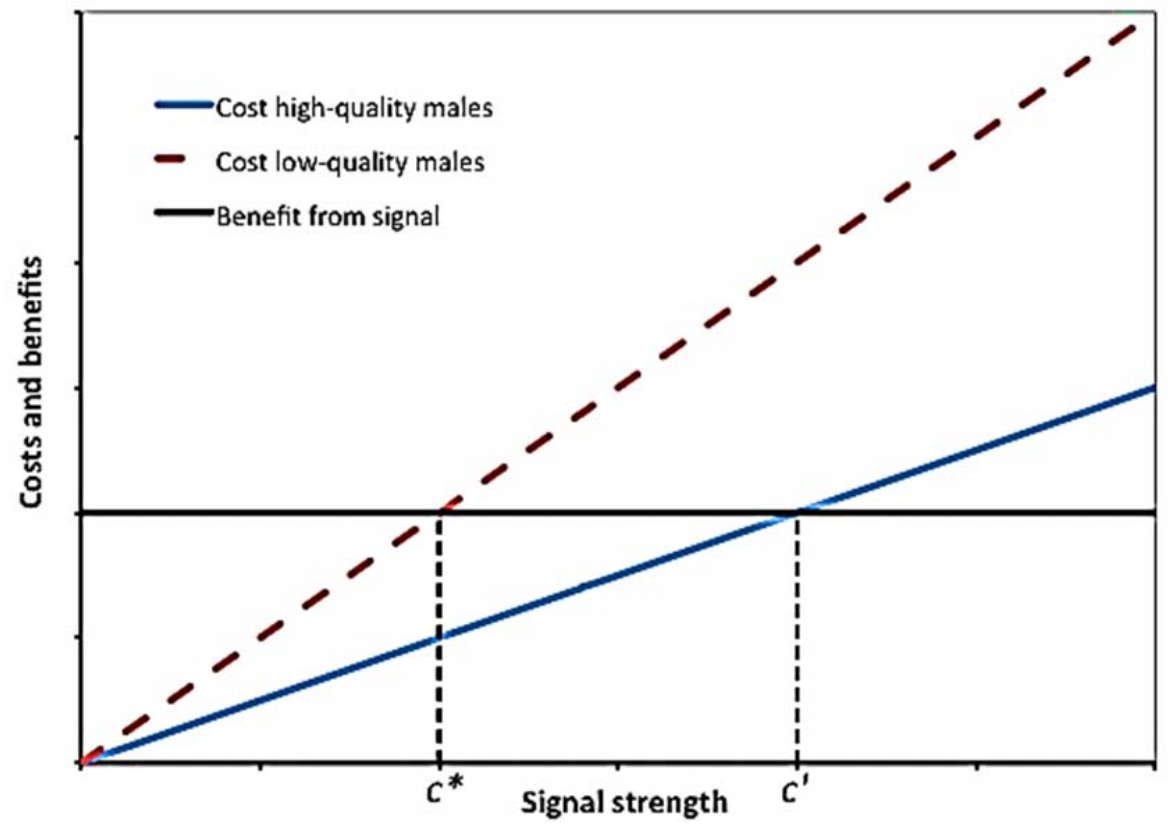

The threshold level $\bar{c}$ that females will set can also be determined. Females set the signal above the level at which a low-quality male is willing to signal. That is, they will set the signal threshold above level $c^{*}$. For any signal threshold up to $c^{\prime}$, high-quality males will be willing to signal to the observing female. If the female sets the threshold at or below $c^{*}$, both high and low-quality males would signal and the conspicuous consumption would not be useful for mate choice. Above $c^{\prime}$, there will be no signals.

Combining the preferred male and female strategies, it can be observed that the level of conspicuous consumption of high-quality males will be between $c^{*}$ and $c^{\prime}$ and females will mate with males who signal in this range. However, high-quality males do not wish to signal more than necessary and they have first mover advantage as they set the signal before the female decides whether to mate. Therefore, high-quality males will signal at the level (or an infinitesimal amount above) that low-quality males are indifferent about. In other words, high-quality males will set the signal just above $c^{*}$.

The females can trust this signal as it is marginally above that which a low-quality male can copy. In this case, no-one has an incentive to deviate. If high-quality males signal at a higher level, they reduce their survival for no mating gain, while a lower signal size will result in no mating benefit as females cannot trust the signal. Low-quality males will not copy the signal, as its cost exceeds its benefit to them. Females will not raise their threshold level of acceptance as they would then miss the opportunity to mate with 
high-quality males, while a reduction in threshold would make cheating attractive to low-quality males.

Given $\bar{c}=c^{*}$, we can use equation (29) to determine the proportion of time that a high-quality male will allocate to subsistence activities. If we denote the level of subsistence activity of a low-quality male at which he is indifferent between signalling or not as $\hat{s}$, we can derive equation (38).

$$
\delta(r \hat{s})\left(q_{B}^{M}+q_{C}^{M}\right)=\delta(r) q_{C}^{M}
$$

If $M_{C}<F_{C}$, the relationship is:

$$
\delta(r \hat{s})=\frac{1}{2} \delta(r)
$$

If $M_{C}>F_{C}$ the relationship is:

$$
\delta(r \hat{s})=\delta(r) \frac{1-\pi_{A}^{S H} \delta(r \bar{s})}{1+\delta(r)\left(1-\pi_{A}^{S H}\right)}
$$

We can then use equation (9), which describes the trade-off between subsistence activity and conspicuous consumption, to state the relationship between survival activities of the high-quality and low-quality types and to determine the level of subsistence activities by the high-quality signalling type:

$$
s^{S H}=1-(1-\hat{s}) \frac{h^{L}}{h^{H}} \equiv s\left(p, \pi_{A}^{S}, h^{L}, h^{H}\right)
$$

The level of signalling by the high-quality signalling male can be derived from equations (39) and (40) using equation (41). Specification of a function for $\delta$ will allow the values of $\hat{s}$ and $s^{S H}$ to be solved.

To determine which of equations (39) and (40) will apply, we must consider whether there will be more males or females in stage C. Using equations (11) and (23), $M_{C}>F_{C}$ if:

$$
\delta\left(r S^{S H}\right)>\frac{1-\left(1-\pi_{A}^{S H}\right) \delta(r)}{2 \pi_{A}^{S H}}
$$


Equation (42) is solved in iteration with equations (39) and (40) to see which applies.

\subsection{Model dynamics}

If the condition in equation (29) is satisfied and the high-quality males signal in a separating equilibrium, their reproductive success will be higher than that for high-quality males that do not signal and the prevalence of the signalling allele in the population will increase. This will in turn increase labour force participation in the luxury sector and the rate of technological progress, driving an increase in income and economic growth.

The evolution of the model agents is driven by the difference equation (36), which describes the change in prevalence of the signalling genotype in the population. A summary of the dynamical system for all endogenous variables is:

$$
\begin{aligned}
& \pi_{A}^{S}(t+1) \equiv \pi\left(p, \pi_{A}^{S}(t), h^{L}, h^{H}\right) \\
& A(t+1)=\left[1+g\left(p, \pi_{A}^{S}(t), h^{k}\right)\right] A(t) \\
& Y(t) \equiv Y(\alpha, \rho, L(t)) \\
& L(t) \equiv L\left(p, \pi_{A}^{S}(t), h^{L}, h^{H}\right)
\end{aligned}
$$

The following quantitative exercise using a simulation illustrates the dynamics. Setting equation (10) as:

$$
\delta^{i k}=r s^{i k}
$$

and setting parameters as in Table 1, the model can be simulated.

Table 1: Model parameters for simulation

\begin{tabular}{|c|c|l|c|}
\hline & & Description & Value \\
\hline \multirow{4}{*}{ Parameters } & $\alpha$ & Output elasticity of labour in luxury sector & 0.5 \\
\cline { 2 - 4 } & $\rho$ & Output elasticity of labour in subsistence sector & 1 \\
\cline { 2 - 4 } & $h^{L}$ & Quality of low-quality males & 0.209 \\
\cline { 2 - 4 } & $h^{H}$ & Quality of high-quality males & 0.15 \\
\cline { 2 - 4 } & $p$ & Proportion of high-quality males at birth & 0.5 \\
\hline
\end{tabular}




\begin{tabular}{|l|c|l|c|}
\hline \multirow{4}{*}{$\begin{array}{l}\text { Initial } \\
\text { values }\end{array}$} & $\pi^{s}$ & Initial prevalence of signalling allele & 0.00001 \\
\cline { 2 - 4 } & $A$ & Level of technology & 1 \\
\cline { 2 - 4 } & $Y$ & Income & 1 \\
\cline { 2 - 4 } & $g$ & Rate of technological progress & 0 \\
\cline { 2 - 4 } & $X$ & Land & 1 \\
\hline
\end{tabular}

In this simulation, the increase in the prevalence of the signalling genotype is rapid, with it taking 29 generations (approximately 600 years) to move from one per cent prevalence to over 99 per cent prevalence. The rate of change is frequency dependent, with the rate of absolute change maximised at moderate levels of prevalence.

\section{Figure 2: Prevalence of signalling genotypes}

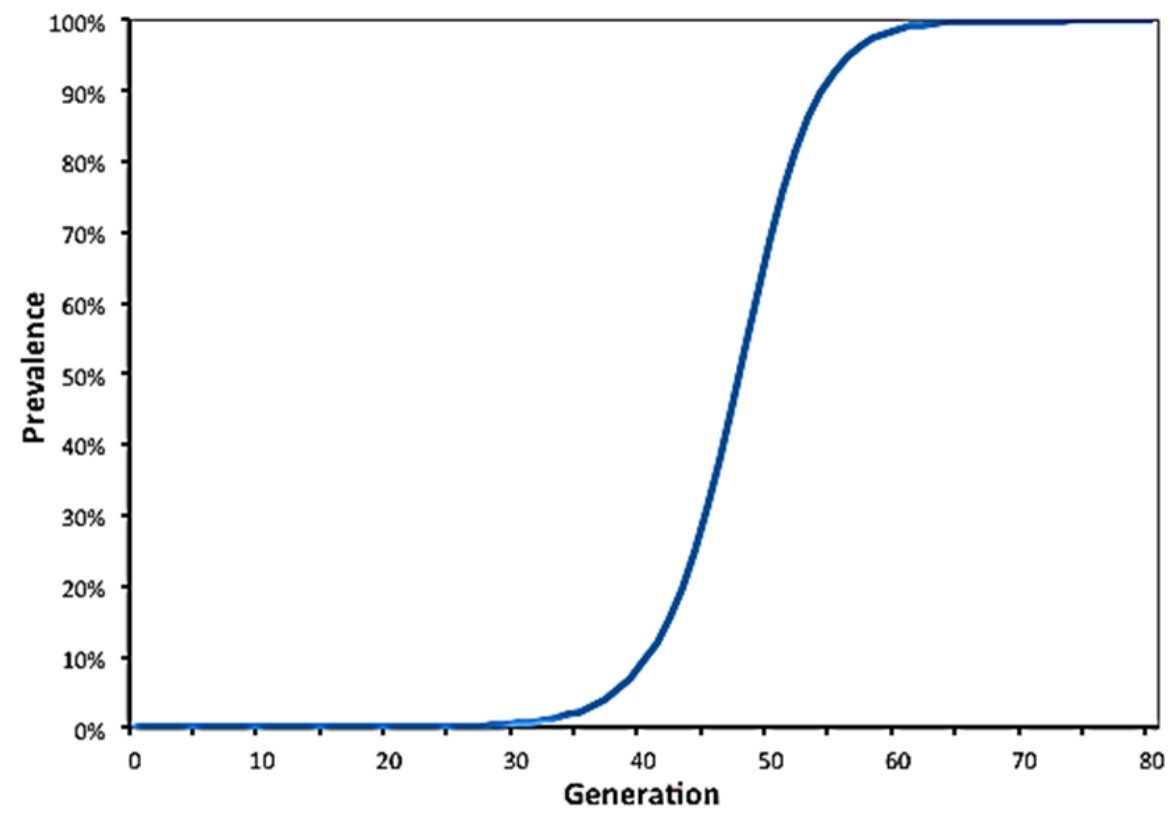

The prevalence of the signalling genotype influences economic growth in two ways. First, the increase in prevalence increases participation in the luxury sector. Figure 3 shows that high-quality signalling males initially allocate 25 per cent of their time to the luxury sector. Their work effort increases to about 29 per cent in response to an increase in the benefit of mating in stage B, as fewer females remain in the breeding pool for stage $\mathrm{C}$. This is equivalent to an upward shift in the benefits to mating line in Figure 1. Between generations 40 and 60 , as the prevalence of the signalling allele increases, the overall labour force participation rapidly increases. 


\section{Figure 3: Allocation of time of agents}

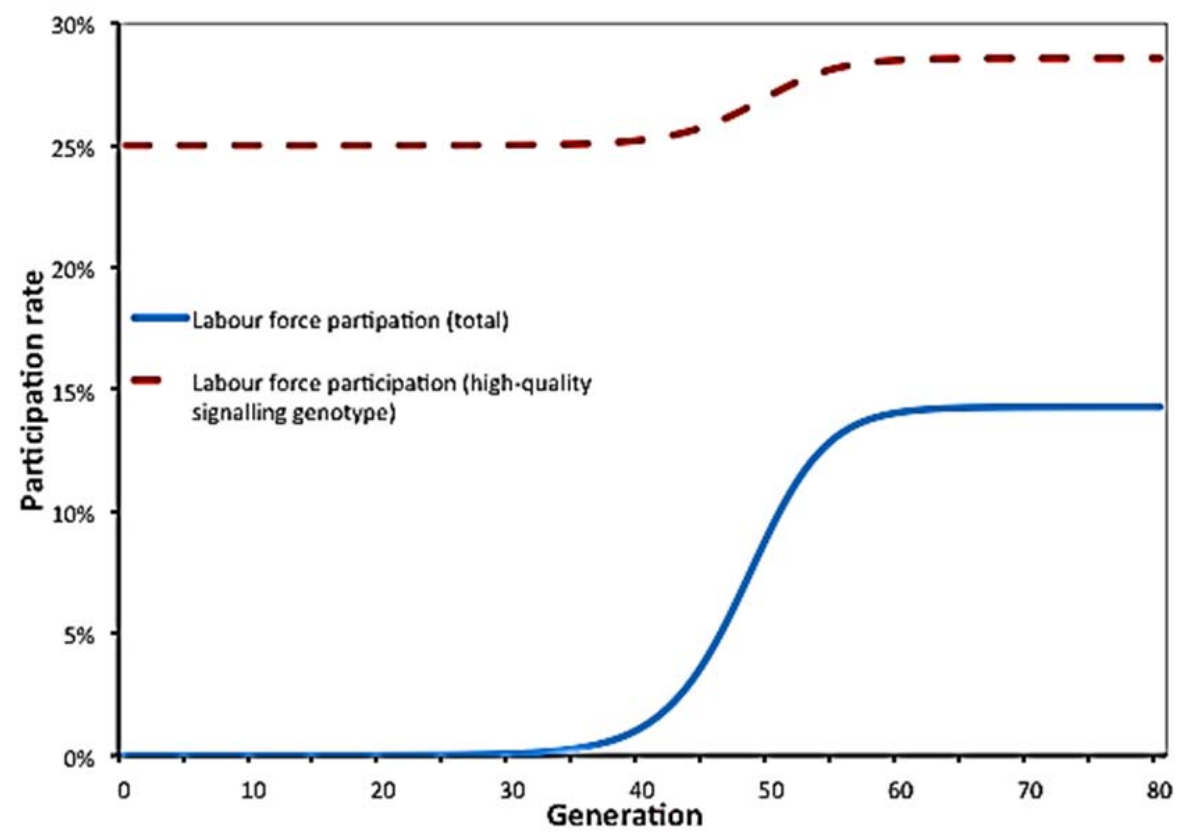

The increase in labour force participation is reflected in the historical record. Reviewing a number of studies, Voth (2000) notes that the average hours worked per day increased from an average of 4.9 hours in hunter-gatherer communities, to 7.4 in mixed communities to 10.9 hours per day in advanced sedentary agricultural communities. Voth also found a rapid increase in labour input around the time of the Industrial Revolution, with the average hours worked by a London resident increasing from 2,288 hours per year in the 1750 s to 3,366 hours per year in 1800-1803 and 1830 .

The second way in which the signalling genotype contributes to economic growth is through technological progress. As technological progress is a function of the population engaged in the labour force, technological progress increases with the increase in the prevalence of the signalling genotype. Figure 4 shows the growth paths in income and technology, both of which show significant increases with the increased prevalence of signalling behaviour. Initially, technological progress is not matched by income growth due to the low proportion of the population that is engaged in the luxury sector. It is only when there is significant use of the growing technological base by a greater proportion of the population that income growth takes off. Once the signalling allele moves to fixation in the population, technological progress becomes the sole source of income growth as there are no new entrants into the labour force. 


\section{Figure 4: Growth rate of technology and income}

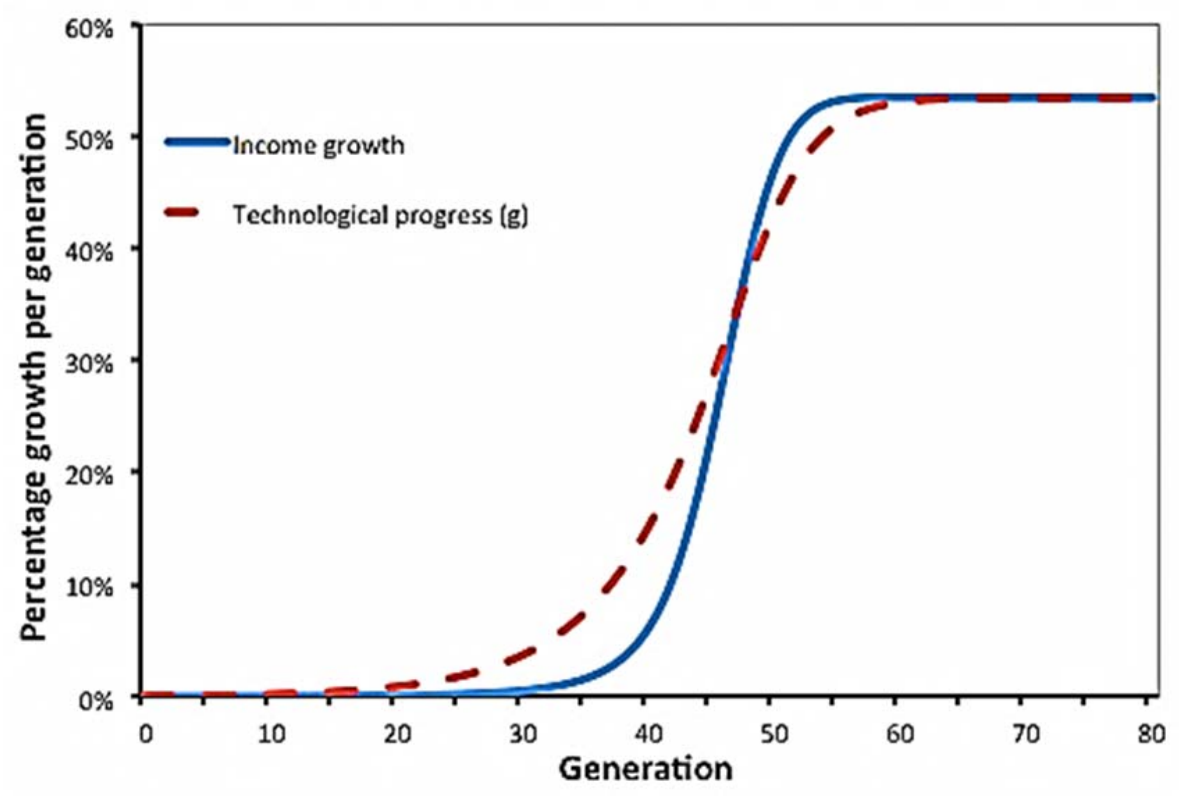

\section{Model with coevolution of male and female preferences}

This section describes a version of the model in which both male and female behaviour is determined genetically. Depending on their genotype, female agents observe the male signal and use that information to infer quality, or they ignore the signal. As a result, male and female signalling and observing behaviour must co-evolve rather than male signalling behaviour exploiting an existing female sensory bias as occurred in the previous model version. Except where noted below, the new model retains the features of the first.

\subsection{The agents}

Each agent now has two autosomal (not sex linked) loci. The allele at each of the two loci expresses signalling and observing strategies for the male and female respectively. While male and female agents carry alleles relating to both signalling and observing behaviour, the signalling allele is expressed phenotypically in the male only, and the observing allele is expressed in the female only.

There are two alleles of each gene: signalling and not signalling $(i \in S, N)$; and observing and not observing $(j \in S, N)$. This leads to four potential haplotypes (the possible combinations of genes), represented by $i j: S S, S N, N S$ and $N N$. 
The frequency of each male phenotype by quality is denoted by $\pi^{i j k}(i \in S, N ; j \in$ $S, N ; k \in H, L)$, while for females it is denoted by $\phi^{i j}(i \in S, N ; j \in S, N ;)$. $\pi^{i j}$ denotes the prevalence of males of genotype $i j$ of either level of quality. Finally, the number of males of type $i$ is:

$$
\Pi_{A}^{i}=\sum_{j=S, N} \pi_{A}^{i j}
$$

while the number of females of type $j$ is:

$$
\Phi_{A}^{j}=\sum_{i=S, N} \phi_{A}^{i j}
$$

The utility function of a male is the number of children they father. Similarly, the utility function of a female is the number of children they bear, which is equal to the quality of the male with whom they mate, as in equations (1) and (2). Children inherit the allele at each locus with equal probability from each parent.

\subsection{The economy}

The economy in the two-locus model is the same as in the single locus model. The one substantive difference is that there are more male genotypes as males also carry the gene that expresses female observing behaviour. Accordingly, the number of efficiency units of labour in the subsistence and luxury sectors are:

$$
\begin{aligned}
& S(t)=M(t) \sum_{k=H, L} \sum_{i=S, N} \sum_{j=S, N} \pi_{A}^{i j k} s^{i j k} h^{k} \\
& L(t)=M(t) h^{H} \sum_{j=S, N} \pi_{A}^{S j H}\left(1-\sum_{j=S, N} s^{S j H}\right)
\end{aligned}
$$

\subsection{The mating season}

As for the single-locus model, each generation lives for one mating season, which comprises three stages. Equal numbers of males and females are born, so before signalling and mortality, the number of each sex is equal.

Males signal subject to a budget constraint and then experience mortality based on the level of subsistence activities. The budget constraint and probability of survival are: 


$$
\begin{aligned}
& c^{i j k} \leq w h^{k}\left(1-s^{S j k}\right) \\
& \delta^{i k}=\delta\left(r s^{i j k}\right) \\
& \delta_{s}^{i k}\left(r s^{i j k}\right)>0 \\
& \delta_{s s}^{i k}\left(r s^{i j k}\right) \leq 0 \\
& \delta(0)=0 \\
& \delta(r) \leq 1
\end{aligned}
$$

As the probability of survival of a male is not affected by the observing allele at locus $j$, the $j$ subscript is dropped.

After pre-breeding mortality in stage A, the number of males who are available to mate in stage $\mathrm{B}$ is:

$$
M_{B}=\sum_{k=H, L} \sum_{i=S, N} \sum_{j=S, N} \pi_{A}^{i j k} \delta^{i k} M_{A}
$$

The prevalence of surviving males of each type is:

$$
\begin{aligned}
& \pi_{B}^{i j k}=\pi_{A}^{i j k} \delta^{i k} \frac{M_{A}}{M_{B}} \\
& i \in S, N \quad j \in S, N \quad k \in H, L
\end{aligned}
$$

The number of females does not change between stage A and B, as there is no female mortality.

A male always agrees to mate with the female he is matched with, as there is no cost to mating for males. The probability of being matched in stage B is one for a male, as male mortality ensures that there are more males than females. The probability of a female being matched with a male is:

$$
q_{B}^{F}=\sum_{k=H, L i=S, N} \sum_{j=S, N} \pi_{A}^{i j k} \delta^{i k}
$$

If a female is paired in stage $\mathrm{B}$, a female of the observing phenotype ( $S S$ or $N S$ ) observes the signal of the male and uses that signal to determine whether she will mate with the male. If she does choose to mate, the female exits the mating pool. If she is of the non-observing phenotype ( $S N$ or $N N$ ), she will mate with the male regardless of his signal or quality. Accordingly, non-observing females are only present in stage $\mathrm{C}$ if they are not paired in stage B. 
The number of males and the ratio of types of males do not change between stages $\mathrm{B}$ and $\mathrm{C}$.

$$
\pi_{C}^{i j k}=\pi_{B}^{i j k}
$$

The number of females available for mating in stage $\mathrm{C}$ decreases by the number who mate in stage B. Females exit the breeding pool if they are a observing genotype and are matched with a high-quality signalling male, or, if they are not a observing genotype and are matched at all.

$$
F_{C}=\left(\Phi_{B}^{S}\left(1-q_{B}^{F} \sum_{j=S, N} \pi_{B}^{S j H}\right)+\Phi_{B}^{N}\left(1-q_{B}^{F}\right)\right) F_{B}
$$

The proportion of females of each phenotype present in stage $\mathrm{C}$ is:

$$
\begin{aligned}
& \Phi_{C}^{S}=\Phi_{B}^{S}\left(1-q_{B}^{F} \sum_{j=S, N} \pi_{B}^{S j H}\right) \frac{F_{B}}{F_{C}} \\
& \Phi_{C}^{N}=\Phi_{B}^{N}\left(1-q_{B}^{F}\right) \frac{F_{B}}{F_{C}}
\end{aligned}
$$

It is possible for males and females to be unmatched in stage $C$ (as in equations (18) and (19)). In stage C, males and females will mate with whoever they are matched, as females will have no further opportunities to mate. Offspring from the mating in stages $\mathrm{B}$ and $\mathrm{C}$ form the next generation.

\subsection{Female optimisation}

A female carrying the observing allele (haplotype $S S$ and $N S$ ) will mate in stage B if the benefit exceeds the expected benefit of waiting. The future benefit is a function of the probability that she will be matched to a male in stage $\mathrm{C}$ and the expected quality of that male. She will mate with the male of quality $h^{k}$ in stage B if:

$$
n\left(h^{k}\right) \geq q_{C}^{F} \sum_{i=S, N} \sum_{j=S, N}\left(\pi_{C}^{i j H} n\left(h^{H}\right)+\pi_{C}^{i j L} n\left(h^{L}\right)\right)
$$


This will only be satisfied for a low-quality male if:

$$
n\left(h^{L}\right) \geq \frac{q_{C}^{F} \sum_{i=S, N} \sum_{j=S, N} \pi_{C}^{i j H}}{1-q_{C}^{F} \sum_{i=S, N} \sum_{j=S, N} \pi_{C}^{i j L}} n\left(h^{H}\right)
$$

As for the single-locus model and the similar condition stated in equation (21), we assume that equation (58) is not satisfied. This is a weaker assumption in the current model due to paired, non-observing females exiting the breeding pool with certainty in stage B, making it unlikely that there will be excess females in stage C. As in the earlier model, the decision of the female is binary, based on the threshold level of conspicuous consumption $\bar{c}$ that is given in equation (22).

\subsection{Male optimisation}

The male's utility (fitness) function is:

$$
\begin{aligned}
& u_{t}^{S j k}=\delta^{S k}\left(\left(\alpha\left(c_{t}^{i j k}\right) \Phi_{B}^{S}+\Phi_{B}^{N}\right) q_{B}^{M}+q_{C}^{M}\right) n\left(h^{k}\right) \\
& u_{t}^{N k}=\delta^{S k}\left(\Phi_{B}^{N} q_{B}^{M}+q_{C}^{M}\right) n\left(h^{k}\right)
\end{aligned}
$$

Substituting equation (9) into equations (59) and (60), a male of generation $t$ faces the following optimisation problem:

$$
\begin{aligned}
& \left\{s_{t}^{S j k}\right\}=\operatorname{argmax}\left\{\delta^{S k}\left(\left(\alpha\left(w_{t} h_{k}\left(1-s_{t}^{S j k}\right)\right) \Phi_{B}^{S}+\Phi_{B}^{N}\right) q_{B}^{M}+q_{C}^{M}\right) n\left(h^{k}\right)\right\} \\
& \left\{s_{t}^{N j k}\right\}=\operatorname{argmax}\left\{\delta^{N k} q_{C}^{M} n\left(h^{k}\right)\right\}
\end{aligned}
$$

Solving equation (61) for the signalling genotype gives:

$$
\delta_{s}^{S k}\left(\left(\alpha \Phi_{B}^{S}+\Phi_{B}^{N}\right) q_{B}^{M}+q_{C}^{M}\right)=\delta^{S k} w_{t} h^{k} \alpha_{s} q_{B}^{M}
$$

As before, the male invests in conspicuous consumption until the marginal gain in fitness through additional mating opportunity is equal to the marginal loss through decreased survival. 
Since the female decision is binary, a high-quality signalling male will signal where the following condition holds:

$$
\left(q_{B}^{M}+q_{C}^{M}\right) \delta^{S H}>\left(\Phi_{A}^{N}+q_{C}^{M}\right) \delta^{N H}
$$

If $M_{C}<F_{C}$, equation (64) is satisfied where:

$$
2 \delta^{S H}>\delta^{N H}\left(\Phi_{A}^{N}+1\right)
$$

This condition reflects that high-quality, signalling males mate with certainty in both periods, while all other male phenotypes mate in stage B if they are paired with a non-choosy female, and with certainty in stage C. If most females are of the observing genotype, a male will be willing to sacrifice only a small probability of survival to signal to females.

If $M_{C}>F_{C}$, equation (64) is satisfied where:

$$
\left(1+q_{C}^{M}\right) \delta^{S H}>\left(\Phi_{A}^{N}+q_{C}^{M}\right) \delta^{N H}
$$

The condition in equation (66) is easier to satisfy than that in equation (65). This is because the reduced probability of being paired in stage $\mathrm{C}$ makes the opportunity to pair in stage B relatively more important.

For the non-signalling and low-quality phenotypes, they spend all of their time on survival activities.

$$
\begin{aligned}
& S_{t}^{N j k}=1 \\
& s_{t}^{S j L}=1
\end{aligned}
$$




\subsection{Offspring}

Offspring are born and raised at the end of the mating season. Assuming the signalobserving females accept the high-quality males who signal, the offspring of each genotype $\left(n^{i j}\right)$ born from mating in stage B are:

$$
\begin{aligned}
n_{B}^{S S}= & \left(\left(\pi_{B}^{S S H}\left(\phi_{B}^{S S}+\frac{1}{2} \phi_{B}^{N S}\right)+\pi_{B}^{S N H}\left(\frac{1}{2} \phi_{B}^{S S}+\frac{1}{4} \phi_{B}^{N S}\right)\right) n\left(h^{H}\right)\right. \\
& \left.+\sum_{k=H, L}\left(\pi_{B}^{S S k}\left(\frac{1}{2} \phi_{B}^{S N}+\frac{1}{4} \phi_{B}^{N N}\right)+\frac{1}{4} \pi_{B}^{N S k} \phi_{B}^{S N}\right) n\left(h^{k}\right)\right) M_{B} \\
n_{B}^{S N}= & \left(\left(\pi_{B}^{S N H}\left(\frac{1}{2} \phi_{B}^{S S}+\frac{1}{4} \phi_{B}^{N S}\right)\right) n\left(h^{H}\right)+\sum_{k=H, L}\left(\pi_{B}^{S S k}\left(\frac{1}{2} \phi^{S N}+\frac{1}{4} \phi_{B}^{N N}\right)\right.\right. \\
& \left.\left.+\pi_{B}^{S N k}\left(\phi_{B}^{S N}+\frac{1}{2} \phi_{B}^{N N}\right)+\frac{1}{4} \pi_{B}^{N S k} \phi_{B}^{S N}+\frac{1}{2} \pi_{B}^{N N k} \phi_{B}^{S N}\right) n\left(h^{k}\right)\right) M_{B} \\
n_{B}^{N S}= & \left(\left(\frac{1}{2} \pi_{B}^{S S H} \phi^{N S}+\frac{1}{4} \pi_{B}^{S N H} \phi_{B}^{N S}\right) n\left(h^{H}\right)\right. \\
& \left.+\sum_{k=H, L}\left(\frac{1}{4} \pi_{B}^{S S k} \phi_{B}^{N N}+\pi_{B}^{N S k}\left(\frac{1}{4} \phi_{B}^{S N}+\frac{1}{2} \phi_{B}^{N N}\right)\right) n\left(h^{k}\right)\right) M_{B} \\
& \left.\left.+\pi_{B}^{N S k}\left(\frac{1}{4} \phi_{B}^{S S}+\frac{1}{2} \phi_{B}^{N N}\right)+\pi_{B}^{N N k}\left(\frac{1}{2} \phi_{B}^{S N}+\phi_{B}^{N N}\right)\right) n\left(h^{k}\right)\right) M_{B} \\
n_{B}^{N N}= & \left(\frac{1}{4} \pi_{B}^{S N H} \phi_{B}^{N S} n\left(h^{H}\right)+\sum_{k=H, L}\left(\frac{1}{4} \pi_{B}^{S S k} \phi_{B}^{N N}+\frac{1}{2} \pi_{B}^{S N k} \phi_{B}^{N N}\right.\right.
\end{aligned}
$$

The offspring born because of mating in stage $\mathrm{C}$ are:

$$
\begin{aligned}
n_{C}^{S S} & =\sum_{k=H, L}\left(\pi_{B}^{S S k}\left(\phi_{C}^{S S}+\frac{1}{2} \phi_{C}^{S N}+\frac{1}{2} \phi_{C}^{N S}+\frac{1}{4} \phi_{C}^{N N}\right)+\pi_{B}^{S N k}\left(\frac{1}{2} \phi_{C}^{S S}+\frac{1}{4} \phi_{C}^{N S}\right)\right. \\
& \left.+\pi_{B}^{N S k}\left(\frac{1}{2} \phi_{C}^{S S}+\frac{1}{4} \phi_{C}^{S N}\right)+\frac{1}{4} \pi_{B}^{N N k} \phi_{C}^{S S}\right) n\left(h^{k}\right) \min \left\{M_{C}, F_{C}\right\} \\
n_{C}^{S N} & =\sum_{k=H, L}\left(\pi_{B}^{S S k}\left(\frac{1}{2} \phi_{C}^{S N}+\frac{1}{4} \phi_{C}^{N N}\right)+\pi_{B}^{S N k}\left(\frac{1}{2} \phi_{C}^{S S}+\phi_{C}^{S N}+\frac{1}{4} \phi_{C}^{N S}+\frac{1}{2} \phi_{C}^{N N}\right)\right. \\
& \left.+\frac{1}{4} \pi_{B}^{N S k} \phi_{C}^{S N}+\pi_{B}^{N N k}\left(\frac{1}{4} \phi_{C}^{S S}+\frac{1}{2} \phi_{C}^{S N}\right)\right) n\left(h^{k}\right) \min \left\{M_{C}, F_{C}\right\}
\end{aligned}
$$




$$
\begin{aligned}
n_{C}^{N S} & =\sum_{k=H, L}\left(\pi_{B}^{S S k}\left(\frac{1}{2} \phi_{C}^{N S}+\frac{1}{4} \phi_{C}^{N N}\right)+\frac{1}{4} \pi_{B}^{S N k} \phi_{C}^{N S}\right. \\
& +\pi_{B}^{N S k}\left(\frac{1}{2} \phi_{C}^{S S}+\frac{1}{4} \phi_{C}^{S N}+\phi_{C}^{N S}+\frac{1}{2} \phi_{C}^{N N}\right) \\
& \left.+\pi_{B}^{N N k}\left(\frac{1}{4} \phi_{C}^{S S}+\frac{1}{2} \phi_{C}^{N S}\right)\right) n\left(h^{k}\right) \min \left\{M_{C}, F_{C}\right\} \\
n_{C}^{N N} & =\sum_{k=H, L}\left(\frac{1}{4} \pi_{B}^{S S k} \phi_{C}^{N N}+\pi_{B}^{S N k}\left(\frac{1}{4} \phi_{C}^{N S}+\frac{1}{2} \phi_{C}^{N N}\right)+\pi_{B}^{N S k}\left(\frac{1}{4} \phi_{C}^{S N}+\frac{1}{2} \phi_{C}^{N N}\right)\right. \\
& \left.+\pi_{B}^{N N k}\left(\frac{1}{4} \phi_{C}^{S S}+\frac{1}{2} \phi_{C}^{S N}+\frac{1}{2} \phi_{C}^{N S}+\phi_{C}^{N N}\right)\right) n\left(h^{k}\right) \min \left\{M_{C}, F_{C}\right\}
\end{aligned}
$$

Whether the signalling or non-signalling male phenotype has a higher fertility rate is dependent on the death rate of signalling genotypes and the number of additional matings the signalling genotypes get due to their signalling. The prevalence of the signalling allele in generation $t+1$ is:

$$
\begin{aligned}
\Pi^{S}(t+1) & =\frac{n_{B}^{S S}+n_{B}^{S N}+n_{C}^{S S}+n_{C}^{S N}}{\sum_{i=S, N} \sum_{j=S, N}\left(n_{B}^{i j}+n_{C}^{i j}\right)} \\
& \equiv \Pi\left(p, \pi_{A}^{i j}(t), h^{L}, h^{H}\right) \quad i \in S, N \quad j \in S, N
\end{aligned}
$$

The prevalence of the signalling type in the population increases if:

$$
\Pi^{S}(t+1)>\Pi^{S}(t)
$$

Equations (76) and (77) can be used to derive the conditions for the male deciding to signal, which were shown in equations (65) and (66). The prevalence of the signalling allele increases in the population if those conditions are met.

The prevalence of the observing allele in generation $t+1$ is:

$$
\begin{aligned}
\Phi^{S}(t+1) & =\frac{\sum_{i=S, N}\left(n_{B}^{i S}+n_{C}^{i S}\right)}{\sum_{i=S, N} \sum_{j=S, N}\left(n_{B}^{i j}+n_{C}^{i j}\right)} \\
& \equiv \Phi\left(p, \pi_{A}^{i j}(t), h^{L}, h^{H}\right) \quad i \in S, N \quad j \in S, N
\end{aligned}
$$


The prevalence of the observing allele increases if the condition given in equation (79), derived from equations (68) through (75) and equation (78), is satisfied.

$$
\begin{aligned}
& \sum_{j=S, N} \pi_{A}^{S j H} \delta^{S H} n\left(h^{H}\right) M_{A} \\
& +\left(1-\sum_{j=S, N} \pi_{B}^{S j H}\right) q_{C}^{F} \sum_{k=H, L} \sum_{i=S, N} \sum_{j=S, N} \pi_{B}^{i j k} n\left(h^{k}\right) \min \left\{M_{C}, F_{C}\right\} \\
& >\sum_{k=H, L} \sum_{i=S, N} \sum_{j=S, N} \pi_{A}^{i j k} \delta^{i k}\left(h^{k}\right) M_{A}
\end{aligned}
$$

This condition shows that the frequency of the observing allele will increase if the number of children born due to mating with high-quality, signalling males in stage B or whoever they are paired with in stage $\mathrm{C}$ exceeds the number of children born if the

female always mates in stage $\mathrm{B}$. If $M_{C}>F_{C}$, this condition is always satisfied as there is no cost to females for rejecting males in stage B. If $M_{C}<F_{C}$, the additional probability of mating with a high-quality male must outweigh the cost of not being paired in stage $\mathrm{C}$.

It is not strictly necessary that equations (65) and (66) for the signalling allele and equation (79) for the observing allele are all satisfied for the prevalence of either allele to increase. As signalling genotypes tend to mate with observing genotypes with higher frequency than other mating combinations, there is a higher than expected proportion of agents carrying both signalling and observing alleles than would be expected from random distribution of the alleles through the population. In evolutionary biology, this is known as linkage disequilibrium (Ridley 2004). With linkage disequilibrium, reproductive success associated with one type of allele may result in another allele increasing in frequency despite there being no fitness advantage for that second allele.

\subsection{Signalling equilibrium}

The signalling equilibrium is similar to that in the single-locus model. As before, the optimal level of conspicuous consumption by a high-quality male is that which a low-quality male will be indifferent about making.

However, as many of the females in the population do not respond to signals, the benefits to signalling for a male are lower based on the initially high probability that they will be paired with a female that does not respond to their signal. Accordingly, 
high-quality signalling males tend to signal through a lower level of conspicuous consumption until the prevalence of observing females increases.

As $\bar{c}$ is the size of the signal for which a low-quality male is indifferent about signalling, we can use equation (64) to determine the proportion of time a high-quality male will allocate to subsistence activities. With $\hat{s}$ the level of subsistence that a low-quality male is indifferent about making, we can derive the following equation:

$$
\left(1+q_{C}^{M}\right) \delta(r \hat{s})=\left(\Phi_{A}^{N}+q_{C}^{M}\right) \delta(r)
$$

If $M_{C}<F_{C}$, the relationship becomes:

$$
\delta(r \hat{s})>\frac{\left(\Phi_{A}^{N}+1\right)}{2} \delta(r)
$$

If $M_{C}>F_{C}$ the relationship becomes:

$$
\delta(r \hat{s})=\frac{\left(\Phi_{A}^{N}+q_{C}^{M}\right)}{\left(1+q_{C}^{M}\right)} \delta(r)
$$

Again, $s^{S H}$, the level of signalling by the high-quality signalling male can be derived from equation (82) using equation (41). Specification of a function for $\delta$ will allow for the relationship between $\hat{s}$ and $s^{S H}$ to be solved.

To determine which of these equations will apply, we must consider whether there will be more males or females in stage C. As such, we will have to solve equation (83) in iteration with equations (81) and (82). $M_{C}>F_{C}$ holds if:

$$
\left(1+\Phi_{B}^{N}\right) \sum_{j=S, N} \sum_{i=S, N} \sum_{k=H, L} \pi_{A}^{i j k} \delta^{i k}>1-\Phi_{B}^{S} \sum_{j=S, N} \pi_{A}^{S j H} \delta^{S H}
$$

\subsection{Model dynamics}

If a high-quality male signals in a separating equilibrium, the prevalence of the signalling allele will increase. This will in turn increase labour force participation and the rate of technological progress, driving an increase in income and economic growth. 
The dynamics of the evolution of the model agents is determined by the difference equations (76) and (78). A summary of the dynamical system for all endogenous variables is:

$$
\begin{aligned}
& \pi_{A}^{i j}(t+1) \equiv \pi\left(p, \pi_{A}^{i j}(t), h^{L}, h^{H}\right) \quad i \in S, N \quad j \in S, N \\
& \phi_{A}^{i j}(t+1) \equiv \pi_{A}^{i j}(t+1) \quad i \in S, N \quad j \in S, N \\
& A(t+1)=\left[1+g\left(p, \pi_{A}^{S j}(t), \phi^{i S}(t), h^{k}\right)\right] A(t) \quad i \in S, N ; \quad j \in S, N \\
& Y(t) \equiv Y(\alpha, \rho, L(t)) \\
& L(t) \equiv L\left(p, \pi_{A}^{S j}(t), \phi^{i S}(t), h^{L}, h^{H}\right) \quad i \in S, N ; \quad j \in S, N
\end{aligned}
$$

Again, the model is simulated using equation (43) for survival probability, and setting the parameters as in Table 2 .

Table 2: Model parameters for simulation

\begin{tabular}{|l|c|l|c|}
\hline & & Description & Value \\
\hline \multirow{4}{*}{ Parameters } & $\alpha$ & Output elasticity of labour & 0.5 \\
\cline { 2 - 4 } & $\rho$ & Output elasticity of labour in subsistence sector & 1 \\
\cline { 2 - 4 } & $h^{L}$ & Quality of low-quality males & 0.209 \\
\cline { 2 - 4 } & $h^{H}$ & Quality of high-quality males & 0.15 \\
\cline { 2 - 4 } Initial & $p$ & Proportion of high-quality males at birth & 0.5 \\
\hline \multirow{5}{*}{ values } & $\pi^{S}$ & Initial prevalence of signalling allele (S) & 0.01 \\
\cline { 2 - 4 } & $\phi^{S}$ & Initial prevalence of observing allele (S) & 0.01 \\
\cline { 2 - 4 } & $A$ & Level of technology & 1 \\
\cline { 2 - 4 } & $Y$ & Income & 1 \\
\cline { 2 - 4 } & $g$ & Rate of technological progress & 0 \\
\cline { 2 - 4 } & $X$ & Land & 1 \\
\hline
\end{tabular}

Figure 5 shows the proportion of signalling and observing alleles in the population. The increase in prevalence of the signalling allele is significantly slower than that in the first model in which all females have a genetic predisposition to observe male conspicuous consumption. It takes approximately 350 generations for the prevalence of the signalling allele and almost 500 generations for the prevalence of the observing allele to 
double to two per cent. Over 700 generations have passed before the prevalence of either reaches 10 per cent, but then the spread of the alleles increases markedly and over the next 150 generations, each allele increases to a prevalence of over 99 per cent.

The prevalence of observing females increases in tandem with the proportion of signalling males. This makes the signalling or observing behaviour more rewarding, meaning that the strength of selection on each allele increases as the prevalence of the other increases.

\section{Figure 5: Prevalence of signalling and observing alleles}

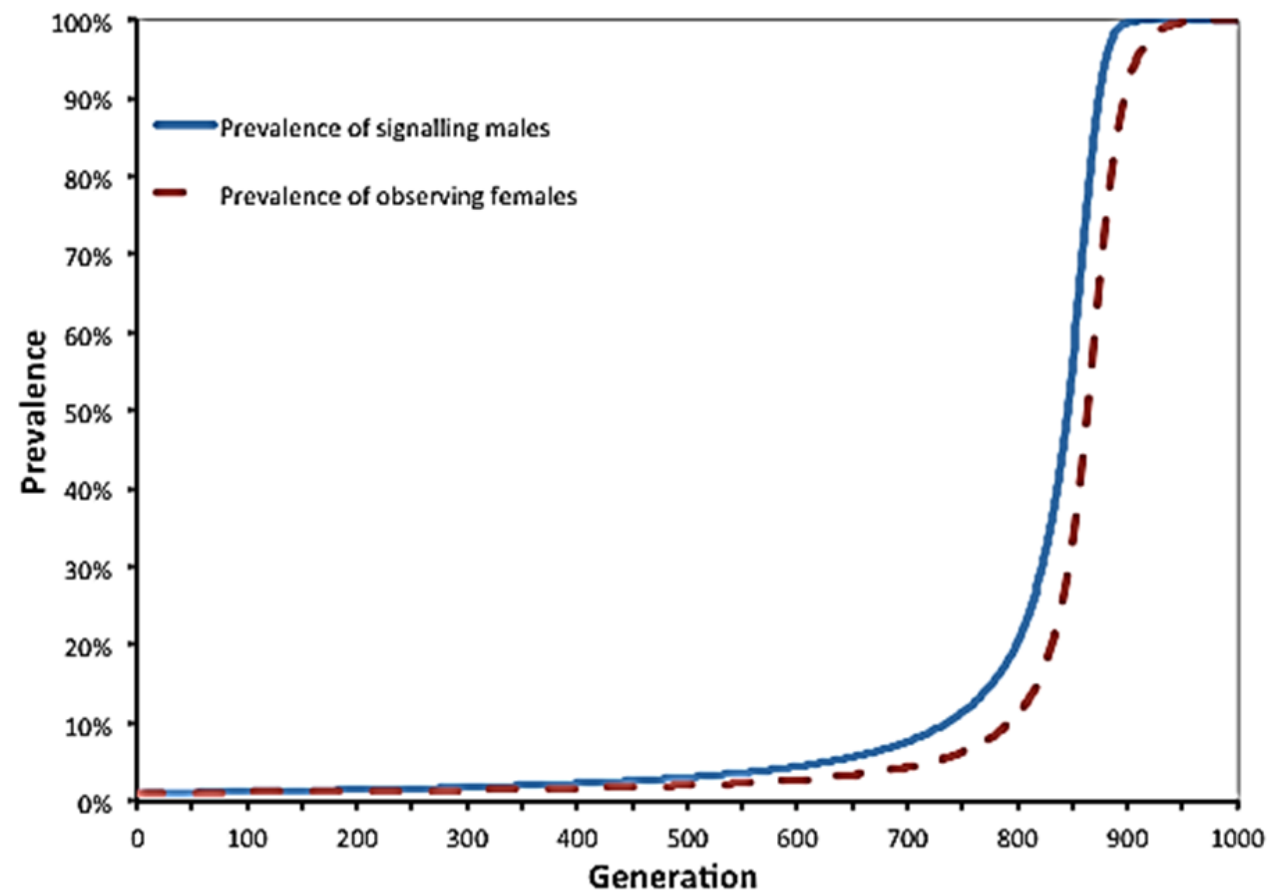

As before, the proportion of the signalling genotype feeds into the economy through increased labour force participation and increased technological progress through the scale effect. Labour force participation, even for signalling genotypes, is initially low due to the low benefits to signalling from the low proportion of observing females. It is only when the prevalence of observing females increases that significant time is allocated to labour in the luxury sector. Total labour force participation increases due to both increasing participation by signalling genotypes and their increasing prevalence. 
Figure 6: Allocation of time of agents

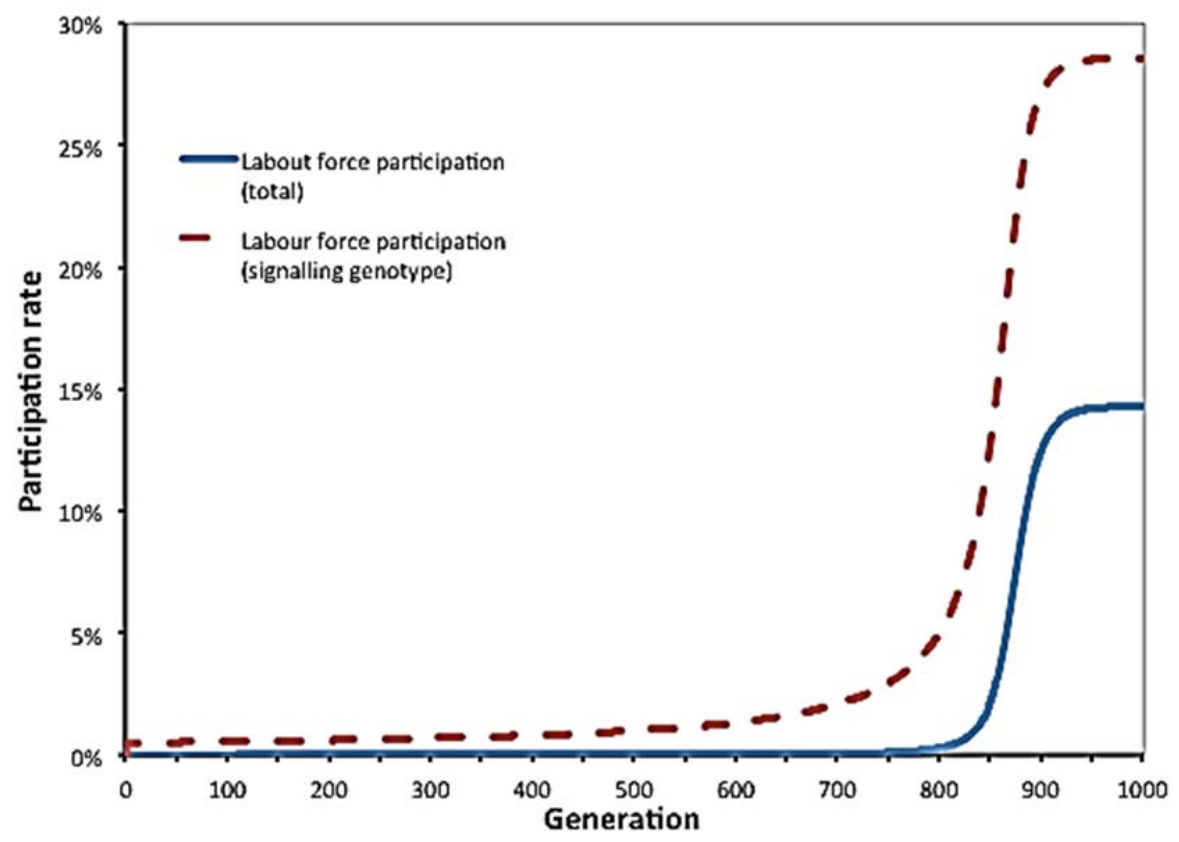

Figure 7 shows the growth paths in technology and income. For the first 500 generations, the rate of technological progress exceeds income growth due to the low proportion of the population that is engaged in the luxury sector. It is only when there is significant use of the growing technological base by a greater proportion of the population that income growth takes off. Once the signalling allele moves to fixation in the population, technological progress becomes the sole source of income growth, as there are no new entrants into the labour force.

\section{Figure 7: Growth rate of technology and income}

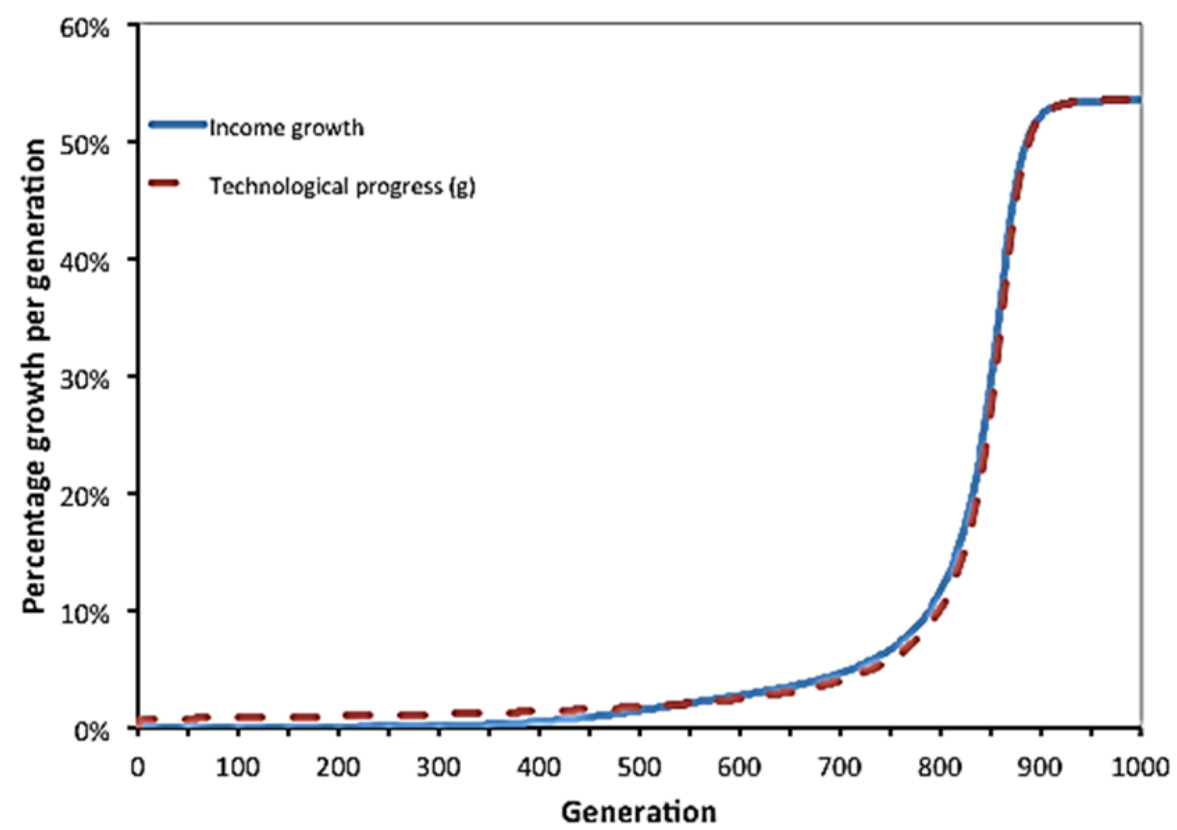




\section{Discussion}

The two models presented above provide a basis for the hypothesis that the male signalling behaviour necessary to attract potential mates underpins modern levels of economic growth. As females prefer males who conspicuously consume, an increasing proportion of males engage in innovation, labour and other productive activities in order to engage in conspicuous consumption. These activities contribute to technological progress and economic growth.

Which of the two versions of the model is more realistic is unclear. Positive responses to expensive watches and cars, to which females have had limited exposure in our evolutionary history, suggest significant flexibility over short timeframes in human perception of what is a reliable signal. Conversely, anthropological evidence and the ubiquity of conspicuous consumption in human society suggest a deep evolutionary basis to this trait, which may have developed over significant time (Sundie et al. 2011).

The core condition for a handicap to be an honest signal is different costs (or benefits) of signalling between high and low-quality signallers. In our model, the difference in costs to signalling arises from the difference in wages that each high and low-quality male can earn in the luxury sector of the economy, which produces conspicuous consumption goods. Even if there was no such wage difference, the necessary condition for existence of the handicap as an honest signal could have been met through alternative means. The models could be reframed so that high and low-quality males experienced different costs to allocating time away from subsistence activities, with the survival probability for low-quality males declining faster. By amending the survival equation (10) to also be a function of quality and stating the second order equation as a strict inequality, as shown in equation (84), the condition for the handicap principle would hold even in the absence of a wage differential. The increased survival cost faced by a low-quality male would allow a separating equilibrium to exist.

$$
\begin{aligned}
& \delta^{i k}=\delta\left(r s^{i k}+h^{k}\right) \quad \delta_{s}^{i k}\left(r s^{i k}+h^{k}\right)>0 \quad \delta_{s s}^{i k}\left(r s^{i k}+h^{k}\right)<0 \\
& \delta(0)=0 \quad \delta(r+1) \leq 1
\end{aligned}
$$


If it were assumed that the "quality" trait affected multiple areas, including survival probability and labour efficiency, the condition for the handicap would be met in multiple dimensions.

The two models differ greatly in the speed at which the conspicuous consumption behaviour spreads through the population. The first model produces significant changes in economic behaviour within one to two hundred years, resulting a rapid take-off in economic growth, similar to that which occurred around the time of the Industrial Revolution. The second model gives rise to longer-term trends in economic growth, which, when combined with population growth, may not result in observable per capita income changes for long periods.

In both models, sexual selection does not affect the quality of the agents. Quality is allocated randomly at birth, which made the model tractable for an analysis of the handicap principle. If quality were genetically transmitted between generations, selection of high-quality individuals would tend to drive the genes associated with high quality to fixation, at which point female choice would become obsolete. A more realistic but complicated scenario would be to introduce multiple genes associated with quality and allow mutations of these genes. This would allow selection by females to remain important, while allowing qualitative population changes to occur. We consider that this scenario would be more representative of the human evolutionary history, with the propensity for conspicuous consumption and qualitative traits both being selected for in the population.

In addition to being a signal of quality, conspicuous consumption is a signal of underlying wealth, which is likely to be of value to a female in itself. Female interest in wealth accumulation is likely to play a significant role in the evolution of a preference for conspicuous consumption. In the models in this paper, agents do not accumulate wealth as there is no capital and there is no transmission of resources from males to females. The ability to accumulate wealth may change the inherent trade-offs between quality and signalling ability, particularly if resources can be transmitted to children.

One omission is the positive effect on survival of the activities undertaken to support conspicuous consumption. The labour and innovation of previous centuries has not only improved the methods to acquire resources for conspicuous consumption, but has also affected basic survival probability. In modern developed-country economies, survival to 
adulthood is likely with probability above 99 per cent (Department of Economic and Social Affairs 2011). Since conspicuous consumption imposes no real cost on survival in modern contexts, everyone engages in conspicuous consumption to the extent their wealth permits. This might be incorporated into the model through allowing some portion of returns to conspicuous consumption to eventually be used to improve survival probability or by providing for spill-over of technological progress into the subsistence sector.

This is not to say, however, that conspicuous consumption can have no survival cost today. Conspicuous consumption also occurs in poor societies, often at significant cost to the signallers. It has been theorised that conspicuous consumption is more important in poor societies than in societies with higher income as in developed countries people can signal through career, qualifications or other costly methods of demonstrating quality (Moav \& Neeman 2012).

\section{References}

Andersson, M 1994, Sexual Selection, Princeton University Press, Princeton.

Basolo, AL 1990, 'Female Preference Predates the Evolution of the Sword in Swordtail Fish', Science, vol. 250, no. 4982, pp. 808-810.

Bateman, AJ 1948, 'Intra-sexual selection in Drosophila', Heredity, vol. 2, no. 3, pp. 349-368.

Borgerhoff Mulder, M 1990, 'Kipsigis Women's Preferences for Wealthy Men: Evidence for Female Choice in Mammals', Behavioral Ecology and Sociobiology, vol. 27, no. 4, pp. 255-264.

Brown, GR, Laland, KN \& Mulder, MB 2009, 'Bateman's principles and human sex roles', Trends in Ecology and Evolution, vol. 24, no. 6, pp. 297-304.

Clark, G 2007, A Farewell to Alms: A Brief Economic History of the World, Princeton University Press, Princeton and Oxford.

Cronk, L 1991, 'Wealth, Status, and Reproductive Success among the Mukogodo of Kenya', American Anthropologist, vol. 93, no. 2, pp. 345-360.

Darwin, C 1871, The Descent of Man and Selection in Relation to Sex, John Murray, London.

Department of Economic and Social Affairs 2011, 2009-10 Demographic Yearbook, United Nations, New York. 
Fisher, RA 1930, The Genetical Theory of Natural Selection, Clarendon Press, Oxford.

De Fraja, G 2009, 'The origin of utility: Sexual selection and conspicuous consumption', Journal of Economic Behavior \& Organization, vol. 72, no. 1, pp. 5169.

Frank, RH 1999, Luxury Fever, The Free Press, New York.

Galor, O \& Michalopoulos, S 2011, 'Evolution and the Growth Process: Natural Selection of Entrepreneurial Traits', Journal of Economic Theory.

Galor, O \& Moav, O 2002, 'Natural Selection and the Origin of Economic Growth', Quarterly Journal of Economics, vol. 117, no. 4, pp. 1133-1191.

Grafen, A 1990a, 'Biological signals as handicaps', Journal of Theoretical Biology, vol. 144 , no. 4, pp. 517-546.

Grafen, A 1990b, 'Sexual selection unhandicapped by the fisher process', Journal of Theoretical Biology, vol. 144, no. 4, pp. 473-516.

Griskevicius, V, Tybur, JM, Sundie, JM, Cialdini, RB, Miller, GF \& Kenrick, DT 2007, 'Blatant benevolence and conspicuous consumption: When romantic motives elicit strategic costly signals.', Journal of Personality and Social Psychology, vol. 93, no. 1, pp. $85-102$.

Hopcroft, RL 2006, 'Sex, status, and reproductive success in the contemporary United States', Evolution and Human Behaviour, vol. 27, no. 2, pp. 104-120.

Kremer, M 1993, 'Population Growth and Technological Change: One Million B.C. to 1990', Quarterly Journal of Economics, vol. 108, no. 3, pp. 681-716.

Maynard Smith, J 1978, The Evolution of Sex, Cambridge University Press, Cambridge.

Miller, GF 1999, 'Waste is good', Prospect, no. 38.

Miller, GF 2001, The Mating Mind: How Sexual Choice Shaped the Evolution of Human Nature, Anchor, New York.

Moav, O \& Neeman, Z 2012, 'Saving Rates and Poverty: The Role of Conspicuous Consumption and Human Capital', The Economic Journal, p. no.

Mulder, MB 1987, 'On Cultural and Reproductive Success: Kipsigis Evidence', American Anthropologist, vol. 89, no. 3, pp. 617-634.

R Development Core Team 2010, R: A Language and Environment for Statistical Computing, R Foundation for Statistical Computing, Vienna, Austria.

Ridley, M 2004, Evolution, Blackwell Publishing, Malden.

Romer, PM 1990, 'Endogenous Technological Change', Journal of Political Economy, vol. 98, no. 5, pp. S71-S102.

Ryan, MJ 1990, 'Sexual selection, sensory systems and sensory exploitation', Oxford Surveys in Evolutionary Biology, vol. 7, pp. 157-195. 
Ryan, MJ 1998, 'Sexual Selection, Receiver Biases, and the Evolution of Sex Differences', Science, vol. 281, no. 5385, pp. 1999-2003.

Saad, G 2007, The Evolutionary Bases of Consumption, Lawrence Erlbaum Associates, Mahwah.

Spence, M 1973, 'Job Market Signaling', The Quarterly Journal of Economics, vol. 87, no. 3, pp. 355-374.

Sundie, JM, Kenrick, DT, Griskevicius, V, Tybur, JM, Vohs, KD \& Beal, DJ 2011, 'Peacocks, Porsches, and Thorstein Veblen: Conspicuous Consumption as a Sexual Signaling System', Journal of Personality and Social Psychology, vol. 100, no. 4, pp. 664-680.

Trivers, RL 1972, 'Parental investment and sexual selection', in, Sexual Selection and the Descent of Man 1871-1971, Aldine Publishing Company, Chicago.

Veblen, T 1899, The Theory of the Leisure Class, Macmillan, New York, London.

Voth, H-J 2000, Time and Work in England 1750-1830, Oxford University Press, Oxford.

Wade, MJ 1979, 'Sexual Selection and Variance in Reproductive Success', The American Naturalist, vol. 114, no. 5, pp. 742-747.

Wade, MJ \& Shuster, SM 2004, 'Estimating the Strength of Sexual Selection From YChromosome And Mitochondrial DNA Diversity’, Evolution, vol. 58, no. 7, pp. 16131616.

Zahavi, A 1975, 'Mate selection--A selection for a handicap', Journal of Theoretical Biology, vol. 53, no. 1, pp. 205-214.

Zak, PJ \& Park, KW 2002, 'Population Genetics and Economic Growth', Journal of Bioeconomics, vol. 4, no. 1, pp. 1-38. 


\section{Appendix A: $\mathbf{R}$ code for simulations}

[For the reviewer only - not for publication]

The simulations in this paper were conducted using $\mathrm{R}$, a free language and environment for statistical computing. The software is available from http://www.r-project.org ( $R$ Development Core Team 2010)

\section{A.1 Single-locus genetic model}

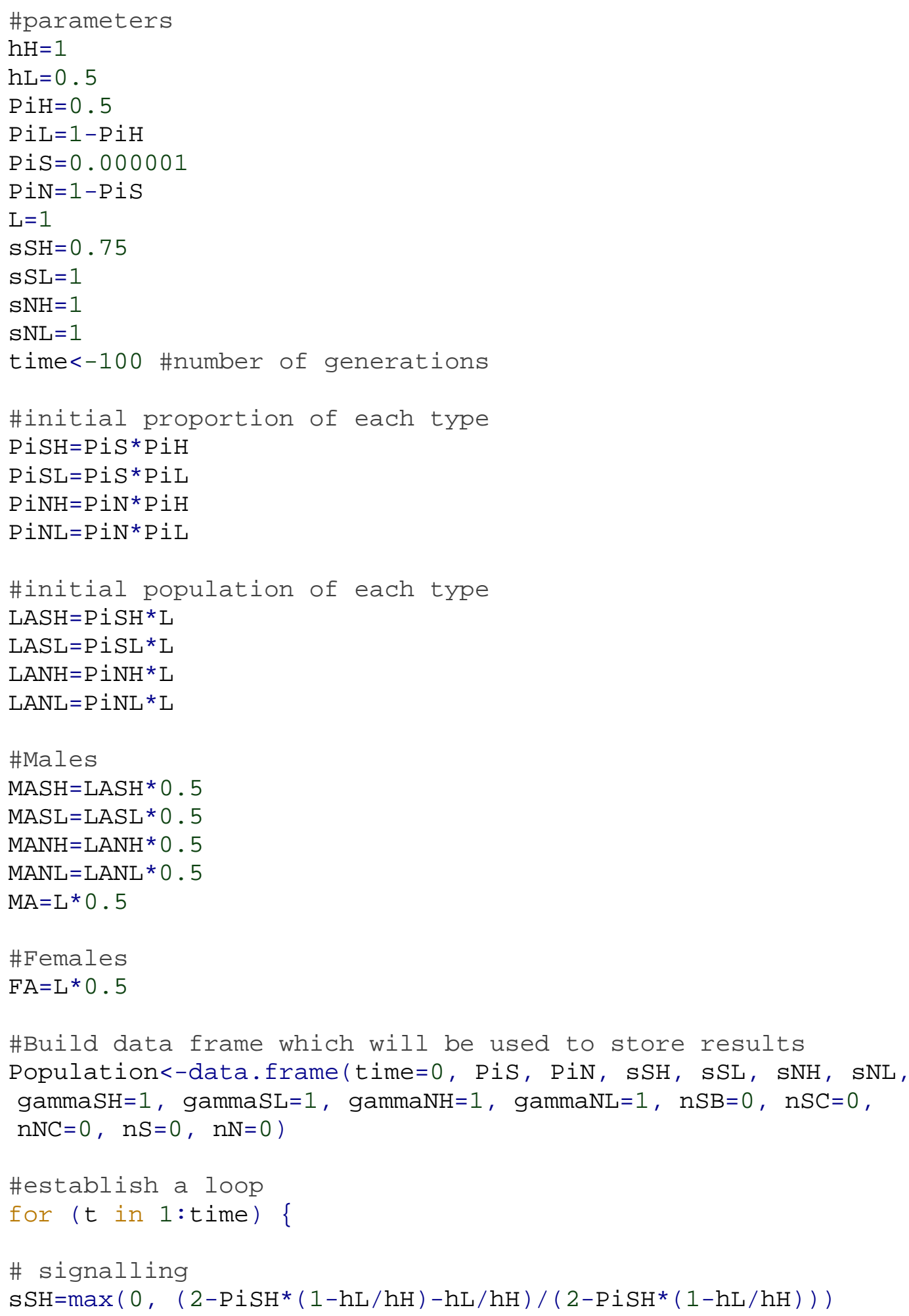




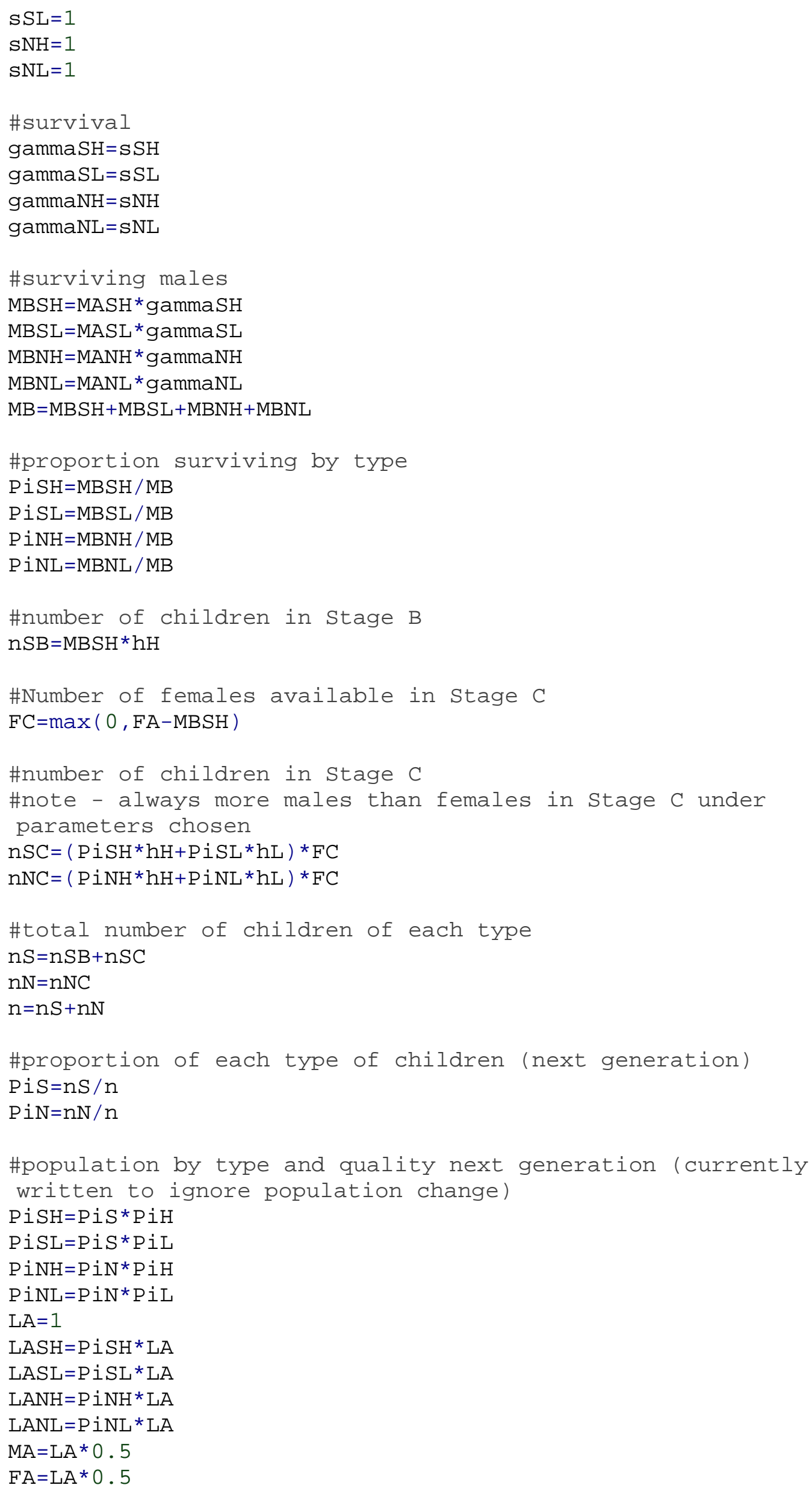




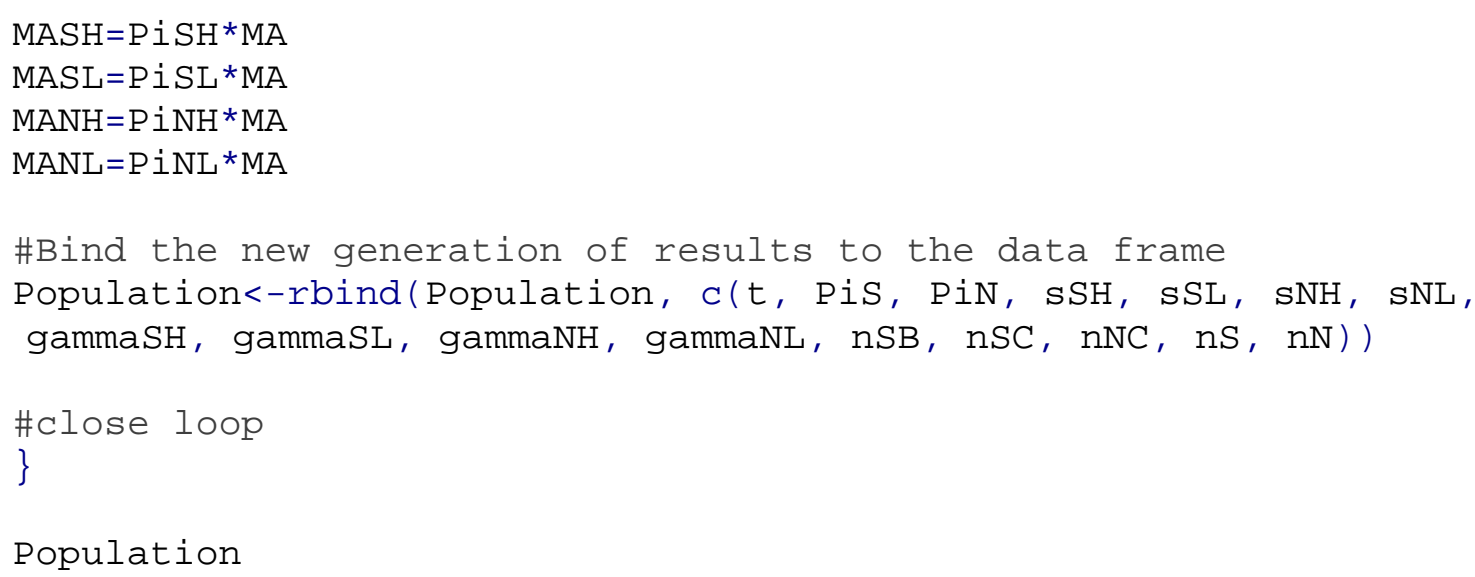

\section{A.2 Two-locus genetic model}

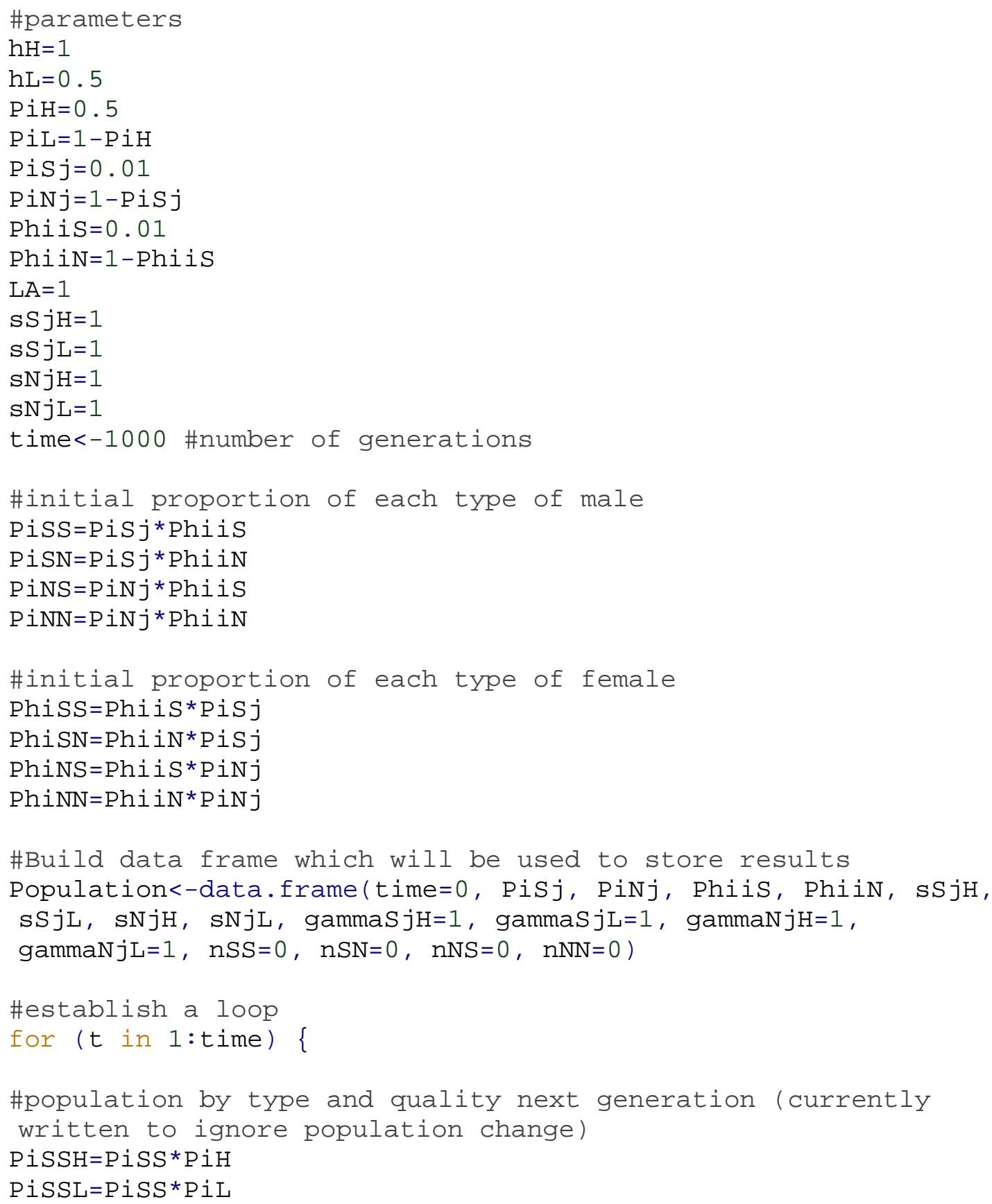




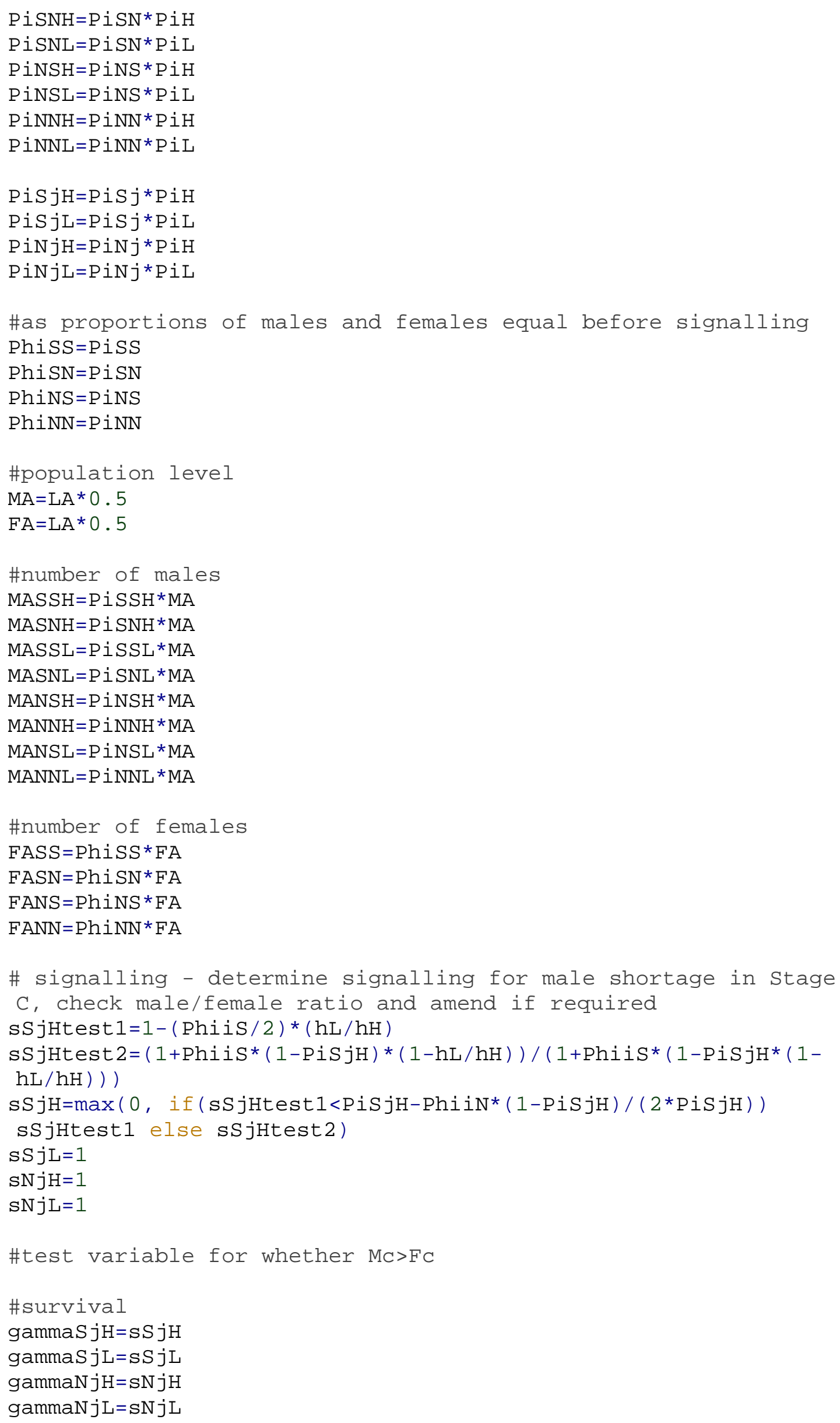




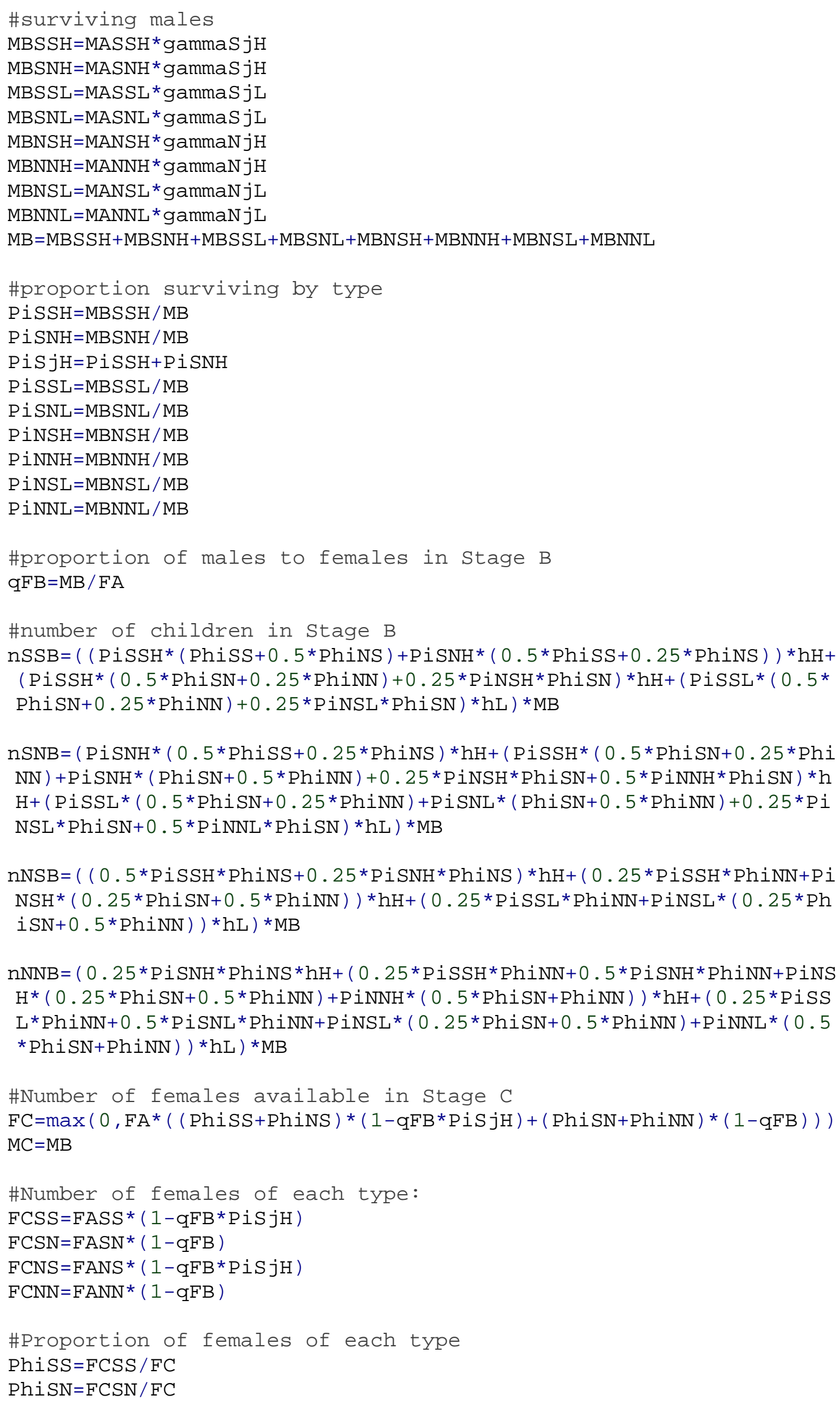


PhiNS $=$ FCNS $/ F C$

PhiNN=FCNN/FC

\#number of children in Stage $C$

nSSC $=\left(\left(\mathrm{PiSSH}{ }^{*}\left(\mathrm{PhiSS}+0.5^{*} \mathrm{PhiSN}+0.5^{*} \mathrm{PhiNS}+0.25^{*} \mathrm{PhiNN}\right)+\mathrm{PiSNH}{ }^{*}\left(0.5^{*} \mathrm{P}\right.\right.\right.$ hiSS $\left.\left.+0.25^{*} \mathrm{PhiNS}\right)+\mathrm{PiNSH}^{*}\left(0.5^{*} \mathrm{PhiSS}+0.25^{*} \mathrm{PhiSN}\right)+0.25^{*} \mathrm{PiNNH}{ }^{*} \mathrm{PhiSS}\right)$

${ }^{*} \mathrm{hH}+\left(\mathrm{PiSSL}\right.$ * $\left(\mathrm{PhiSS}+0.5{ }^{*} \mathrm{PhiSN}+0.5{ }^{*} \mathrm{PhiNS}+0.25{ }^{*} \mathrm{PhiNN}\right)+\mathrm{PiSNL}$ * $\left(0.5{ }^{*} \mathrm{Ph}\right.$ iSS $\left.\left.+0.25^{\star} \mathrm{PhiNS}\right)+\mathrm{PiNSL}{ }^{*}\left(0.5^{*} \mathrm{PhiSS}+0.25^{*} \mathrm{PhiSN}\right)+0.25^{*} \mathrm{PiNNL}{ }^{*} \mathrm{PhiSS}\right)$ * $\mathrm{hL}){ }^{*} \min (\mathrm{MC}, \mathrm{FC})$

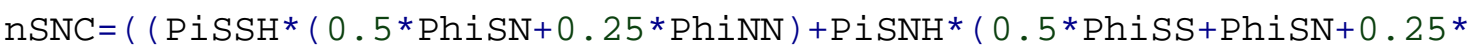

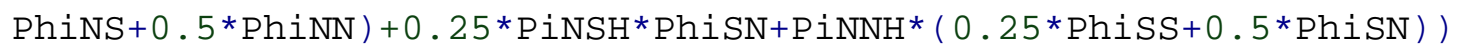
${ }^{*} \mathrm{hH}+\left(\mathrm{PiSSL}{ }^{*}\left(0.5^{*} \mathrm{PhiSN}+0.25{ }^{*} \mathrm{PhiNN}\right)+\mathrm{PiSNL}\right.$ * $\left(0.5{ }^{*} \mathrm{PhiSS}+\mathrm{PhiSN}+0.25^{*} \mathrm{P}\right.$

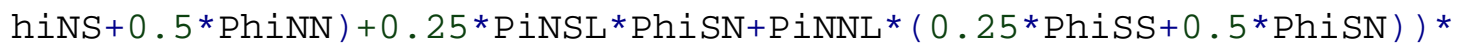
$\mathrm{hL}){ }^{*} \min (\mathrm{MC}, \mathrm{FC})$

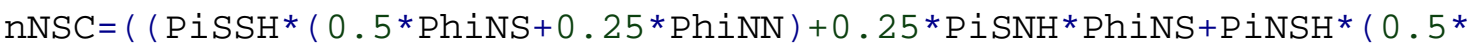
PhiSS $+0.25^{*}$ PhiSN + PhiNS $+0.5^{*}$ PhiNN $)+P i N N H^{*}\left(0.25^{*}\right.$ PhiSS $+0.5^{*}$ PhiNS $)$ ) ${ }^{*} \mathrm{hH}+\left(\mathrm{PiSSL}{ }^{*}\left(0.5^{*} \mathrm{PhiNS}+0.25^{*} \mathrm{PhiNN}\right)+0.25^{*} \mathrm{PiSNL}{ }^{*} \mathrm{PhiNS}+\mathrm{PiNSL}{ }^{*}\left(0.5^{*} \mathrm{P}\right.\right.$

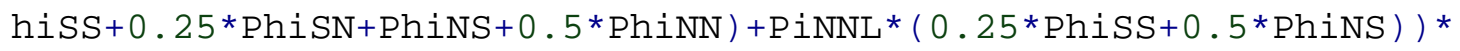
$h L) * \min (M C, F C)$

nNNC $=\left(\left(\odot .25{ }^{*} \mathrm{PiSSH}{ }^{*} \mathrm{PhiNN}+\mathrm{PiSNH}{ }^{*}\left(0.25{ }^{*} \mathrm{PhiNS}+\odot .5{ }^{*} \mathrm{PhiNN}\right)+\mathrm{PiNSH}{ }^{*}(0.25\right.\right.$ $\left.\left.{ }^{*} \mathrm{PhiSN}+0.5{ }^{*} \mathrm{PhiNN}\right)+\mathrm{PiNNH}{ }^{*}\left(0.25^{*} \mathrm{PhiSS}+0.5{ }^{*} \mathrm{PhiSN}+0.5{ }^{*} \mathrm{PhiNS}+\mathrm{PhiNN}\right)\right)$ ${ }^{*} \mathrm{hH}+\left(0.25{ }^{*} \mathrm{PiSSL}{ }^{*} \mathrm{PhiNN}+\mathrm{PiSNL}\right.$ * $\left(0.25{ }^{*} \mathrm{PhiNS}+0.5{ }^{*} \mathrm{PhiNN}\right)+\mathrm{PiNSL}$ * $(0.25$ *

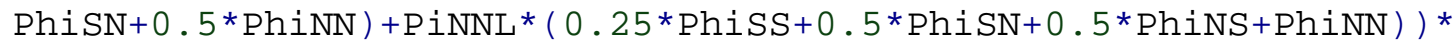
$\mathrm{hL}){ }^{*} \min (\mathrm{MC}, \mathrm{FC})$

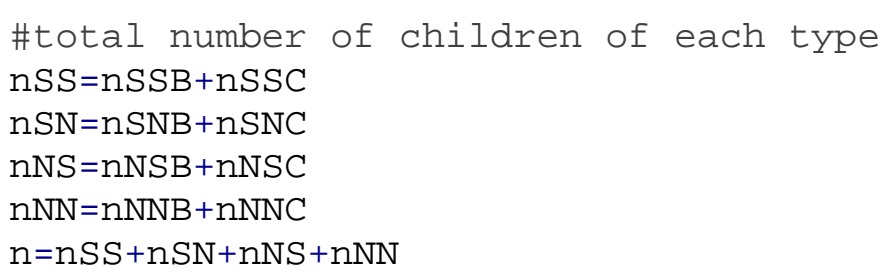




\section{Appendix B: Mathematical derivations}

[For the reviewer only - not for publication]

\section{B.1 Equations (30) and (31) derived using equations (36) and (37)}

$$
\begin{aligned}
& \frac{n_{B}^{S}+n_{C}^{S}}{n_{B}^{S}+n_{C}^{S}+n_{C}^{N}}>\pi_{A}^{S} \\
& \frac{\pi_{A}^{S H} \delta^{S H} n\left(h^{H}\right) M_{A}+\sum_{k=H, L} \pi_{C}^{S k} n\left(h^{k}\right) \min \left\{M_{C}, F_{C}\right\}}{\pi_{A}^{S H} \delta^{S H} n\left(h^{H}\right) M_{A}+\sum_{k=H, L} \pi_{C}^{S k} n\left(h^{k}\right) \min \left\{M_{C}, F_{C}\right\}+\sum_{k=H, L} \pi_{C}^{N k} n\left(h^{k}\right) \min \left\{M_{C}, F_{C}\right\}} \\
& >\pi_{A}^{S}
\end{aligned}
$$

Multiply through denominator and expand sums:

$$
\begin{aligned}
& \pi_{A}^{S H} \delta^{S H} n\left(h^{H}\right) M_{A}+\left(\pi_{A}^{S H} \delta^{S H} n\left(h^{H}\right)+\pi_{A}^{S L} \delta^{S L} n\left(h^{L}\right)\right) \min \left\{M_{C}, F_{C}\right\} \\
& >\pi_{A}^{S}\left(\pi_{A}^{S H} \delta^{S H} n\left(h^{H}\right) M_{A}\right. \\
& \left.+\left(\left(\pi_{A}^{S H} \delta^{S H}+\pi_{A}^{N H} \delta^{N H}\right) n\left(h^{H}\right)+\left(\pi_{A}^{S L} \delta^{S L}+\pi_{A}^{N L} \delta^{N L}\right) n\left(h^{L}\right)\right) \min \left\{M_{C}, F_{C}\right\}\right) \\
& \pi_{A}^{N k} \pi_{A}^{S H} \delta^{S H} n\left(h^{H}\right) M_{A} \\
& +\pi_{A}^{N}\left(\pi_{A}^{S H} \delta^{S H} n\left(h^{H}\right)+\pi_{A}^{S L} \delta^{S L} n\left(h^{L}\right)\right) n\left(h^{k}\right) \min \left\{M_{A}, F_{C} \frac{M_{A}}{M_{B}}\right\} \\
& >\pi_{A}^{S}\left(\pi_{A}^{N H} \delta^{N H} n\left(h^{H}\right)+\pi_{A}^{N L} \delta^{N L} n\left(h^{L}\right)\right) \min \left\{M_{A}, F_{C} \frac{M_{A}}{M_{B}}\right\}
\end{aligned}
$$

As the death rates are the same for the $S L$ and $N L$ genotypes and substitute $\mathrm{p}$ and 1-p for the proportions of the high and low- quality types

$$
\begin{aligned}
& p \pi_{A}^{N} \pi_{A}^{S} \delta^{S H} n\left(h^{H}\right) M_{A} \\
& +\pi_{A}^{N}\left(p \pi_{A}^{S} \delta^{S H} n\left(h^{H}\right)+(1-p) \pi_{A}^{S} \delta^{N L} n\left(h^{L}\right)\right) \min \left\{M_{A}, F_{C} \frac{M_{A}}{M_{B}}\right\} \\
& >\pi_{A}^{S}\left(p \pi_{A}^{N} \delta^{N H} n\left(h^{H}\right)+(1-p) \pi_{A}^{N} \delta^{N L} n\left(h^{L}\right)\right) \min \left\{M_{A}, F_{C} \frac{M_{A}}{M_{B}}\right\}
\end{aligned}
$$




$$
\begin{aligned}
& p \delta^{S H} n\left(h^{H}\right) M_{A} \\
& +\left(p \delta^{S H} n\left(h^{H}\right)+(1-p) \delta^{N L} n\left(h^{L}\right)\right) \min \left\{M_{A}, F_{C} \frac{M_{A}}{M_{B}}\right\} \\
& >\left(p \delta^{N H} n\left(h^{H}\right)+(1-p) \delta^{N L} n\left(h^{L}\right)\right) \min \left\{M_{A}, F_{C} \frac{M_{A}}{M_{B}}\right\} \\
& p \delta^{S H} n\left(h^{H}\right) M_{A}+p \delta^{S H} n\left(h^{H}\right) \min \left\{M_{A}, F_{C} \frac{M_{A}}{M_{B}}\right\} \\
& >p \delta^{N H} n\left(h^{H}\right) \min \left\{M_{A}, F_{C} \frac{M_{A}}{M_{B}}\right\} \\
& \delta^{S H} M_{A}+\delta^{S H} \min \left\{M_{A}, F_{C} \frac{M_{A}}{M_{B}}\right\}>\delta^{N H} \min \left\{M_{A}, F_{C} \frac{M_{A}}{M_{B}}\right\}
\end{aligned}
$$

If $M_{C}<F_{C}$, the proportion of the signalling allele is increasing if:

$$
2 \delta^{S H}>\delta^{N H}
$$

If $M_{C}>F_{C}$, the proportion of the signalling allele is increasing if:

$$
\begin{gathered}
\delta^{S H}+\delta^{S H} \frac{F_{C}}{M_{B}}>\delta^{N H} \frac{F_{C}}{M_{B}} \\
\delta^{S H}\left(1+\frac{F_{C}}{M_{C}}\right)>\delta^{N H} \frac{F_{C}}{M_{C}} \\
\delta^{S H}\left(1+\frac{M_{C}}{F_{C}}\right)>\delta^{N H} \\
\delta^{S H}\left(\begin{array}{c}
\sum_{k=H, L}\left(\pi_{A}^{S k} \delta^{S k}+\pi_{A}^{N k} \delta^{N k}\right) \\
1-\sum_{k=H, L} \pi_{A}^{S k} \delta^{S k}
\end{array}\right)>\delta^{N H}
\end{gathered}
$$




\section{B.2 Equation (40)}

$$
\begin{aligned}
& \delta(r \hat{s})\left(q_{B}^{M}+q_{C}^{M}\right)=\delta(r) q_{C}^{M} \\
& \delta(r \hat{s})\left(1+\frac{F_{C}}{M_{B}}\right)=\delta(r) \frac{F_{C}}{M_{B}} \\
& \delta(r \hat{s})\left(M_{B}+F_{C}\right)=\delta(r) F_{C} \\
& \delta(r \hat{s})=\delta(r) \frac{\left(1-\pi_{A}^{S H} \delta(r \bar{s})\right)}{\sum_{k=H, L}\left(\pi_{A}^{S k} \delta^{S k}+\pi_{A}^{N k} \delta^{N k}\right)+\left(1-\pi_{A}^{S H} \delta(r \bar{s})\right)} \\
& \delta(r \hat{s})=\delta(r) \frac{1-\pi_{A}^{S H} \delta(r \bar{s})}{1+\delta(r)\left(1-\pi_{A}^{S H}\right)}
\end{aligned}
$$

\section{B.3 Equation (42) derived using equations (11) and (23)}

$\mathrm{M}_{\mathrm{C}}>\mathrm{F}_{\mathrm{C}}$ where:

$$
\begin{aligned}
& \sum_{k=H, L}\left(\pi_{A}^{S k} \delta^{S k}+\pi_{A}^{N k} \delta^{N k}\right) M_{A}>\left(1-q_{B}^{F} \pi_{B}^{S H}\right) F_{B} \\
& \sum_{k=H, L}\left(\pi_{A}^{S k} \delta^{S k}+\pi_{A}^{N k} \delta^{N k}\right) M_{A}>\left(1-\frac{M_{B}}{F_{B}} \pi_{A}^{S H} \delta(r \bar{s}) \frac{M_{A}}{M_{B}}\right) F_{A} \\
& \left(\pi_{A}^{S L}+\pi_{A}^{S L}+\pi_{A}^{S L}\right) \delta(r)+\pi_{A}^{S H} \delta(r \bar{s})>1-\pi_{A}^{S H} \delta(r \bar{s}) \\
& \left(1-\pi_{A}^{S H}\right) \delta(r)+2 \pi_{A}^{S H} \delta(r \bar{s})>1 \\
& \delta(r \bar{s})>\frac{1-\left(1-\pi_{A}^{S H}\right) \delta(r)}{2 \pi_{A}^{S H}}
\end{aligned}
$$




\section{B.4 Derivation of equations (65) and (66) using equations (76) and (77)}

For the frequency of the signalling allele to be increasing, the following must be satisfied and $\phi_{A}^{S j}=\phi_{C}^{S j}$ as there is no expression of the gene at the first locus in females:

$$
\begin{aligned}
& \sum_{j=S, N} \frac{n_{B}^{S j}+n_{C}^{S j}}{n_{B}^{S j}+n_{B}^{N j}+n_{C}^{S j}+n_{C}^{N j}>\Pi_{A}^{S}} \\
& \left(\sum_{j=S, N} \pi_{B}^{S j H}\left(\phi_{A}^{S S}+\frac{1}{2} \phi_{A}^{N S}\right) n\left(h^{H}\right)+\sum_{k=H, L} \sum_{j=S, N}\left(\pi_{B}^{S j k}\left(\phi_{A}^{S N}+\frac{1}{2} \phi_{A}^{N N}\right)+\frac{1}{2} \pi_{B}^{N j k} \phi_{A}^{S N}\right) n\left(h^{k}\right)\right) M_{B} \\
& +\sum_{k=H, L}\left(\sum_{j=S, N} \pi_{A}^{S j k} \delta^{S k} \sum_{j=S, N}\left(\phi_{A}^{S j}+\frac{1}{2} \phi_{A}^{N j}\right)+\frac{1}{2} \sum_{j=S, N} \pi_{A}^{N j k} \delta^{N k} \sum_{j=S, N} \phi_{A}^{S j}\right) n\left(h^{k}\right) \min \left\{M_{A}, \frac{M_{A}}{M_{C}} F_{C}\right\} \\
& >\prod_{A}^{S}\left(\pi_{B}^{S j H}\left(\phi_{A}^{S S}+\frac{1}{2} \phi_{A}^{N S}\right) n\left(h^{H}\right) M_{B}+\sum_{k=H, L}\left(\pi_{B}^{S j k}\left(\phi_{A}^{S N}+\frac{1}{2} \phi_{A}^{N N}\right)+\frac{1}{2} \pi_{B}^{N j k} \phi_{A}^{S N}\right) n\left(h^{k}\right) M_{B}\right. \\
& +\sum_{k=H, L}\left(\sum_{j=S, N} \pi_{A}^{S j k} \delta^{S k} \sum_{j=S, N}\left(\phi_{A}^{S j}+\frac{1}{2} \phi_{A}^{N j}\right)+\frac{1}{2} \sum_{j=S, N} \pi_{A}^{N j k} \delta^{N k} \sum_{j=S, N} \phi_{A}^{S j}\right) n\left(h^{k}\right) \min \left\{M_{A}, \frac{M_{A}}{M_{C}} F_{C}\right\} \\
& +\frac{1}{2} \sum_{j=S, N} \pi_{B}^{S j H} \phi_{A}^{N S} n\left(h^{H}\right) M_{B}+\sum_{k=H, L}\left(\frac{1}{2} \sum_{j=S, N} \pi_{B}^{S j k} \phi_{A}^{N N}+\sum_{j=S, N} \pi_{B}^{N j k}\left(\frac{1}{2} \phi_{A}^{S N}+\phi_{A}^{N N}\right)\right) n\left(h^{k}\right) M_{B} \\
& \left.+\sum_{k=H, L}\left(\frac{1}{2} \sum_{j=S, N} \pi_{A}^{S j k} \delta^{S k} \sum_{j=S, N} \phi_{A}^{N j}+\sum_{j=S, N} \pi_{A}^{N j k} \delta^{N k} \sum_{j=S, N}\left(\frac{1}{2} \phi_{A}^{S j}+\phi_{A}^{N j}\right)\right) n\left(h^{k}\right) \min \left\{M_{A}, \frac{M_{A}}{M_{C}} F_{C}\right\}\right)
\end{aligned}
$$

As there is no selection on the low-quality agents, regardless of phenotype, the portions of the above condition relating to the low-quality agents should cancel out. Separating them from the remainder of the equation: 


$$
\begin{aligned}
& \left(\sum_{j=S, N} \pi_{B}^{S L L}\left(\phi_{A}^{S N}+\frac{1}{2} \phi_{A}^{N N}\right)+\frac{1}{2} \pi_{B}^{N L} \phi_{A}^{S N}\right) n\left(h^{L}\right) M_{B} \\
& +\left(\pi_{A}^{S L} \delta^{S L} \sum_{j=S, N}\left(\phi_{A}^{S j}+\frac{1}{2} \phi_{A}^{N j}\right)+\frac{1}{2} \sum_{j=S, N} \pi_{A}^{N j L} \delta^{N L} \sum_{j=S, N} \phi_{A}^{S j}\right) n\left(h^{L}\right) \min \left\{M_{A}, \frac{M_{A}}{M_{C}} F_{C}\right\} \\
& >\prod_{A}^{S}\left(\left(\sum_{j=S, N} \pi_{B}^{S j L}\left(\phi_{A}^{S N}+\frac{1}{2} \phi_{A}^{N N}\right)+\frac{1}{2} \sum_{j=S, N} \pi_{B}^{N j L} \phi_{A}^{S N}\right) n\left(h^{L}\right) M_{B}\right. \\
& +\left(\sum_{j=S, N} \pi_{A}^{S j L} \delta^{S L} \sum_{j=S, N}\left(\phi_{A}^{S j}+\frac{1}{2} \phi_{A}^{N j}\right)+\frac{1}{2} \sum_{j=S, N} \pi_{A}^{N j L} \delta^{N L} \sum_{j=S, N} \phi_{A}^{S j}\right) n\left(h^{L}\right) \min \left\{M_{A}, \frac{M_{A}}{M_{C}} F_{C}\right\} \\
& +\left(\frac{1}{2} \sum_{j=S, N} \pi_{B}^{S j L} \phi_{A}^{N N}+\sum_{j=S, N} \pi_{B}^{N j L}\left(\frac{1}{2} \phi_{A}^{S N}+\phi_{A}^{N N}\right)\right) n\left(h^{L}\right) M_{B} \\
& \left.+\left(\frac{1}{2} \sum_{j=S, N} \pi_{A}^{S j L} \delta^{S L} \sum_{j=S, N} \phi_{A}^{N j}+\sum_{j=S, N} \pi_{A}^{N j L} \delta^{N L} \sum_{j=S, N}\left(\frac{1}{2} \phi_{A}^{S j}+\phi_{A}^{N j}\right)\right) n\left(h^{L}\right) \min \left\{M_{A}, \frac{M_{A}}{M_{C}} F_{C}\right\}\right)
\end{aligned}
$$

Cancel out $n\left(h^{L}\right)$ and (1-p) for low-quality, equate death rate for SL with NL as death rate the same for each, and simplify:

$$
\begin{aligned}
& \left(\Pi_{A}^{N} \Pi_{A}^{S}\left(\phi_{A}^{S N}+\frac{1}{2} \phi_{A}^{N N}\right)+\frac{1}{2} \Pi_{A}^{N} \Pi_{A}^{N} \phi_{A}^{S N}\right) M_{A} \\
& +\left(\Pi_{A}^{N} \Pi_{A}^{S} \sum_{j=S, N}\left(\phi_{A}^{S j}+\frac{1}{2} \phi_{A}^{N j}\right)+\frac{1}{2} \Pi_{A}^{N} \Pi_{A}^{N} \sum_{j=S, N} \phi_{A}^{S j}\right) \min \left\{M_{A}, \frac{M_{A}}{M_{C}} F_{C}\right\} \\
& =\Pi_{A}^{S}\left(\frac{1}{2} \Pi_{A}^{S} \phi_{A}^{N N} M_{A}+\Pi_{A}^{N}\left(\frac{1}{2} \phi_{A}^{S N}+\phi_{A}^{N N}\right) M_{A}\right. \\
& \left.+\left(\frac{1}{2} \Pi_{A}^{S} \sum_{j=S, N} \phi_{A}^{N j}+\Pi_{A}^{N} \sum_{j=S, N}\left(\frac{1}{2} \phi_{A}^{S j}+\phi_{A}^{N j}\right)\right) \min \left\{M_{A}, \frac{M_{A}}{M_{C}} F_{C}\right\}\right) \\
& \left(\Pi_{A}^{N} \Pi_{A}^{S}\left(\frac{1}{2} \phi_{A}^{S N}-\frac{1}{2} \phi_{A}^{N N}\right)+\frac{1}{2} \Pi_{A}^{N} \Pi_{A}^{N} \phi_{A}^{S N}\right) M_{A} \\
& +\left(\Pi_{A}^{N} \Pi_{A}^{S} \sum_{j=S, N}\left(\frac{1}{2} \phi_{A}^{S j}-\frac{1}{2} \phi_{A}^{N j}\right)+\frac{1}{2} \Pi_{A}^{N} \Pi_{A}^{N} \sum_{j=S, N} \phi_{A}^{S j}\right) \min \left\{M_{A}, \frac{M_{A}}{M_{C}} F_{C}\right\} \\
& =\frac{1}{2} \Pi_{A}^{S} \Pi_{A}^{S} \phi_{A}^{N N} M_{A}+\frac{1}{2} \Pi_{A}^{S} \Pi_{A}^{S} \sum_{j=S, N} \phi_{A}^{N j} \min \left\{M_{A}, \frac{M_{A}}{M_{C}} F_{C}\right\}
\end{aligned}
$$




$$
\begin{aligned}
& \text { As } \phi_{A}^{i j}=\pi_{A}^{i j} \text { and } \phi_{A}^{N N}=\sum_{j=S, N} \phi_{A}^{N j} \sum_{i=S, N} \phi_{A}^{i N} \\
& \left(\Pi_{A}^{N} \Pi_{A}^{S}\left(\pi_{A}^{S N}-\pi_{A}^{N N}\right)+\Pi_{A}^{N} \Pi_{A}^{N} \Pi_{A}^{S} \Phi_{A}^{N}\right) M_{A} \\
& +\left(\Pi_{A}^{N} \Pi_{A}^{S}\left(\Pi_{A}^{S}-\Pi_{A}^{N}\right)+\Pi_{A}^{N} \Pi_{A}^{N} \Pi_{A}^{S}\right) \min \left\{M_{A}, \frac{M_{A}}{M_{C}} F_{C}\right\} \\
& =\Pi_{A}^{S} \Pi_{A}^{S} \Pi_{A}^{N} \Phi_{A}^{N} M_{A}+\Pi_{A}^{S} \Pi_{A}^{S} \Pi_{A}^{N} \min \left\{M_{A}, \frac{M_{A}}{M_{C}} F_{C}\right\} \\
& \left(\Pi_{A}^{S}\left(\pi_{A}^{S N}-\pi_{A}^{N N}\right)+\Pi_{A}^{N} \Pi_{A}^{S} \Phi_{A}^{N}\right) M_{A} \\
& +\left(\Pi_{A}^{S}\left(\Pi_{A}^{S}-\Pi_{A}^{N}\right)+\Pi_{A}^{N} \Pi_{A}^{S}\right) \min \left\{M_{A}, \frac{M_{A}}{M_{C}} F_{C}\right\} \\
& =\Pi_{A}^{S} \Pi_{A}^{S} \Phi_{A}^{N} M_{A}+\Pi_{A}^{S} \Pi_{A}^{S} \min \left\{M_{A}, \frac{M_{A}}{M_{C}} F_{C}\right\} \\
& \Pi_{A}^{S} \Pi_{A}^{N}-\Pi_{A}^{N} \Pi_{A}^{N}+\Pi_{A}^{N} \Phi_{A}^{N}=\Pi_{A}^{S} \Phi_{A}^{N} \\
& \left(\Pi_{A}^{S}\left(\pi_{A}^{S N}-\pi_{A}^{N N}\right)+\Pi_{A}^{N} \Pi_{A}^{S} \Phi_{A}^{N}\right) M_{A}=\Pi_{A}^{S} \Pi_{A}^{S} \Phi_{A}^{N} M_{A} \\
& \Pi_{A}^{S}\left(\pi_{A}^{S N}-\pi_{A}^{N N}\right)+\Pi_{A}^{N} \Pi_{A}^{S} \Phi_{A}^{N}=\Pi_{A}^{S} \Pi_{A}^{S} \Phi_{A}^{N}
\end{aligned}
$$

All terms cancel out. 
After eliminating the alleles relating to the low-quality males, the remainder of the inequality becomes:

$$
\begin{aligned}
& p\left(\Pi_{B}^{S}\left(\phi_{A}^{S S}+\frac{1}{2} \phi_{A}^{N S}\right) n\left(h^{H}\right)+\Pi_{B}^{S}\left(\phi_{A}^{S N}+\frac{1}{2} \phi_{A}^{N N}\right) n\left(h^{H}\right)+\frac{1}{2} \Pi_{B}^{N} \phi_{A}^{S N} n\left(h^{H}\right)\right) M_{B} \\
& +p\left(\Pi_{A}^{S} \delta^{S H}\left(\phi_{A}^{S j}+\frac{1}{2} \phi_{A}^{N j}\right) n\left(h^{H}\right)+\frac{1}{2} \Pi_{A}^{N} \delta^{N H} \phi_{A}^{S j} n\left(h^{H}\right)\right) \min \left\{M_{A}, \frac{M_{A}}{M_{C}} F_{C}\right\} \\
& >p \Pi_{A}^{S}\left(\left(\Pi_{B}^{S}\left(\phi_{A}^{S S}+\frac{1}{2} \phi_{A}^{N S}\right) n\left(h^{H}\right)+\Pi_{B}^{S}\left(\phi_{A}^{S N}+\frac{1}{2} \phi_{A}^{N N}\right) n\left(h^{H}\right)+\frac{1}{2} \Pi_{B}^{N} \phi_{A}^{S N} n\left(h^{H}\right)\right) M_{B}\right. \\
& +\left(\Pi_{A}^{S} \delta^{S H}\left(\phi_{A}^{S j}+\frac{1}{2} \phi_{A}^{N j}\right) n\left(h^{H}\right)+\frac{1}{2} \Pi_{A}^{N} \delta^{N H} \phi_{A}^{S j} n\left(h^{H}\right)\right) \min \left\{M_{A}, \frac{M_{A}}{M_{C}} F_{C}\right\} \\
& +\left(\frac{1}{2} \Pi_{B}^{S} \phi_{A}^{N S} n\left(h^{H}\right)+\frac{1}{2} \Pi_{B}^{S} \phi_{A}^{N N} n\left(h^{H}\right)+\Pi_{B}^{N}\left(\frac{1}{2} \phi_{A}^{S N}+\phi_{A}^{N N}\right) n\left(h^{H}\right)\right) M_{B} \\
& \left.+\left(\frac{1}{2} \Pi_{A}^{S} \delta^{S H} \phi_{A}^{N j} n\left(h^{H}\right)+\Pi_{A}^{N} \delta^{N H}\left(\frac{1}{2} \phi_{A}^{S j}+\phi_{A}^{N j}\right) n\left(h^{H}\right)\right) \min \left\{M_{A}, \frac{M_{A}}{M_{C}} F_{C}\right\}\right)
\end{aligned}
$$

Cancel out $n\left(h^{H}\right)$ and $p$ for high quality, and simplify:

$$
\begin{aligned}
& \left(\Pi_{A}^{N} \Pi_{A}^{S} \delta^{S H}\left(\phi_{A}^{S S}+\frac{1}{2} \phi_{A}^{N S}\right)+\Pi_{A}^{N} \Pi_{A}^{S} \delta^{S H}\left(\phi_{A}^{S N}+\frac{1}{2} \phi_{A}^{N N}\right)+\frac{1}{2} \Pi_{A}^{N} \Pi_{A}^{N} \delta^{N H} \phi_{A}^{S N}\right) M_{A} \\
& +\left(\Pi_{A}^{N} \Pi_{A}^{S} \delta^{S H}\left(\phi_{A}^{S j}+\frac{1}{2} \phi_{A}^{N j}\right)+\frac{1}{2} \Pi_{A}^{N} \Pi_{A}^{N} \delta^{N H} \phi_{A}^{S j}\right) \min \left\{M_{A}, \frac{M_{A}}{M_{C}} F_{C}\right\} \\
& >\left(\frac{1}{2} \Pi_{A}^{S} \Pi_{A}^{S} \delta^{S H} \phi_{A}^{N S}+\frac{1}{2} \Pi_{A}^{S} \Pi_{A}^{S} \delta^{S H} \phi_{A}^{N N}+\Pi_{A}^{S} \Pi_{A}^{N} \delta^{N H}\left(\frac{1}{2} \phi_{A}^{S N}+\phi_{A}^{N N}\right)\right) M_{A} \\
& +\left(\frac{1}{2} \Pi_{A}^{S} \Pi_{A}^{S} \delta^{S H} \phi_{A}^{N j}+\Pi_{A}^{S} \Pi_{A}^{N} \delta^{N H}\left(\frac{1}{2} \phi_{A}^{S j}+\phi_{A}^{N j}\right)\right) \min \left\{M_{A}, \frac{M_{A}}{M_{C}} F_{C}\right\} \\
& \left(\Pi_{A}^{N} \Pi_{A}^{S} \delta^{S H}\left(\phi_{A}^{S S}+\frac{1}{2} \phi_{A}^{N S}+\phi_{A}^{S N}+\frac{1}{2} \phi_{A}^{N N}\right)+\frac{1}{2} \Pi_{A}^{N} \Pi_{A}^{N} \delta^{N H} \phi_{A}^{S N}\right) M_{A} \\
& +\left(\Pi_{A}^{N} \Pi_{A}^{S} \delta^{S H}\left(\frac{1}{2} \phi_{A}^{S j}+\frac{1}{2} \phi_{A}^{N j}\right)+\frac{1}{2} \Pi_{A}^{N} \Pi_{A}^{N} \delta^{N H} \phi_{A}^{S j}\right) \min \left\{M_{A}, \frac{M_{A}}{M_{C}} F_{C}\right\} \\
& >\left(\frac{1}{2} \Pi_{A}^{S} \Pi_{A}^{S} \delta^{S H} \phi_{A}^{N S}+\frac{1}{2} \Pi_{A}^{S} \Pi_{A}^{S} \delta^{S H} \phi_{A}^{N N}+\Pi_{A}^{S} \Pi_{A}^{N} \delta^{N H}\left(\frac{1}{2} \phi_{A}^{S N}+\phi_{A}^{N N}\right)\right) M_{A} \\
& +\Pi_{A}^{S} \Pi_{A}^{N} \delta^{N H}\left(\frac{1}{2} \phi_{A}^{S j}+\phi_{A}^{N j}\right) \min \left\{M_{A}, \frac{M_{A}}{M_{C}} F_{C}\right\}
\end{aligned}
$$




$$
\begin{aligned}
& \operatorname{As} \phi_{A}^{i j}=\pi_{A}^{i j} \text { : } \\
& \left(\Pi_{A}^{N} \Pi_{A}^{S} \delta^{S H}\left(\Pi_{A}^{S}+\frac{1}{2} \Pi_{A}^{N}\right)+\frac{1}{2} \Pi_{A}^{N} \Pi_{A}^{N} \delta^{N H} \phi_{A}^{S N}\right) M_{A} \\
& +\left(\Pi_{A}^{N} \Pi_{A}^{S} \delta^{S H}\left(\frac{1}{2} \Pi_{A}^{S}+\frac{1}{2} \Pi_{A}^{N}\right)+\frac{1}{2} \Pi_{A}^{N} \Pi_{A}^{N} \delta^{N H} \Pi_{A}^{S}\right) \min \left\{M_{A}, \frac{M_{A}}{M_{C}} F_{C}\right\} \\
& >\left(\frac{1}{2} \Pi_{A}^{S} \Pi_{A}^{S} \delta^{S H} \phi_{A}^{N S}+\frac{1}{2} \Pi_{A}^{S} \Pi_{A}^{S} \delta^{S H} \phi_{A}^{N N}+\Pi_{A}^{S} \Pi_{A}^{N} \delta^{N H}\left(\frac{1}{2} \phi_{A}^{S N}+\phi_{A}^{N N}\right)\right) M_{A} \\
& +\Pi_{A}^{S} \Pi_{A}^{N} \delta^{N H}\left(\frac{1}{2} \Pi_{A}^{S}+\Pi_{A}^{N}\right) \min \left\{M_{A}, \frac{M_{A}}{M_{C}} F_{C}\right\} \\
& \left(\Pi_{A}^{N} \Pi_{A}^{S} \Pi_{A}^{S} \delta^{S H}+\frac{1}{2} \Pi_{A}^{N} \Pi_{A}^{S} \Pi_{A}^{N} \delta^{S H}+\frac{1}{2} \Pi_{A}^{N} \Pi_{A}^{N} \Pi_{A}^{S} \Phi_{A}^{N} \delta^{N H}\right) M_{A} \\
& +\left(\frac{1}{2} \Pi_{A}^{N} \Pi_{A}^{S} \Pi_{A}^{S} \delta^{S H}+\frac{1}{2} \Pi_{A}^{N} \Pi_{A}^{S} \Pi_{A}^{N} \delta^{S H}+\frac{1}{2} \Pi_{A}^{N} \Pi_{A}^{N} \Pi_{A}^{S} \delta^{N H}\right) \min \left\{M_{A}, \frac{M_{A}}{M_{C}} F_{C}\right\} \\
& >\left(\frac{1}{2} \Pi_{A}^{S} \Pi_{A}^{S} \Pi_{A}^{N} \Phi_{A}^{S} \delta^{S H}+\frac{1}{2} \Pi_{A}^{S} \Pi_{A}^{S} \Pi_{A}^{N} \Phi_{A}^{N} \delta^{S H}\right. \\
& \left.+\frac{1}{2} \Pi_{A}^{S} \Pi_{A}^{N} \Pi_{A}^{S} \Phi_{A}^{N} \delta^{N H}+\Pi_{A}^{S} \Pi_{A}^{N} \Pi_{A}^{N} \Phi_{A}^{N} \delta^{N H}\right) M_{A} \\
& +\left(\frac{1}{2} \Pi_{A}^{S} \Pi_{A}^{S} \Pi_{A}^{N} \delta^{N H}+\Pi_{A}^{S} \Pi_{A}^{N} \Pi_{A}^{N} \delta^{N H}\right) \min \left\{M_{A}, \frac{M_{A}}{M_{C}} F_{C}\right\} \\
& \left(\frac{1}{2} \Pi_{A}^{N} \Pi_{A}^{S} \Pi_{A}^{S} \delta^{S H}+\frac{1}{2} \Pi_{A}^{N} \Pi_{A}^{S} \Pi_{A}^{N} \delta^{S H}\right) M_{A} \\
& +\left(\frac{1}{2} \Pi_{A}^{N} \Pi_{A}^{S} \Pi_{A}^{S} \delta^{S H}+\frac{1}{2} \Pi_{A}^{N} \Pi_{A}^{S} \Pi_{A}^{N} \delta^{S H}\right) \min \left\{M_{A}, \frac{M_{A}}{M_{C}} F_{C}\right\} \\
& >\left(\frac{1}{2} \Pi_{A}^{S} \Pi_{A}^{N} \Pi_{A}^{S} \Phi_{A}^{N} \delta^{N H}+\frac{1}{2} \Pi_{A}^{S} \Pi_{A}^{N} \Pi_{A}^{N} \Phi_{A}^{N} \delta^{N H}\right) M_{A} \\
& +\left(\frac{1}{2} \Pi_{A}^{S} \Pi_{A}^{S} \Pi_{A}^{N} \delta^{N H}+\frac{1}{2} \Pi_{A}^{S} \Pi_{A}^{N} \Pi_{A}^{N} \delta^{N H}\right) \min \left\{M_{A}, \frac{M_{A}}{M_{C}} F_{C}\right\} \\
& \left(\Pi_{A}^{S} \delta^{S H}+\Pi_{A}^{N} \delta^{S H}\right) M_{A}+\left(\Pi_{A}^{S} \delta^{S H}+\Pi_{A}^{N} \delta^{S H}\right) \min \left\{M_{A}, \frac{M_{A}}{M_{C}} F_{C}\right\} \\
& >\left(\Pi_{A}^{S} \Phi_{A}^{N} \delta^{N H}+\Pi_{A}^{N} \Phi_{A}^{N} \delta^{N H}\right) M_{A}+\left(\Pi_{A}^{S} \delta^{N H}+\Pi_{A}^{N} \delta^{N H}\right) \min \left\{M_{A}, \frac{M_{A}}{M_{C}} F_{C}\right\}
\end{aligned}
$$




$$
\begin{aligned}
& \left(\Pi_{A}^{S}+\Pi_{A}^{N}\right) \delta^{S H} M_{A}+\left(\Pi_{A}^{S}+\Pi_{A}^{N}\right) \delta^{S H} \min \left\{M_{A}, \frac{M_{A}}{M_{C}} F_{C}\right\} \\
& >\left(\left(\Pi_{A}^{S}+\Pi_{A}^{N}\right) \Phi_{A}^{N} \delta^{N H}\right) M_{A} \\
& +\left(\Pi_{A}^{S}+\Pi_{A}^{N}\right) \delta^{N H} \min \left\{M_{A}, \frac{M_{A}}{M_{C}} F_{C}\right\} \\
& \delta^{S H} M_{A}+\delta^{S H} \min \left\{M_{A}, \frac{M_{A}}{M_{C}} F_{C}\right\}>\Phi_{A}^{N} \delta^{N H} M_{A}+\delta^{N H} \min \left\{M_{A}, \frac{M_{A}}{M_{C}} F_{C}\right\}
\end{aligned}
$$

If $M_{C}<F_{C}$ :

$$
2 \delta^{S H}>\delta^{N H}\left(\Phi_{A}^{N}+1\right)
$$

\section{If $M_{C}>F_{C}$ :}

$$
\begin{aligned}
& \delta^{S H}+\delta^{S H} \frac{F_{C}}{M_{C}}>\Phi_{A}^{N} \delta^{N H}+\delta^{N H} \frac{F_{C}}{M_{C}} \\
& \left(1+q_{C}^{M}\right) \delta^{S H}>\left(\Phi_{A}^{N}+q_{C}^{M}\right) \delta^{N H}
\end{aligned}
$$

\section{B.5 Equation (79)}

Increasing if

$$
\frac{n_{B}^{i S}+n_{C}^{i S}}{n_{B}^{i S}+n_{B}^{i N}+n_{C}^{i S}+n_{C}^{i N}}>\Phi_{A}^{S}
$$




$$
\begin{aligned}
& \left(\left(\pi_{B}^{S S H} \Phi_{A}^{S}+\frac{1}{2} \pi_{B}^{S N H} \Phi_{A}^{S}\right) n\left(h^{H}\right)+\sum_{k=H, L}\left(\frac{1}{2} \pi_{B}^{S S k} \Phi_{A}^{N}+\frac{1}{2} \pi_{B}^{N S k} \Phi_{A}^{N}\right) n\left(h^{k}\right)\right) M_{B} \\
& +\sum_{k=H, L}\left(\pi_{B}^{S S k}\left(\Phi_{C}^{S}+\frac{1}{2} \Phi_{C}^{N}\right)+\frac{1}{2} \pi_{B}^{S N k} \Phi_{C}^{S}+\pi_{B}^{N S k}\left(\Phi_{C}^{S}+\frac{1}{2} \Phi_{C}^{N}\right)+\frac{1}{2} \pi_{B}^{N N k} \Phi_{C}^{S}\right) n\left(h^{k}\right) \min \left\{M_{C}, F_{C}\right\} \\
& >\Phi_{A}^{S}\left(\left(\left(\pi_{B}^{S S H} \Phi_{A}^{S}+\frac{1}{2} \pi_{B}^{S N H} \Phi_{A}^{S}+\frac{1}{2} \pi_{B}^{S N H} \Phi_{A}^{S}\right) n\left(h^{H}\right)+\sum_{k=H, L}\left(\frac{1}{2} \pi_{B}^{S S k} \Phi_{A}^{N}+\frac{1}{2} \pi_{B}^{N S k} \Phi_{A}^{N}\right) n\left(h^{k}\right)\right.\right. \\
& \left.+\sum_{k=H, L}\left(\frac{1}{2} \pi_{B}^{S S k} \Phi_{A}^{N}+\pi_{B}^{S N k} \Phi_{A}^{N}+\frac{1}{2} \pi_{B}^{N S k} \Phi_{A}^{N}+\pi_{B}^{N N k} \Phi_{A}^{N}\right) n\left(h^{k}\right)\right) M_{B} \\
& +\sum_{k=H, L}\left(\pi_{B}^{S S k}\left(\Phi_{C}^{S}+\frac{1}{2} \Phi_{C}^{N}\right)+\frac{1}{2} \pi_{B}^{S N k} \Phi_{C}^{S}+\pi_{B}^{N S k}\left(\Phi_{C}^{S}+\frac{1}{2} \Phi_{C}^{N}\right)+\frac{1}{2} \pi_{B}^{N N k} \Phi_{C}^{S}\right) n\left(h^{k}\right) \min \left\{M_{C}, F_{C}\right\} \\
& \left.+\sum_{k=H, L}\left(\frac{1}{2} \pi_{B}^{S S k} \Phi_{C}^{N}+\pi_{B}^{S N k}\left(\frac{1}{2} \Phi_{C}^{S}+\Phi_{C}^{N}\right)+\frac{1}{2} \pi_{B}^{N S k} \Phi_{C}^{N}+\pi_{B}^{N N k}\left(\frac{1}{2} \Phi_{C}^{S}+\Phi_{C}^{N}\right)\right) n\left(h^{k}\right) \min \left\{M_{C}, F_{C}\right\}\right) \\
& \left(\left(\pi_{B}^{S S H} \Phi_{A}^{S}+\frac{1}{2} \pi_{B}^{S N H} \Phi_{A}^{S}\right) n\left(h^{H}\right)+\sum_{k=H, L}\left(\frac{1}{2} \pi_{B}^{S S k} \Phi_{A}^{N}+\frac{1}{2} \pi_{B}^{N S k} \Phi_{A}^{N}\right) n\left(h^{k}\right)\right) M_{B} \\
& +\sum_{k=H, L}\left(\pi_{B}^{S S k}\left(\Phi_{C}^{S}+\frac{1}{2} \Phi_{C}^{N}\right)+\frac{1}{2} \pi_{B}^{S N k} \Phi_{C}^{S}+\pi_{B}^{N S k}\left(\Phi_{C}^{S}+\frac{1}{2} \Phi_{C}^{N}\right)+\frac{1}{2} \pi_{B}^{N N k} \Phi_{C}^{S}\right) n\left(h^{k}\right) \min \left\{M_{C}, F_{C}\right\} \\
& >\Phi_{A}^{S}\left(\left(\Phi_{A}^{S}\left(\pi_{B}^{S S H}+\pi_{B}^{S N H}\right) n\left(h^{H}\right)+\Phi_{A}^{N} \sum_{k=H, L} \sum_{j=S, N}\left(\pi_{B}^{S j k}+\pi_{B}^{N j k}\right) n\left(h^{k}\right)\right) M_{B}\right. \\
& \left.+\sum_{k=H, L} \sum_{j=S, N}\left(\pi_{B}^{S j k}+\pi_{B}^{N j k}\right) n\left(h^{k}\right) \min \left\{M_{C}, F_{C}\right\}\right) \\
& \left(\frac{1}{2} \pi_{B}^{S N H} \Phi_{A}^{S} n\left(h^{H}\right)+\sum_{k=H, L}\left(\frac{1}{2} \pi_{B}^{S S k} \Phi_{A}^{N}+\frac{1}{2} \pi_{B}^{N S k} \Phi_{A}^{N}\right) n\left(h^{k}\right)\right) M_{B} \\
& +\sum_{k=H, L}\left(\pi_{B}^{S S k}\left(\Phi_{C}^{S}+\frac{1}{2} \Phi_{C}^{N}\right)+\frac{1}{2} \pi_{B}^{S N k} \Phi_{C}^{S}+\pi_{B}^{N S k}\left(\Phi_{C}^{S}+\frac{1}{2} \Phi_{C}^{N}\right)+\frac{1}{2} \pi_{B}^{N N k} \Phi_{C}^{S}\right) n\left(h^{k}\right) \min \left\{M_{C}, F_{C}\right\} \\
& >\Phi_{A}^{S} \Phi_{A}^{N} \sum_{k=H, L} \sum_{j=S, N}\left(\pi_{B}^{S j k}+\pi_{B}^{N j k}\right) n\left(h^{k}\right) M_{B}+\Phi_{A}^{S} \sum_{k=H, L} \sum_{j=S, N}\left(\pi_{B}^{S j k}+\pi_{B}^{N j k}\right) n\left(h^{k}\right) \min \left\{M_{C}, F_{C}\right\}
\end{aligned}
$$




$$
\begin{aligned}
& \left(\frac{1}{2} \pi_{B}^{S N H} \Phi_{A}^{S} n\left(h^{H}\right)+\sum_{k=H, L}\left(\frac{1}{2} \pi_{B}^{S S k} \Phi_{A}^{N}+\frac{1}{2} \pi_{B}^{N S k} \Phi_{A}^{N}\right) n\left(h^{k}\right)\right) M_{B} \\
& +\sum_{k=H, L}\left(\pi_{B}^{S S k}\left(\frac{1}{2}+\frac{1}{2} \Phi_{C}^{S}\right)+\frac{1}{2} \pi_{B}^{S N k} \Phi_{C}^{S}+\pi_{B}^{N S k}\left(\frac{1}{2}+\frac{1}{2} \Phi_{C}^{S}\right)+\frac{1}{2} \pi_{B}^{N N k} \Phi_{C}^{S}\right) n\left(h^{k}\right) \min \left\{M_{C}, F_{C}\right\} \\
& >\Phi_{A}^{S} \Phi_{A}^{N} \sum_{k=H, L} \sum_{j=S, N}\left(\pi_{B}^{S j k}+\pi_{B}^{N j k}\right) n\left(h^{k}\right) M_{B}+\Phi_{A}^{S} \sum_{k=H, L} \sum_{j=S, N}\left(\pi_{B}^{S j k}+\pi_{B}^{N j k}\right) n\left(h^{k}\right) \min \left\{M_{C}, F_{C}\right\} \\
& \frac{1}{2} \pi_{B}^{S N H} \Phi_{A}^{S} n\left(h^{H}\right) M_{B}+\frac{1}{2} \Phi_{C}^{S} \sum_{k=H, L} \sum_{j=S, N}\left(\pi_{B}^{S j k}+\pi_{B}^{N j k}\right) n\left(h^{k}\right) \min \left\{M_{C}, F_{C}\right\} \\
& >\frac{1}{2} \Phi_{A}^{S} \Phi_{A}^{N} \sum_{k=H, L} \sum_{j=S, N}\left(\pi_{B}^{S j k}+\pi_{B}^{N j k}\right) n\left(h^{k}\right) M_{A}+\frac{1}{2} \Phi_{A}^{S} \sum_{k=H, L} \sum_{j=S, N}\left(\pi_{B}^{S j k}+\pi_{B}^{N j k}\right) n\left(h^{k}\right) \min \left\{M_{C}, F_{C}\right\} \\
& \pi_{B}^{S N H} n\left(h^{H}\right) M_{B}+\left(1-q_{B}^{F} \sum_{j=S, N} \pi_{B}^{S j H}\right) \frac{F_{B}}{F_{C}} \sum_{k=H, L} \sum_{j=S, N}\left(\pi_{B}^{S j k}+\pi_{B}^{N j k}\right) n\left(h^{k}\right) \min \left\{M_{C}, F_{C}\right\} \\
& >\Phi_{A}^{N} \sum_{k=H, L} \sum_{j=S, N}\left(\pi_{B}^{S j k}+\pi_{B}^{N j k}\right) n\left(h^{k}\right) M_{B}+\sum_{k=H, L} \sum_{j=S, N}\left(\pi_{B}^{S j k}+\pi_{B}^{N j k}\right) n\left(h^{k}\right) \min \left\{M_{C}, F_{C}\right\} \\
& \pi_{B}^{S N H} n\left(h^{H}\right) M_{B}+\left(\left(1-q_{B}^{F} \sum_{j=S, N} \pi_{B}^{S j H}\right) \frac{F_{B}}{F_{C}}-1\right) \sum_{k=H, L} \sum_{j=S, N}\left(\pi_{B}^{S j k}+\pi_{B}^{N j k}\right) n\left(h^{k}\right) \min \left\{M_{C}, F_{C}\right\} \\
& >\Phi_{A}^{N} \sum_{k=H, L} \sum_{j=S, N}\left(\pi_{B}^{S j k}+\pi_{B}^{N j k}\right) n\left(h^{k}\right) M_{B} \\
& \pi_{B}^{S N H} n\left(h^{H}\right) M_{B}+\left(\left(1-q_{B}^{F} \sum_{j=S, N} \pi_{B}^{S j H}-\frac{F_{C}}{F_{B}}\right) \frac{F_{B}}{F_{C}}\right) \sum_{k=H, L} \sum_{j=S, N}\left(\pi_{B}^{S j k}+\pi_{B}^{N j k}\right) n\left(h^{k}\right) \min \left\{M_{C}, F_{C}\right\} \\
& >\Phi_{A}^{N} \sum_{k=H, L} \sum_{j=S, N}\left(\pi_{B}^{S j k}+\pi_{B}^{N j k}\right) n\left(h^{k}\right) M_{B} \\
& \pi_{B}^{S N H} n\left(h^{H}\right) M_{B}+\left(1-q_{B}^{F} \sum_{j=S, N} \pi_{B}^{S j H}-\Phi_{A}^{S}\left(1-q_{B}^{F} \sum_{j=S, N} \pi_{B}^{S j H}\right)\right. \\
& \left.-\Phi_{A}^{N}\left(1-q_{B}^{F}\right)\right) \frac{F_{B}}{F_{C}} \sum_{k=H, L} \sum_{j=S, N}\left(\pi_{B}^{S j k}+\pi_{B}^{N j k}\right) n\left(h^{k}\right) \min \left\{M_{C}, F_{C}\right\} \\
& >\Phi_{A}^{N} \sum_{k=H, L} \sum_{j=S, N}\left(\pi_{B}^{S j k}+\pi_{B}^{N j k}\right) n\left(h^{k}\right) M_{B}
\end{aligned}
$$




$$
\begin{aligned}
& \Phi_{A}^{N} \pi_{B}^{S j H} n\left(h^{H}\right) M_{B} \\
& \left.+\left(\Phi_{A}^{S}-1\right) q_{B}^{F} \sum_{j=S, N} \pi_{B}^{S j H}+\Phi_{A}^{N} q_{B}^{F}\right) \frac{F_{B}}{F_{C}} \sum_{k=H, L} \sum_{j=S, N}\left(\pi_{B}^{S j k}+\pi_{B}^{N j k}\right) n\left(h^{k}\right) \min \left\{M_{C}, F_{C}\right\} \\
& >\Phi_{A}^{N} \sum_{k=H, L} \sum_{j=S, N}\left(\pi_{B}^{S j k}+\pi_{B}^{N j k}\right) n\left(h^{k}\right) M_{B} \\
& \sum_{j=S, N} \pi_{B}^{S j H} n\left(h^{H}\right) M_{B}+\left(-q_{B}^{F} \sum_{j=S, N} \pi_{B}^{S j H}+q_{B}^{F}\right) \frac{F_{B}}{F_{C}} \sum_{k=H, L} \sum_{j=S, N}\left(\pi_{B}^{S j k}+\pi_{B}^{N j k}\right) n\left(h^{k}\right) \min \left\{M_{C}, F_{C}\right\} \\
& >\sum_{k=H, L} \sum_{j=S, N}\left(\pi_{B}^{S j k}+\pi_{B}^{N j k}\right) n\left(h^{k}\right) M_{B} \\
& \pi_{B}^{S j H} n\left(h^{H}\right) M_{B}+q_{B}^{F}\left(1-\sum_{j=S, N} \pi_{B}^{S j H}\right) \frac{F_{B}}{F_{C}} \sum_{k=H, L} \sum_{j=S, N}\left(\pi_{B}^{S j k}+\pi_{B}^{N j k}\right) n\left(h^{k}\right) \min \left\{M_{C}, F_{C}\right\} \\
& >\sum_{k=H, L} \sum_{j=S, N}\left(\pi_{B}^{S j k}+\pi_{B}^{N j k}\right) n\left(h^{k}\right) M_{B} \\
& \sum_{j=S, N} \pi_{B}^{S j H} n\left(h^{H}\right) M_{B}+\left(1-\sum_{j=S, N} \pi_{B}^{S j H}\right) q_{C}^{F} \sum_{k=H, L} \sum_{j=S, N}\left(\pi_{B}^{S j k}+\pi_{B}^{N j k}\right) n\left(h^{k}\right) \min \left\{M_{C}, F_{C}\right\} \\
& \sum_{j=S, N} \pi_{B}^{S j H} n\left(h^{H}\right) M_{B}+\left(1-\sum_{j=S, N} \pi_{B}^{S j H}\right) \frac{M_{B}}{F_{B}} \frac{F_{B}}{F_{C}} \sum_{k=H, L} \sum_{j=S, N}\left(\pi_{B}^{S j k}+\pi_{B}^{N j k}\right) n\left(h^{k}\right) \min \left\{M_{C}, F_{C}\right\} \\
& >\sum_{k=H, L} \sum_{j=S, N}\left(\pi_{B}^{S j k}+\pi_{B}^{N j k}\right) n\left(h^{k}\right) M_{B} \\
& >
\end{aligned}
$$

If $M_{C}<F_{C}$ :

$$
\begin{aligned}
& \sum_{j=S, N} \pi_{A}^{S j H} \delta^{S H} n\left(h^{H}\right) M_{A}+\left(1-\sum_{j=S, N} \pi_{B}^{S j H}\right) q_{C}^{F} \sum_{k=H . L} \sum_{j=S, N}\left(\pi_{A}^{S j k} \delta^{S j k}+\pi_{A}^{S j k} \delta^{S k}\right) n\left(h^{k}\right) M_{A} \\
& >\sum_{k=H, L} \sum_{j=S, N}\left(\pi_{A}^{S j k} \delta^{S j k}+\pi_{A}^{S j k} \delta^{S k}\right) n\left(h^{k}\right) \\
& \sum_{j=S, N} \pi_{A}^{S j H} \delta^{S H} n\left(h^{H}\right)+\left(1-\sum_{j=S, N} \pi_{B}^{S j H}\right) q_{C}^{F} \sum_{k=H, L} \sum_{j=S, N}\left(\pi_{A}^{S j k} \delta^{S j k}+\pi_{A}^{S j k} \delta^{S k}\right) n\left(h^{k}\right) \\
& >\sum_{k=H, L} \sum_{j=S, N}\left(\pi_{A}^{S j k} \delta^{S j k}+\pi_{A}^{S j k} \delta^{S k}\right) n\left(h^{k}\right)
\end{aligned}
$$




$$
\begin{aligned}
& \sum_{j=S, N} \pi_{A}^{S j H} \delta^{S H} n\left(h^{H}\right)+\left(1-\sum_{j=S, N} \pi_{B}^{S j H}\right) q_{C}^{F} \sum_{k=H, L} \sum_{j=S, N}\left(\pi_{A}^{S j k} \delta^{S j k}+\pi_{A}^{S j k} \delta^{S k}\right) n\left(h^{k}\right) \\
& >\sum_{k=H, L} \sum_{j=S, N}\left(\pi_{A}^{S j k} \delta^{S j k}+\pi_{A}^{S j k} \delta^{S k}\right) n\left(h^{k}\right)
\end{aligned}
$$

If $F_{C}<M_{C}$ :

$$
\begin{aligned}
& \sum_{j=S, N} \pi_{A}^{S j H} \delta^{S H} n\left(h^{H}\right) M_{A}+\left(1-\pi_{B}^{S j H}\right) q_{C}^{F} \sum_{k=H, L} \sum_{j=S, N}\left(\pi_{B}^{S j k}+\pi_{B}^{N j k}\right) n\left(h^{k}\right) F_{C} \\
& >\sum_{k=H, L} \sum_{j=S, N}\left(\pi_{A}^{S j k} \delta^{S k}+\pi_{A}^{N j k} \delta^{N k}\right) n\left(h^{k}\right) M_{A} \\
& \sum_{j=S, N} \pi_{A}^{S j H} \delta^{S H} n\left(h^{H}\right) M_{A}+\left(1-\sum_{j=S, N} \pi_{B}^{S j H}\right) \frac{M_{C}}{F_{C}} \sum_{k=H, L} \sum_{j=S, N}\left(\pi_{B}^{S j k}+\pi_{B}^{N j k}\right) n\left(h^{k}\right) F_{C} \\
& >\sum_{k=H, L} \sum_{j=S, N}\left(\pi_{A}^{S j k} \delta^{S k}+\pi_{A}^{N j k} \delta^{N k}\right) n\left(h^{k}\right) M_{A} \\
& \sum_{j=S, N} \pi_{A}^{S H H} \delta^{S H} n\left(h^{H}\right) M_{A}+\left(1-\sum_{j=S, N} \pi_{B}^{S j H}\right) \sum_{k=H, L} \sum_{j=S, N}\left(\pi_{B}^{S j k}+\pi_{B}^{N j k}\right) n\left(h^{k}\right) M_{B} \\
& >\sum_{k=H, L} \sum_{j=S, N}\left(\pi_{A}^{S j k} \delta^{S k}+\pi_{A}^{N j k} \delta^{N k}\right) n\left(h^{k}\right) M_{A} \\
& \sum_{j=S, N} \pi_{A}^{S j H} \delta^{S H} n\left(h^{H}\right)+\left(1-\sum_{j=S, N} \pi_{B}^{S H H}\right) \sum_{k=H, L} \sum_{j=S, N}\left(\pi_{A}^{S j k} \delta^{S k}+\pi_{A}^{S k k} \delta^{S k}\right) n\left(h^{k}\right) \\
& >\sum_{k=H, L} \sum_{j=S, N}\left(\pi_{A}^{S j k} \delta^{S k}+\pi_{A}^{N j k} \delta^{N k}\right) n\left(h^{k}\right) \\
& \sum_{j=S, N} \pi_{A}^{S j H} \delta^{S H} n\left(h^{H}\right)>\sum_{j=S, N} \pi_{B}^{S j H} \sum_{k=H, L} \sum_{j=S, N}\left(\pi_{A}^{S j k} \delta^{S k}+\pi_{A}^{N j k} \delta^{N k}\right) n\left(h^{k}\right) \\
& \sum_{j=S, N} \pi_{A}^{S j H} \delta^{S H} n\left(h^{H}\right)>\sum_{j=S, N} \pi_{A}^{S j H} \delta^{S H} \frac{M_{A}}{M_{B}} \sum_{k=H, L} \sum_{j=S, N}\left(\pi_{A}^{S j k} \delta^{S k}+\pi_{A}^{N j k} \delta^{N k}\right) n\left(h^{k}\right) \\
& \sum_{k=H, L} \sum_{j=S, N}\left(\pi_{B}^{S j k}+\pi_{B}^{N j k}\right) n\left(h^{H}\right)>\sum_{k=H, L} \sum_{j=S, N}\left(\pi_{B}^{S j k}+\pi_{B}^{N j k}\right) n\left(h^{k}\right)
\end{aligned}
$$

This condition always holds. 


\section{Appendix C: Simulation notes}

[For the reviewer only - not for publication]

\section{C.1 Single-locus genetic model}

To determine the level of signalling by the high-quality male, solve equations (39) and (40) as an equality.

Let $\delta(r s)=r s$ and setting $\rho=1$, so $r=1$, equation (39) becomes:

$$
\begin{aligned}
& \hat{s}=\frac{1}{2} \\
& \bar{s}=1-\frac{1}{2} \frac{h^{L}}{h^{H}}
\end{aligned}
$$

Equation (40) becomes:

$$
\hat{s}=\frac{1-\pi_{A}^{S H} \bar{S}}{2-\pi_{A}^{S H}}
$$

Substitute equation (41) into equation (87):

$$
\begin{aligned}
& \hat{s}=\frac{1-\pi_{A}^{S H}\left(1-(1-\hat{s}) \frac{h^{L}}{h^{H}}\right)}{2-\pi_{A}^{S H}} \\
& \hat{s}=\frac{1-\pi_{A}^{S H}\left(1-\frac{h^{L}}{h^{H}}\right)-\hat{s} \pi_{A}^{S H} \frac{h^{L}}{h^{H}}}{2-\pi_{A}^{S H}} \\
& \hat{s}\left(1+\frac{\left.\left.\pi_{A}^{S H} \frac{h^{L}}{h^{H}}\right)=\frac{1-\pi_{A}^{S H}\left(1-\frac{h^{L}}{h^{H}}\right)}{2-\pi_{A}^{S H}}\right)}{\left(2-\pi_{A}^{S H}\left(1-\frac{h^{L}}{h^{H}}\right)\right)=1-\pi_{A}^{S H}\left(1-\frac{h^{L}}{h^{H}}\right)}\right.
\end{aligned}
$$




$$
\hat{s}=\frac{1-\pi_{A}^{S H}\left(1-\frac{h^{L}}{h^{H}}\right)}{2-\pi_{A}^{S H}\left(1-\frac{h^{L}}{h^{H}}\right)}
$$

Solving for $\bar{s}$ in equation (88):

$$
\begin{aligned}
& \bar{s}=1-\left(\begin{array}{c}
1-\pi_{A}^{S H}\left(1-\frac{h^{L}}{h^{H}}\right) \\
2-\pi_{A}^{S H}\left(1-\frac{h^{L}}{h^{H}}\right)
\end{array}\right) \frac{h^{L}}{h^{H}} \\
& \bar{s}=1-\left(\frac{1}{2-\pi_{A}^{S H}\left(1-\frac{h^{L}}{h^{H}}\right)}\right) \frac{h^{L}}{h^{H}} \\
& \bar{s}=\frac{\left(\pi_{A}^{S H}\left(1-\frac{h^{L}}{h^{H}}\right)-\frac{h^{L}}{h^{H}}\right.}{2-\pi_{A}^{S H}\left(1-\frac{h^{L}}{h^{H}}\right)}
\end{aligned}
$$

To determine whether $M_{C}$ is greater than $F_{C}$, the agent will need to check whether equation (42) holds:

$$
\begin{aligned}
& \delta^{S H}>\frac{1-\left(1-\pi^{S H}\right) \delta(1)}{2 \pi_{A}^{S H}} \\
& \delta^{S H}>\frac{1}{2}
\end{aligned}
$$

With $\delta(s)=s$, the signalling level determined from equation (39) is always such that, while $\hat{s}$ equals one half, $\bar{s}$ is higher, meaning that $M_{C}$ will always exceed $F_{C}$. Hence, equation (40) must be used to determine the level of signalling by the high-quality, signalling male. 


\section{C.2 Two-locus genetic model}

Using equation (81) and setting $\delta(r s)=s$ and $\rho=1$, so $r=1$, gives:

$$
\hat{s}=\frac{\left(\Phi_{A}^{N}+1\right)}{2}
$$

To solve for $\bar{s}$, substitute equation (90) into equation (41):

$$
\bar{S}=1-\left(\frac{\Phi_{A}^{S}}{2}\right) \frac{h^{L}}{h^{H}}
$$

From equation (82) and $\delta(r s)=s$ :

$$
\begin{aligned}
& \hat{s}=\frac{\Phi_{A}^{N}+q_{C}^{M}}{1+q_{C}^{M}} \\
& \hat{s}=\frac{\Phi_{A}^{N}+\frac{\left(\Phi_{B}^{S}\left(1-q_{B}^{F} \pi_{B}^{S j H}\right)+\Phi_{B}^{N}\left(1-q_{B}^{F}\right)\right)}{\sum_{k=H, L} \sum_{j=S, N}\left(\pi_{A}^{S j k} \delta^{S k}+\pi_{A}^{N j k} \delta^{N k}\right)}}{1+\frac{\left(\Phi_{B}^{S}\left(1-q_{B}^{F} \sum_{j=S, N} \pi_{B}^{S j H}\right)+\Phi_{B}^{N}\left(1-q_{B}^{F}\right)\right)}{\sum_{k=H, L} \sum_{j=S, N}\left(\pi_{A}^{S j k} \delta^{S k}+\pi_{A}^{N j k} \delta^{N k}\right)}} \\
& \hat{s}=\frac{\Phi_{A}^{N} \sum_{k=H, L} \sum_{j=S, N}\left(\pi_{A}^{S j k} \delta^{S k}+\pi_{A}^{N j k} \delta^{N k}\right)+\left(\Phi_{B}^{S}\left(1-q_{B}^{F} \sum_{j=S, N} \pi_{B}^{S j H}\right)+\Phi_{B}^{N}\left(1-q_{B}^{F}\right)\right)}{\sum_{k=H, L} \sum_{j=S, N}\left(\pi_{A}^{S j k} \delta^{S k}+\pi_{A}^{N j k} \delta^{N k}\right)+\left(\Phi_{B}^{S}\left(1-q_{B}^{F} \sum_{j=S, N} \pi_{B}^{S j H}\right)+\Phi_{B}^{N}\left(1-q_{B}^{F}\right)\right)} \\
& \hat{s}=\frac{\Phi_{A}^{N} \sum_{k=H, L} \sum_{j=S, N}\left(\pi_{A}^{S j k} \delta^{S k}+\pi_{A}^{N j k} \delta^{N k}\right)+\Phi_{B}^{S}\left(1-\sum_{j=S, N} \pi_{A}^{S j H} \delta^{S H}\right)+\Phi_{B}^{N}\left(1-\frac{M_{B}}{F_{B}}\right)}{\sum_{k=H, L} \sum_{j=S, N}\left(\pi_{A}^{S j k} \delta^{S k}+\pi_{A}^{N j k} \delta^{N k}\right)+\Phi_{B}^{S}\left(1-\sum_{j=S, N} \pi_{A}^{S j H} \delta^{S H}\right)+\Phi_{B}^{N}\left(1-\frac{M_{B}}{F_{B}}\right)} \\
& \hat{S}=\frac{\Phi_{B}^{S}\left(1-\sum_{j=S, N} \pi_{A}^{S j H} \delta^{S H}\right)+\Phi_{A}^{N}}{\left(1-\Phi_{B}^{N}\right) \sum_{k=H, L} \sum_{j=S, N}\left(\pi_{A}^{S j k} \delta^{S k}+\pi_{A}^{N j k} \delta^{N k}\right)+\Phi_{B}^{S}\left(1-\sum_{j=S, N} \pi_{A}^{S j H} \delta^{S H}\right)+\Phi_{B}^{N}}
\end{aligned}
$$




$$
\begin{aligned}
& \hat{s}=\frac{1-\Phi_{B}^{S} \sum_{j=S, N} \pi_{A}^{S j H} \delta^{S H}}{\left(1-\Phi_{B}^{N}\right) \sum_{k=H, L} \sum_{j=S, N}\left(\pi_{A}^{S j k} \delta^{S k}+\pi_{A}^{N j k} \delta^{N k}\right)+1-\Phi_{B}^{S} \sum_{j=S, N} \pi_{A}^{S j H} \delta^{S H}} \\
& \hat{s}=\frac{1-\Phi_{B}^{S} \pi_{A}^{S j H} \delta^{S H}}{1-\Phi_{A}^{S} \pi_{A}^{S j H} \delta^{S H}+\Phi_{A}^{S} \sum_{k=H, L} \sum_{j=S, N}\left(\pi_{A}^{S j k} \delta^{S k}+\pi_{A}^{N j k} \delta^{N k}\right)} \\
& \hat{s}=\frac{1-\Phi_{B}^{S} \sum_{j=S, N} \pi_{A}^{S j H} \bar{s}}{1-\Phi_{A}^{S} \pi_{A}^{S j H} \bar{S}+\Phi_{A}^{S} \sum_{j=S, N}\left(\pi_{A}^{S j H} \bar{S}+\pi_{A}^{S j L}+\pi_{A}^{N j H}++\pi_{A}^{N j L}\right)} \\
& \hat{s}=\frac{1-\Phi_{A}^{S} \sum_{j=S, N} \pi_{A}^{S j H} \bar{S}}{1+\Phi_{A}^{S} \sum_{j=S, N}\left(\pi_{A}^{S j L}+\pi_{A}^{N j H}+\pi_{A}^{N j L}\right)}
\end{aligned}
$$

Substitute equation (41) into equation (91):

$$
\begin{aligned}
& \hat{s}=\frac{1-\Phi_{A}^{S} \sum_{j=S, N} \pi_{A}^{S j H}\left(1-(1-\hat{s}) \frac{h^{L}}{h^{H}}\right)}{1+\Phi_{A}^{S} \sum_{j=S, N}\left(\pi_{A}^{S j L}+\pi_{A}^{N j H}+\pi_{A}^{N j L}\right)} \\
& \hat{s}=\frac{1-\Phi_{A}^{S} \sum_{j=S, N} \pi_{A}^{S j H}+\Phi_{A}^{S} \sum_{j=S, N} \pi_{A}^{S j H} \frac{h^{L}}{h^{H}}-\Phi_{A}^{S} \sum_{j=S, N} \pi_{A}^{S j H} \hat{s} \frac{h^{L}}{h^{H}}}{1+\Phi_{A}^{S} \sum_{j=S, N}\left(\pi_{A}^{S j L}+\pi_{A}^{N j H}+\pi_{A}^{N j L}\right)} \\
& \hat{s}=\frac{1-\Phi_{A}^{S} \sum_{j=S, N} \pi_{A}^{S j H}+\Phi_{A}^{S} \sum_{j=S, N} \pi_{A}^{S j H} \frac{h^{L}}{h^{H}}}{1+\Phi_{A}^{S} \sum_{j=S, N}\left(\pi_{A}^{S j L}+\pi_{A}^{N j H}+\pi_{A}^{N j L}\right)}-\frac{\Phi_{A}^{S} \sum_{j=S, N} \pi_{A}^{S j H} \hat{s} \frac{h^{L}}{h^{H}}}{1+\Phi_{A}^{S} \sum_{j=S, N}\left(\pi_{A}^{S j L}+\pi_{A}^{N j H}+\pi_{A}^{N j L}\right)} \\
& \hat{s}\left(1+\frac{\Phi_{A}^{S} \sum_{j=S, N} \pi_{A}^{S j H} \frac{h^{L}}{h^{H}}}{1+\Phi_{A}^{S} \sum_{j=S, N}\left(\pi_{A}^{S j L}+\pi_{A}^{N j H}+\pi_{A}^{N j L}\right)}\right)=\frac{1-\Phi_{A}^{S} \sum_{j=S, N} \pi_{A}^{S j H}+\Phi_{A}^{S} \sum_{j=S, N} \pi_{A}^{S j H} \frac{h^{L}}{h^{H}}}{1+\Phi_{A}^{S} \sum_{j=S, N}\left(\pi_{A}^{S j L}+\pi_{A}^{N j H}+\pi_{A}^{N j L}\right)}
\end{aligned}
$$




$$
\begin{aligned}
& \hat{s}\left(1+\Phi_{A}^{S} \sum_{j=S, N}\left(\pi_{A}^{S j L}+\pi_{A}^{N j H}+\pi_{A}^{N j L}\right)+\Phi_{A}^{S} \sum_{j=S, N} \pi_{A}^{S j H} \frac{h^{L}}{h^{H}}\right) \\
& =1-\Phi_{A}^{S} \sum_{j=S, N} \pi_{A}^{S j H}+\Phi_{A}^{S} \sum_{j=S, N} \pi_{A}^{S j H} \frac{h^{L}}{h^{H}} \\
& \hat{s}=\frac{1-\Phi_{A}^{S} \sum_{j=S, N} \pi_{A}^{S j H}+\Phi_{A}^{S} \sum_{j=S, N} \pi_{A}^{S j H} \frac{h^{L}}{h^{H}}}{1+\Phi_{A}^{S} \sum_{j=S, N} \pi_{A}^{S j H}+\Phi_{A}^{S} \sum_{j=S, N} \pi_{A}^{S j H} \frac{h^{L}}{h^{H}}} \\
& \hat{s}=\frac{1-\Phi_{A}^{S} \sum_{j=S, N} \pi_{A}^{S j H}\left(1-\frac{h^{L}}{h^{H}}\right)}{1+\Phi_{A}^{S} \sum_{j=S, N} \pi_{A}^{S j H}\left(1+\frac{h^{L}}{h^{H}}\right)}
\end{aligned}
$$

Using equations (41) and (91):

$$
\begin{aligned}
& \bar{s}=1-\left(1-\frac{1-\Phi_{A}^{S} \sum_{j=S, N} \pi_{A}^{S j H} \bar{S}}{1+\Phi_{A}^{S} \sum_{j=S, N}\left(\pi_{A}^{S j L}+\pi_{A}^{N j H}+\pi_{A}^{N j L}\right)}\right) \frac{h^{L}}{h^{H}} \\
& \bar{S}=1-\left(1-\frac{1}{1+\Phi_{A}^{S} \sum_{j=S, N}\left(\pi_{A}^{S j L}+\pi_{A}^{N j H}+\pi_{A}^{N j L}\right)}\right) \frac{h^{L}}{h^{H}}-\frac{\Phi_{A}^{S} \sum_{j=S, N} \pi_{A}^{S j H} \bar{S}}{1+\Phi_{A}^{S} \sum_{j=S, N}\left(\pi_{A}^{S j L}+\pi_{A}^{N j H}+\pi_{A}^{N j L}\right)} \frac{h^{L}}{h^{H}} \\
& \bar{s}=\frac{1+\left(1-\frac{h^{L}}{h^{H}}\right) \Phi_{A}^{S} \sum_{j=S, N}\left(\pi_{A}^{S j L}+\pi_{A}^{N j H}+\pi_{A}^{N j L}\right)}{1+\Phi_{A}^{S} \sum_{j=S, N}\left(\pi_{A}^{S j L}+\pi_{A}^{N j H}+\pi_{A}^{N j L}\right)}-\frac{\Phi_{A}^{S} \sum_{j=S, N} \pi_{A}^{S j H} \bar{S}}{1+\Phi_{A}^{S} \sum_{j=S, N}\left(\pi_{A}^{S j L}+\pi_{A}^{N j H}+\pi_{A}^{N j L}\right)} \frac{h^{L}}{h^{H}} \\
& \bar{s}\left(1+\frac{\Phi_{A}^{S} \sum_{j=S, N} \pi_{A}^{S j H}}{1+\Phi_{A}^{S} \sum_{j=S, N}\left(\pi_{A}^{S j L}+\pi_{A}^{N j H}+\pi_{A}^{N j L}\right)} \frac{h^{L}}{h^{H}}\right) \\
& =\frac{1+\left(1-\frac{h^{L}}{h^{H}}\right) \Phi_{A}^{S} \sum_{j=S, N}\left(\pi_{A}^{S j L}+\pi_{A}^{N j H}+\pi_{A}^{N j L}\right)}{1+\Phi_{A}^{S} \sum_{j=S, N}\left(\pi_{A}^{S j L}+\pi_{A}^{N j H}+\pi_{A}^{N j L}\right)}
\end{aligned}
$$




$$
\begin{aligned}
& \bar{s}\left(\frac{1+\Phi_{A}^{S} \sum_{j=S, N}\left(\pi_{A}^{S j L}+\pi_{A}^{N j H}+\pi_{A}^{N j L}\right)+\Phi_{A}^{S} \sum_{j=S, N} \pi_{A}^{S j H} \frac{h^{L}}{h^{H}}}{1+\Phi_{A}^{S} \sum_{j=S, N}\left(\pi_{A}^{S j L}+\pi_{A}^{N j H}+\pi_{A}^{N j L}\right)}\right) \\
& =\frac{1+\left(1-\frac{h^{L}}{h^{H}}\right) \Phi_{A}^{S} \sum_{j=S, N}\left(\pi_{A}^{S j L}+\pi_{A}^{N j H}+\pi_{A}^{N j L}\right)}{1+\Phi_{A}^{S} \sum_{j=S, N}\left(\pi_{A}^{S j L}+\pi_{A}^{N j H}+\pi_{A}^{N j L}\right)} \\
& \bar{s}=\frac{1+\left(1-\frac{h^{L}}{h^{H}}\right) \Phi_{A}^{S} \sum_{j=S, N}\left(\pi_{A}^{S j L}+\pi_{A}^{N j H}+\pi_{A}^{N j L}\right)}{1+\Phi_{A}^{S} \sum_{j=S, N}\left(\pi_{A}^{S j L}+\pi_{A}^{N j H}+\pi_{A}^{N j L}\right)+\Phi_{A}^{S} \sum_{j=S, N} \pi_{A}^{S j H} \frac{h^{L}}{h^{H}}} \\
& \bar{s}=\frac{1+\Phi_{A}^{S}\left(1-\sum_{j=S, N} \pi_{A}^{S j H}\right)\left(1-\frac{h^{L}}{h^{H}}\right)}{1+\left(1-\frac{h^{L}}{h^{H}}\right) \Phi_{A}^{S}\left(1-\sum_{j=S, N}^{S}\left(1-\sum_{j=S, N} \pi_{A}^{S j H}\left(1-\frac{h^{L}}{h^{H}}\right)\right)\right.} \\
& \overline{1+\Phi_{A}^{S}\left(1-\sum_{j=S, N} \pi_{A}^{S j H}\right)}+\Phi_{A}^{S} \sum_{j=S, N} \pi_{A}^{S j H} \frac{h^{L}}{h^{H}}
\end{aligned}
$$

To determine whether $M_{C}$ is greater than $F_{C}$, the agent will need to check whether equation (83) holds:

$$
\begin{aligned}
& \left(1+\Phi_{B}^{N}\right) \sum_{j=S, N} \sum_{k=H, L}\left(\pi_{A}^{S j k} \delta^{S k}+\pi_{A}^{N j k} \delta^{N k}\right)>1-\Phi_{B}^{S} \sum_{j=S, N} \pi_{A}^{S j H} \delta^{S H} \\
& \left(1+\Phi_{B}^{N}\right) \sum_{j=S, N}\left(\pi_{A}^{S j H} \bar{S}+\pi_{A}^{S j L}+\pi_{A}^{N j H}+\pi_{A}^{N j L}\right)>1-\Phi_{B}^{S} \sum_{j=S, N} \pi_{A}^{S j H} \bar{S} \\
& 2 \sum_{j=S, N} \pi_{A}^{S j H} \bar{S}+\left(1+\Phi_{B}^{N}\right) \sum_{j=S, N}\left(\pi_{A}^{S j L}+\pi_{A}^{N j H}+\pi_{A}^{N j L}\right)>1 \\
& \bar{s}>\frac{1-\left(1+\Phi_{B}^{N}\right) \sum_{j=S, N}\left(\pi_{A}^{S j L}+\pi_{A}^{N j H}+\pi_{A}^{N j L}\right)}{2 \sum_{j=S, N} \pi_{A}^{S j H}}
\end{aligned}
$$




$$
\begin{gathered}
\bar{S}>\frac{1-\left(1-\sum_{j=S, N} \pi_{A}^{S j H}\right)-\Phi_{A}^{N}\left(1-\sum_{j=S, N} \pi_{A}^{S j H}\right)}{2 \sum_{j=S, N} \pi_{A}^{S j H}} \\
\bar{S}>\frac{\sum_{j=S, N} \pi_{A}^{S j H}-\Phi_{A}^{N}\left(1-\sum_{j=S, N} \pi_{A}^{S j H}\right)}{2 \sum_{j=S, N} \pi_{A}^{S j H}}
\end{gathered}
$$




\section{ECONOMICS DISCUSSION PAPERS}

2010

\begin{tabular}{|c|c|c|}
\hline $\begin{array}{l}\text { DP } \\
\text { NUMBER }\end{array}$ & AUTHORS & TITLE \\
\hline 10.01 & Hendry, D.F. & $\begin{array}{l}\text { RESEARCH AND THE ACADEMIC: A TALE OF } \\
\text { TWO CULTURES }\end{array}$ \\
\hline 10.02 & McLure, M., Turkington, D. and Weber, E.J. & A CONVERSATION WITH ARNOLD ZELLNER \\
\hline 10.03 & $\begin{array}{l}\text { Butler, D.J., Burbank, V.K. and } \\
\text { Chisholm, J.S. }\end{array}$ & $\begin{array}{l}\text { THE FRAMES BEHIND THE GAMES: PLAYER'S } \\
\text { PERCEPTIONS OF PRISONER'S DILEMMA, } \\
\text { CHICKEN, DICTATOR, AND ULTIMATUM GAMES }\end{array}$ \\
\hline 10.04 & Harris, R.G., Robertson, P.E. and Xu, J.Y. & $\begin{array}{l}\text { THE INTERNATIONAL EFFECTS OF CHINA'S } \\
\text { GROWTH, TRADE AND EDUCATION BOOMS }\end{array}$ \\
\hline 10.05 & Clements, K.W., Mongey, S. and Si, J. & $\begin{array}{l}\text { THE DYNAMICS OF NEW RESOURCE PROJECTS } \\
\text { A PROGRESS REPORT }\end{array}$ \\
\hline 10.06 & Costello, G., Fraser, P. and Groenewold, N. & $\begin{array}{l}\text { HOUSE PRICES, NON-FUNDAMENTAL } \\
\text { COMPONENTS AND INTERSTATE SPILLOVERS: } \\
\text { THE AUSTRALIAN EXPERIENCE }\end{array}$ \\
\hline 10.07 & Clements, $\mathrm{K}$. & $\begin{array}{l}\text { REPORT OF THE } 2009 \text { PHD CONFERENCE IN } \\
\text { ECONOMICS AND BUSINESS }\end{array}$ \\
\hline 10.08 & Robertson, P.E. & $\begin{array}{l}\text { INVESTMENT LED GROWTH IN INDIA: HINDU } \\
\text { FACT OR MYTHOLOGY? }\end{array}$ \\
\hline 10.09 & Fu, D., Wu, Y. and Tang, Y. & $\begin{array}{l}\text { THE EFFECTS OF OWNERSHIP STRUCTURE AND } \\
\text { INDUSTRY CHARACTERISTICS ON EXPORT } \\
\text { PERFORMANCE }\end{array}$ \\
\hline 10.10 & Wu, Y. & $\begin{array}{l}\text { INNOVATION AND ECONOMIC GROWTH IN } \\
\text { CHINA }\end{array}$ \\
\hline 10.11 & Stephens, B.J. & $\begin{array}{l}\text { THE DETERMINANTS OF LABOUR FORCE } \\
\text { STATUS AMONG INDIGENOUS AUSTRALIANS }\end{array}$ \\
\hline 10.12 & Davies, $\mathrm{M}$. & $\begin{array}{l}\text { FINANCING THE BURRA BURRA MINES, SOUTH } \\
\text { AUSTRALIA: LIQUIDITY PROBLEMS AND } \\
\text { RESOLUTIONS }\end{array}$ \\
\hline 10.13 & Tyers, R. and Zhang, Y. & APPRECIATING THE RENMINBI \\
\hline 10.14 & Clements, K.W., Lan, Y. and Seah, S.P. & $\begin{array}{l}\text { THE BIG MAC INDEX TWO DECADES ON } \\
\text { AN EVALUATION OF BURGERNOMICS }\end{array}$ \\
\hline 10.15 & Robertson, P.E. and Xu, J.Y. & $\begin{array}{l}\text { IN CHINA'S WAKE: } \\
\text { HAS ASIA GAINED FROM CHINA'S GROWTH? }\end{array}$ \\
\hline 10.16 & Clements, K.W. and Izan, H.Y. & $\begin{array}{l}\text { THE PAY PARITY MATRIX: A TOOL FOR } \\
\text { ANALYSING THE STRUCTURE OF PAY }\end{array}$ \\
\hline 10.17 & Gao, G. & WORLD FOOD DEMAND \\
\hline 10.18 & Wu, Y. & $\begin{array}{l}\text { INDIGENOUS INNOVATION IN CHINA: } \\
\text { IMPLICATIONS FOR SUSTAINABLE GROWTH }\end{array}$ \\
\hline 10.19 & Robertson, P.E. & DECIPHERING THE HINDU GROWTH EPIC \\
\hline 10.20 & Stevens, G. & $\begin{array}{l}\text { RESERVE BANK OF AUSTRALIA-THE ROLE OF } \\
\text { FINANCE }\end{array}$ \\
\hline 10.21 & Widmer, P.K., Zweifel, P. and Farsi, M. & $\begin{array}{l}\text { ACCOUNTING FOR HETEROGENEITY IN THE } \\
\text { MEASUREMENT OF HOSPITAL PERFORMANCE }\end{array}$ \\
\hline
\end{tabular}




\begin{tabular}{|l|l|l|}
\hline 10.22 & McLure, M. & $\begin{array}{l}\text { ASSESSMENTS OF A. C. PIGOU'S FELLOWSHIP } \\
\text { THESES }\end{array}$ \\
\hline 10.23 & Poon, A.R. & $\begin{array}{l}\text { THE ECONOMICS OF NONLINEAR PRICING: } \\
\text { EVIDENCE FROM AIRFARES AND GROCERY } \\
\text { PRICES }\end{array}$ \\
\hline 10.24 & Halperin, D. & $\begin{array}{l}\text { FORECASTING METALS RETURNS: A BAYESIAN } \\
\text { DECISION THEORETIC APPROACH }\end{array}$ \\
\hline 10.25 & Clements, K.W. and Si. J. & $\begin{array}{l}\text { THE INVESTMENT PROJECT PIPELINE: COST } \\
\text { ESCALATION, LEAD-TIME, SUCCESS, FAILURE } \\
\text { AND SPEED }\end{array}$ \\
\hline 10.26 & Chen, A., Groenewold, N. and Hagger, A.J. & $\begin{array}{l}\text { THE REGIONAL ECONOMIC EFFECTS OF A } \\
\text { REDUCTION IN CARBON EMISSIONS }\end{array}$ \\
\hline 10.27 & $\begin{array}{l}\text { Siddique, A., Selvanathan, E.A. and } \\
\text { Selvanathan, S. }\end{array}$ & $\begin{array}{l}\text { REMITTANCES AND ECONOMIC GROWTH: } \\
\text { EMPIRICAL EVIDENCE FROM BANGLADESH, } \\
\text { INDIA AND SRI LANKA }\end{array}$ \\
\hline
\end{tabular}




\section{ECONOMICS DISCUSSION PAPERS}

2011

\begin{tabular}{|c|c|c|}
\hline $\begin{array}{l}\text { DP } \\
\text { NUMBER }\end{array}$ & AUTHORS & TITLE \\
\hline 11.01 & Robertson, P.E. & $\begin{array}{l}\text { DEEP IMPACT: CHINA AND THE WORLD } \\
\text { ECONOMY }\end{array}$ \\
\hline 11.02 & Kang, C. and Lee, S.H. & $\begin{array}{l}\text { BEING KNOWLEDGEABLE OR SOCIABLE? } \\
\text { DIFFERENCES IN RELATIVE IMPORTANCE OF } \\
\text { COGNITIVE AND NON-COGNITIVE SKILLS }\end{array}$ \\
\hline 11.03 & Turkington, D. & DIFFERENT CONCEPTS OF MATRIX CALCULUS \\
\hline 11.04 & Golley, J. and Tyers, R. & $\begin{array}{l}\text { CONTRASTING GIANTS: DEMOGRAPHIC CHANGE } \\
\text { AND ECONOMIC PERFORMANCE IN CHINA AND } \\
\text { INDIA }\end{array}$ \\
\hline 11.05 & Collins, J., Baer, B. and Weber, E.J. & $\begin{array}{l}\text { ECONOMIC GROWTH AND EVOLUTION: } \\
\text { PARENTAL PREFERENCE FOR QUALITY AND } \\
\text { QUANTITY OF OFFSPRING }\end{array}$ \\
\hline 11.06 & Turkington, D. & $\begin{array}{l}\text { ON THE DIFFERENTIATION OF THE LOG } \\
\text { LIKELIHOOD FUNCTION USING MATRIX } \\
\text { CALCULUS }\end{array}$ \\
\hline 11.07 & Groenewold, N. and Paterson, J.E.H. & $\begin{array}{l}\text { STOCK PRICES AND EXCHANGE RATES IN } \\
\text { AUSTRALIA: ARE COMMODITY PRICES THE } \\
\text { MISSING LINK? }\end{array}$ \\
\hline 11.08 & Chen, A. and Groenewold, N. & $\begin{array}{l}\text { REDUCING REGIONAL DISPARITIES IN CHINA: IS } \\
\text { INVESTMENT ALLOCATION POLICY EFFECTIVE? }\end{array}$ \\
\hline 11.09 & Williams, A., Birch, E. and Hancock, P. & $\begin{array}{l}\text { THE IMPACT OF ON-LINE LECTURE RECORDINGS } \\
\text { ON STUDENT PERFORMANCE }\end{array}$ \\
\hline 11.10 & Pawley, J. and Weber, E.J. & $\begin{array}{l}\text { INVESTMENT AND TECHNICAL PROGRESS IN THE } \\
\text { G7 COUNTRIES AND AUSTRALIA }\end{array}$ \\
\hline 11.11 & Tyers, R. & $\begin{array}{l}\text { AN ELEMENTAL MACROECONOMIC MODEL FOR } \\
\text { APPLIED ANALYSIS AT UNDERGRADUATE LEVEL }\end{array}$ \\
\hline 11.12 & Clements, K.W. and Gao, G. & QUALITY, QUANTITY, SPENDING AND PRICES \\
\hline 11.13 & Tyers, R. and Zhang, Y. & $\begin{array}{l}\text { JAPAN'S ECONOMIC RECOVERY: INSIGHTS FROM } \\
\text { MULTI-REGION DYNAMICS }\end{array}$ \\
\hline 11.14 & McLure, M. & A. C. PIGOU'S REJECTION OF PARETO'S LAW \\
\hline 11.15 & Kristoffersen, I. & $\begin{array}{l}\text { THE SUBJECTIVE WELLBEING SCALE: HOW } \\
\text { REASONABLE IS THE CARDINALITY } \\
\text { ASSUMPTION? }\end{array}$ \\
\hline 11.16 & Clements, K.W., Izan, H.Y. and Lan, Y. & VOLATILITY AND STOCK PRICE INDEXES \\
\hline 11.17 & Parkinson, $\mathrm{M}$. & $\begin{array}{l}\text { SHANN MEMORIAL LECTURE 2011: SUSTAINABLE } \\
\text { WELLBEING - AN ECONOMIC FUTURE FOR } \\
\text { AUSTRALIA }\end{array}$ \\
\hline 11.18 & Chen, A. and Groenewold, N. & $\begin{array}{l}\text { THE NATIONAL AND REGIONAL EFFECTS OF } \\
\text { FISCAL DECENTRALISATION IN CHINA }\end{array}$ \\
\hline 11.19 & Tyers, R. and Corbett, J. & $\begin{array}{l}\text { JAPAN'S ECONOMIC SLOWDOWN AND ITS } \\
\text { GLOBAL IMPLICATIONS: A REVIEW OF THE } \\
\text { ECONOMIC MODELLING }\end{array}$ \\
\hline 11.20 & $\mathrm{Wu}, \mathrm{Y}$. & $\begin{array}{l}\text { GAS MARKET INTEGRATION: GLOBAL TRENDS } \\
\text { AND IMPLICATIONS FOR THE EAS REGION }\end{array}$ \\
\hline
\end{tabular}




\begin{tabular}{|l|l|l|}
\hline 11.21 & Fu, D., Wu, Y. and Tang, Y. & $\begin{array}{l}\text { DOES INNOVATION MATTER FOR CHINESE HIGH- } \\
\text { TECH EXPORTS? A FIRM-LEVEL ANALYSIS }\end{array}$ \\
\hline 11.22 & Fu, D. and Wu, Y. & $\begin{array}{l}\text { EXPORT WAGE PREMIUM IN CHINA'S } \\
\text { MANUFACTURING SECTOR: A FIRM LEVEL } \\
\text { ANALYSIS }\end{array}$ \\
\hline 11.23 & Li, B. and Zhang, J. & $\begin{array}{l}\text { SUBSIDIES IN AN ECONOMY WITH ENDOGENOUS } \\
\text { CYCLES OVER NEOCLASSICAL INVESTMENT AND } \\
\text { NEO-SCHUMPETERIAN INNOVATION REGIMES }\end{array}$ \\
\hline 11.24 & Krey, B., Widmer, P.K. and Zweifel, P. & $\begin{array}{l}\text { EFFICIENT PROVISION OF ELECTRICITY FOR THE } \\
\text { UNITED STATES AND SWITZERLAND }\end{array}$ \\
\hline 11.25 & Wu, Y. & $\begin{array}{l}\text { ENERGY INTENSITY AND ITS DETERMINANTS IN } \\
\text { CHINA'S REGIONAL ECONOMIES }\end{array}$ \\
\hline & & \\
\hline
\end{tabular}




\begin{tabular}{|c|c|c|}
\hline \multicolumn{3}{|c|}{$\begin{array}{l}\text { ECONOMICS DISCUSSION PAPERS } \\
2012\end{array}$} \\
\hline $\begin{array}{l}\text { DP } \\
\text { NUMBER }\end{array}$ & AUTHORS & TITLE \\
\hline 12.01 & Clements, K.W., Gao, G., and Simpson, T. & $\begin{array}{l}\text { DISPARITIES IN INCOMES AND PRICES } \\
\text { INTERNATIONALLY }\end{array}$ \\
\hline 12.02 & Tyers, R. & $\begin{array}{l}\text { THE RISE AND ROBUSTNESS OF ECONOMIC } \\
\text { FREEDOM IN CHINA }\end{array}$ \\
\hline 12.03 & Golley, J. and Tyers, R. & $\begin{array}{l}\text { DEMOGRAPHIC DIVIDENDS, DEPENDENCIES } \\
\text { AND ECONOMIC GROWTH IN CHINA AND INDIA }\end{array}$ \\
\hline 12.04 & Tyers, R. & LOOKING INWARD FOR GROWTH \\
\hline 12.05 & Knight, K. and McLure, M. & THE ELUSIVE ARTHUR PIGOU \\
\hline 12.06 & McLure, M. & $\begin{array}{l}\text { ONE HUNDRED YEARS FROM TODAY: A. C. } \\
\text { PIGOU'S WEALTH AND WELFARE }\end{array}$ \\
\hline 12.07 & Khuu, A. and Weber, E.J. & HOW AUSTRALIAN FARMERS DEAL WITH RISK \\
\hline 12.08 & Chen, M. and Clements, K.W. & PATTERNS IN WORLD METALS PRICES \\
\hline 12.09 & Clements, K.W. & UWA ECONOMICS HONOURS \\
\hline 12.10 & Golley, J. and Tyers, R. & $\begin{array}{l}\text { CHINA'S GENDER IMBALANCE AND ITS } \\
\text { ECONOMIC PERFORMANCE }\end{array}$ \\
\hline 12.11 & Weber, E.J. & $\begin{array}{l}\text { AUSTRALIAN FISCAL POLICY IN THE } \\
\text { AFTERMATH OF THE GLOBAL FINANCIAL } \\
\text { CRISIS }\end{array}$ \\
\hline 12.12 & Hartley, P.R. and Medlock III, K.B. & $\begin{array}{l}\text { CHANGES IN THE OPERATIONAL EFFICIENCY } \\
\text { OF NATIONAL OIL COMPANIES }\end{array}$ \\
\hline 12.13 & Li, L. & $\begin{array}{l}\text { HOW MUCH ARE RESOURCE PROJECTS WORTH? } \\
\text { A CAPITAL MARKET PERSPECTIVE }\end{array}$ \\
\hline 12.14 & Chen, A. and Groenewold, N. & $\begin{array}{l}\text { THE REGIONAL ECONOMIC EFFECTS OF A } \\
\text { REDUCTION IN CARBON EMISSIONS AND AN } \\
\text { EVALUATION OF OFFSETTING POLICIES IN } \\
\text { CHINA }\end{array}$ \\
\hline 12.15 & Collins, J., Baer, B. and Weber, E.J. & $\begin{array}{l}\text { SEXUAL SELECTION, CONSPICUOUS } \\
\text { CONSUMPTION AND ECONOMIC GROWTH }\end{array}$ \\
\hline
\end{tabular}

